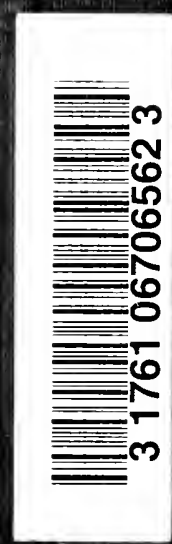




\section{F. H. TUGKER \& CO., LTD. \\ SW A NSEA}

\section{Exporters of}

Anthracite, Steam Coals and Patent Fuel

Agents for

NIXON'S NAVIGATION Co., Ltd.

\section{Shipping Agents and Brokers}

$$
\text { Agents for }
$$

\section{ELLERMAN'S WILSON LINE Ltd.} FURNESS, WITHY \& Co., Ltd. LONDON WELSH STEAMSHIP Co., Itd.

Telegrams: “GENERAL, SWANSEA." Telephone: 793 Central. Pvte. Bch. Exch. 


\section{Colliery Proprietors and}

Agents. Coal Exporters. : Steamship Brokers. :

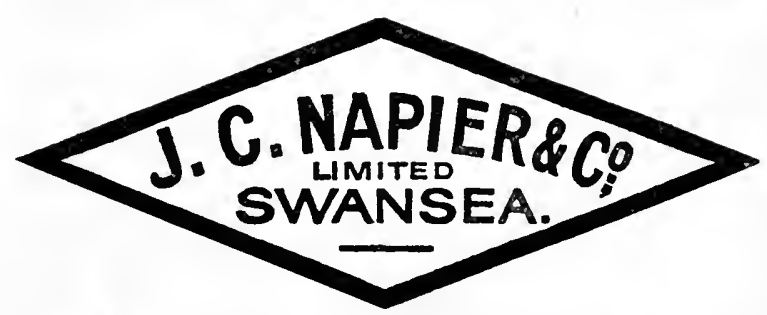

Telegrams-

"Napier, Sivnsea."

Telephone-

No. 1205 Suansea.

SOLE SALES AGENTS FOR-

RHOS, WERNOS, CAERBRYN, CARWAY, GWENDRAETH and PI.ASBACH ANTHRACITE COLLIERIES

Anthracite Large for HopDrying, Horticultural, Lime Burning and all other purposes.
Finest Quality Machinemade Cobbles, Nuts, Beans, Peas, Grains, etc.

London Office:-6 LLOYDS AVENUE, E.C.3 


\section{Anthracite}

\section{Smokeless Durable Clean}

\section{W. H. ESSERY \& Co. Ltd. $S W A N S E A$}

Telegrams:

LSSERY, SWANSEA.
Telephones:

Cestral 551.
Established 1848.

Proprietors and Shippers of the famous Pembrokeshire Anthracite Coals.

\section{Specialities :}

Special Handpicked Large Malting Coal. Machine Cut Cobbles, Washed Nuts, Beans and Peas for Gas Plants. Special Machine Screened Washed Stove Nuts. Best Anthracite Large and Screened Cobbles for Horticultural and Central Heating purposes

\section{Truckloads to any station}

Reg'd Office: Hast Burrows, SWANSEA.

Branches :

105 PaRK LANE, LEEDS.
15 Canle STreet, ITERPOOL.
St. Pierrf, Crabble, DOVER.

11 REE ALFRED DE VIGNY,

PARIS. 


\section{ANTHRACITE AND THE ANTHRACITE INDUSTRY}




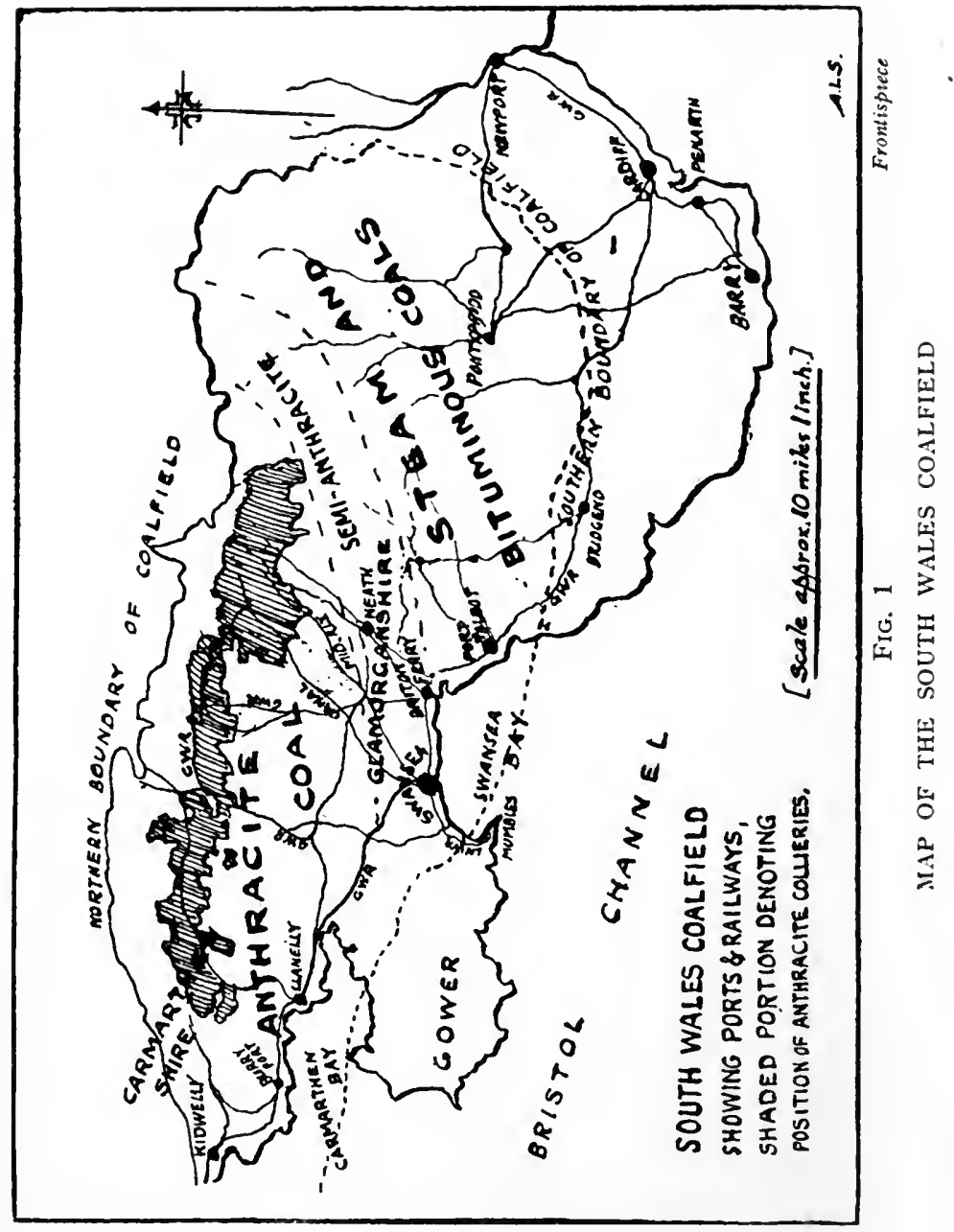




\section{PITMAN'S COMMON COMMODITIES}

AND INDUSTRIES

\section{ANTHRACITE AND THE ANTHRACITE INDUSTRY}

\section{BY \\ A. LEONARD SUMMERS}

AUTHOR OF "ASBESTOS AND THE ASBESTOS INDUSTRY," ETC.

WITH MAP AND IILUSTRATIONS BY THE AUTHOR AND FROM PHOTOGRAPHS

\section{LONDON}

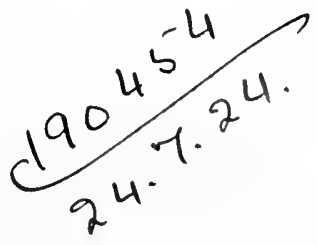

SIR ISAAC PITMAN \& SONS, LTD. PARKER STREET, KINGSWAY, W.C.2 BATH, MELBOURNE, TORONTO, NEW YORK 


\section{THE BEST WELSH ANTHRACITE}

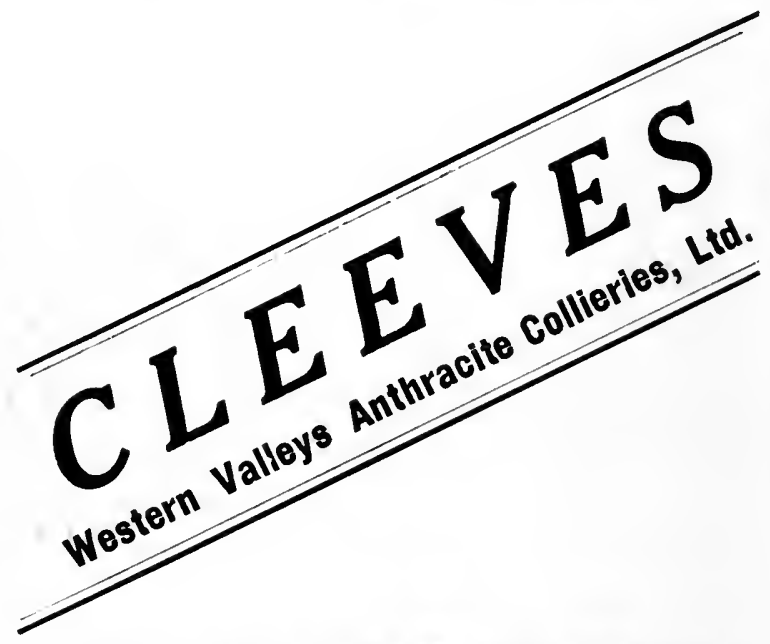

\section{COLLIERY \& STEAMSHIP OWNERS AND COAL EXPORTERS}

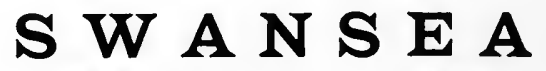

Telegrams :

"Nudicaul " or "Activity."

Telephone:

2054 Docks.

LONDON OFFICE : 120 Fenchurch St. Telegrams : "Nudicanl, London." CARDIFF : 68/69 Exchange Buildings. NEWCASTLE: Milburn House. HULL : Yorkshire Insurance Buildings. LLANELLY : Stafford Chambers.

$$
\begin{aligned}
& \text { " "Nudicaul, Cardiff." } \\
& \text { " “ Heads, Newcastle," } \\
& \text { " "Nudicsul, Hull." } \\
& \text { " "Activity, Llanelly." }
\end{aligned}
$$
Agencies at ROUEN and PARIS. 


\section{FOREWORD}

THE author's acknowledgments are due to Messrs. Cleeves' Western Valleys Anthracite Collieries, Ltd., for the loan of the very interesting photographs of their machinery and coal, and for the privilege of inspecting the up-to-date equipment of their well-organized mines.

It has not been deemed expedient to deal in this volume with plant for gas-production, the various processes having been fully described in the author's previous book, All About Anthracite. 

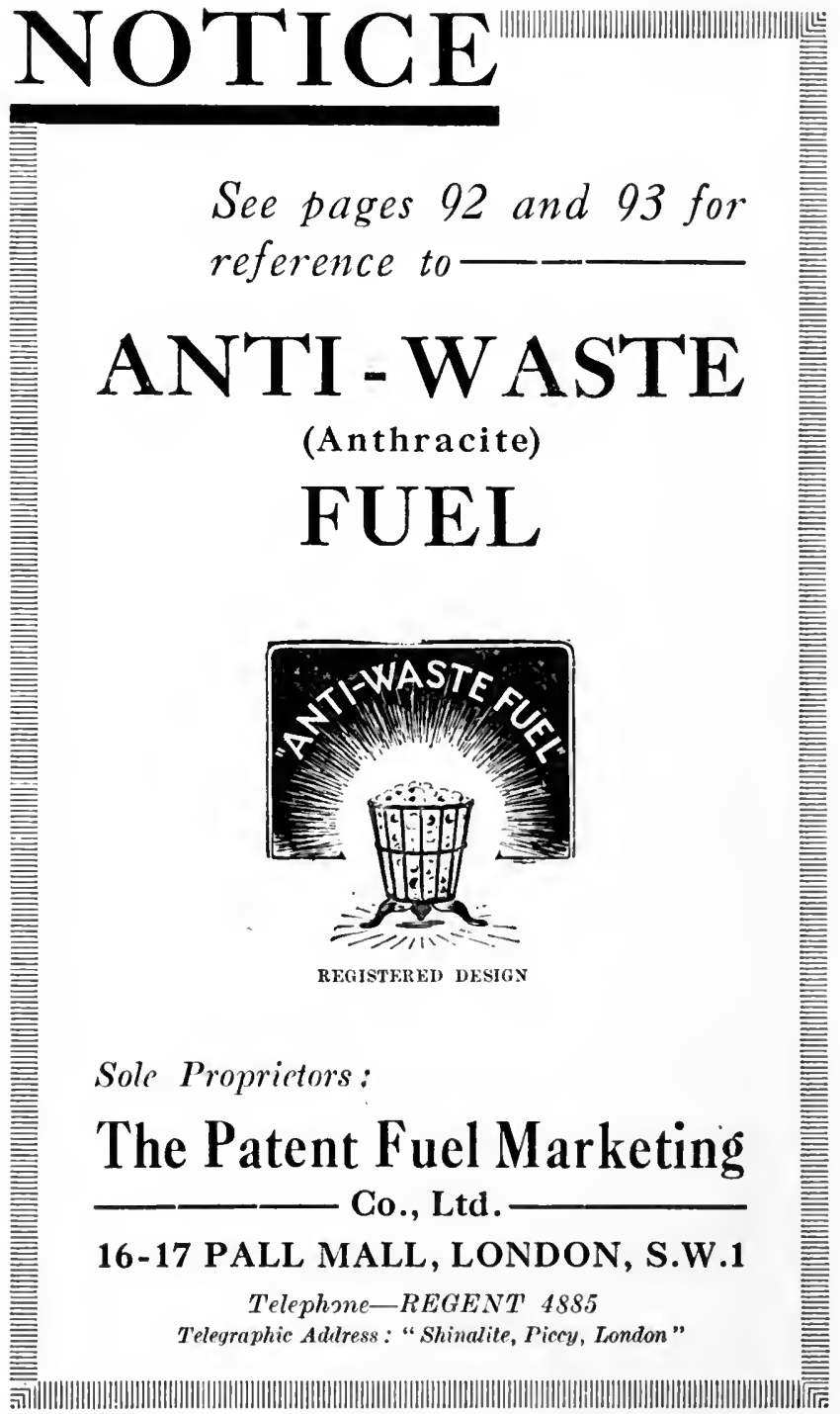


\section{CONTENTS}

PAGE

FOREWORD

\section{CHAPTER I}

THE South Wales coalfield-Primitive mining-Collieries and men employed-Estimated coal reserves-World's increasing demand-Comparative outputs-Welsh triumph-Origin of anthracite-Susceptibilities of seams - Physical features-Volatile variations-Results of borings-Deep mining

\section{CHAPTER II}

THE beautiful anthracite district-Unusual fertilityAbsence of smoke-A picturesque panorama-Tourists' facilities-What is anthracite?-Chemical analysis of the coal-Welsh supremacy-Labour and time saving -An artistic feat-Safety-Heat regulation-Rules for anthracite fires-Anthracite and horticulture- " $\mathrm{Ca}$ ' canny" and under-production-Output per manProportions of coal used industrially . . .

\section{CHAPTER III}

LIFE at the anthracite collieries-Exploiters' difficultiesPower of anthracite-The pioneers-Preparation of anthracite-Sizing and washing coal-Standard sizes -Foreign buyers-The wonderful pit pony . .

\section{CHAPTER IV}

Economics and efficiency-Anthracite in domestic service -Educating the public-Official tests and demonstrations-100 per cent economy-Increased efficiency from decreased consumption-Comparative costs of fuels-Dr. Fisherden's experiments-Fallacy of adding chemicals-Professor Barker's Fuel testsComparative heating values-Chimney-losses-Consumers' reports of stoves-Pre-eminent economy of anthracite-Coalowners and costs-Kitchen conquest -English cookery — the " King of ranges "-Immense 
saving of fuel-Importance of clean fires-Soot and heat losses-Domestic boilers-Anthracite versus gasThe "Therm" and B.T.U.-The "Florence" boilergrate-Welwyn Garden City installations-Anthracite stoves and grates-Capacities of stoves-Dutch stoves and their capacities-Principal stove makers-Stove "scares"-Stove fuel costs-Expert opinions of anthracite-Gas-stove perils.

\section{CHAPTER V}

THE industrial world-Prolific gas-yield of Welsh anthracite-Baking by anthracite-Economic motor-transport-New gas-producer-Anthracite and electrodesSteam raising-Some remarkable economies-Mixed coals-Irish anthracite-Output and resourcesDevelopment prospects-Official reports-Outputs and employees (1918)-Analysis of Irish anthraciteScotch anthracite-An analysis-American anthracite - Comparative outputs-Canadian anthracite-World's largest field-Government's interest-Other anthracites -Anthracite compounds and patent fuels-Spontaneous ignition

\section{CHAPTER VI}

Sмоке abatement and coal conservation-Coal-smoke and public health-Coal statistics-Concentrated poisonsMedical indictments-Atmospheric pollution reportsAnalysis of polluted atmosphere-What constitutes injurious fog-London's canopy of coaldust-The terrible toll of cancer-Financial cost of fogs-Important recommendation of Lord Newton's CommitteePublic control committee-John Evelyn and the smoke nuisance-Fog paralysis of London-Healthy prosecutions-Conserving Britain's coal-electrical generation -Oil versus coal-Anthracite the remedy-By-products of soft coals-Stupendous annual waste of coal and energy-Low-temperature carbonization-Electricity wasteful 


\section{ILLUSTRATIONS}

MAP OF SOUTH WALES COALFIELD

PACE ANTHRACITE "FRENCH" NUTS . . . . . 9 LLANDEBIE (VIEW FROM COLLIERY) • • • 15 ROMAN BRIDGE, NEAR MUMBLES . . . . 17 THATCHED COTTAGES, BLACKPILL • . . . 18 TIRYDAIL RAILWAY STATION • COTTAGE BESIDE ROAD TO NEW CROSS HANDS COLLIERY 20 ANTHRACITE BREAKER . . . . . . 23 THE PRINCIPAL ANTHRACITE COLLIERY . . . 31 THE FIRST PICKING BELTS . . . . . . 33 A TYPICAL MINER'S LAMP . . $\quad$. $\quad$. $\quad 35$ GRATE AT ROYAL HOTEL, BRISTOL . . . . 40 MAIN SCREEN DIVIDING SIZED COALS . . . 49 ANTHRACITE "STOVE" NUTS . . . . . 57 THE "FLORENCE" BOILER-GRATE . . . . . 61 GAS-PRODUCING PLANT • . . . . . . 73 ANTHRACITE "PEAS" . . . . . . . . . 91 PICKING BELT, WITH END LOWERING INTO TRUCKS • 99 BELTS FOR FINAL PICKING AND LOADING . . . 101 


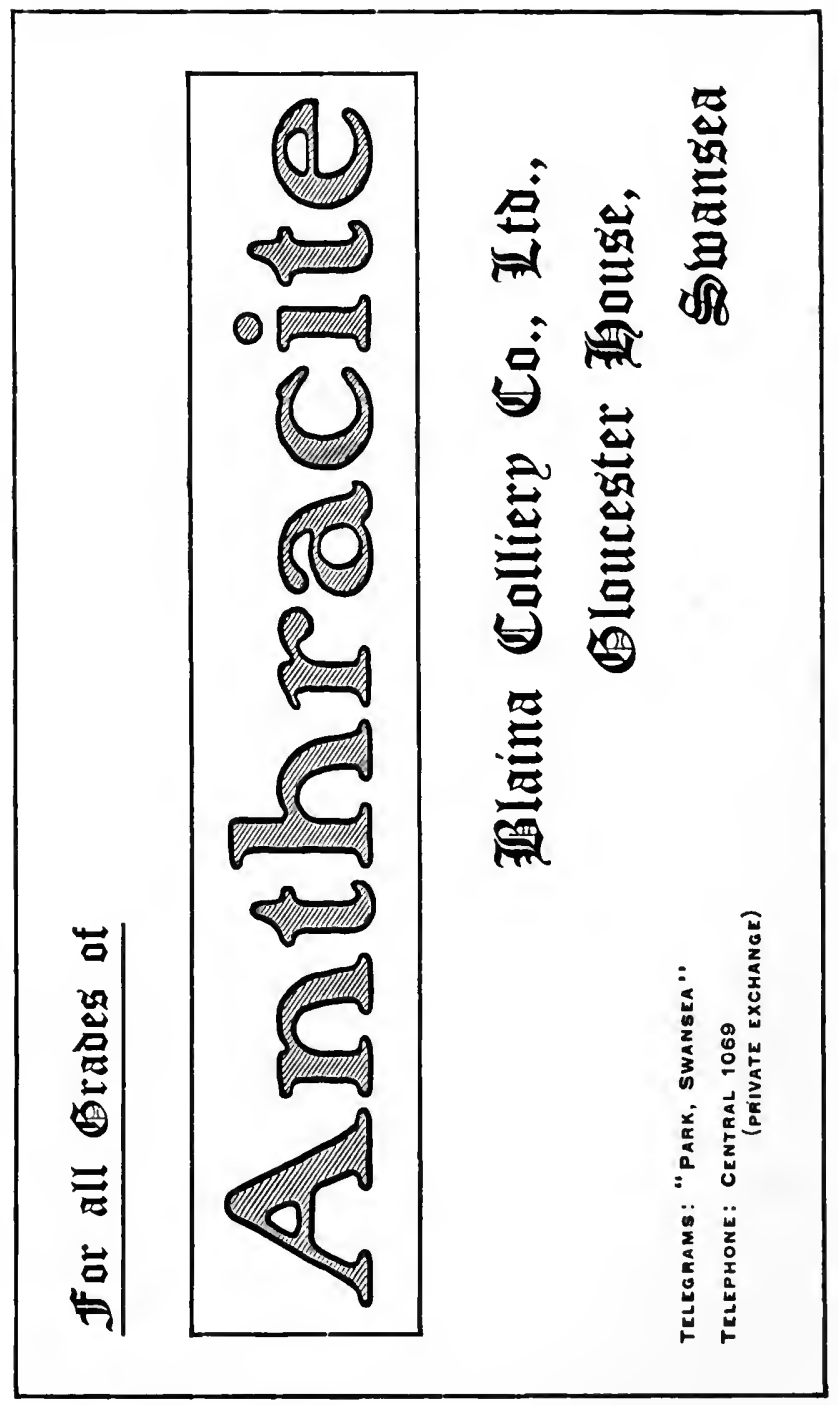




\section{ANTHRACITE}

CHAPTER I

THE WELSH ANTHRACITE COALFIELD

THE South Wales coalfield-Primitive mining-Collieries and men employed-Estimated coal reserves-World's increasing demand-Comparative outputs-Welsh triumph-Origin of anthracite-Susceptibilities of seams-Physical featuresVolatile variations-Results of borings-Deep mining.

THE South Wales coalfield is undoubtedly one of our greatest national assets, yielding nearly one-fifth of the total coal production of the country. Its vital importance to the Empire has been apparent from the dislocation and stagnation of all other industries consequent on the disputes, strikes and disturbances unfortunately prevalent of recent years in the coalmining industry. Covering five counties, it has an estimated area of about 1,000 square miles, of which about 15 per cent is under the sea. The western portion of the field yields hard anthracite and semi-anthracite, while the varieties of the eastern area are dry steam coal, smokeless steam coal, and bituminous coal. Swansea is practically the centre of the anthracite field, but considerable and valuable seams extend for several miles below the sea across Swansea Bay and into Pembrokeshire.

Although the output of Welsh anthracite is only one-twentieth of that of America (Pennsylvania), it has the distinction of being the finest quality in the world, and in world-wide demand. Indeed, in normal times, prior to the Great War, of its modest annual output of $5,000,000$ tons, about 67 per cent was 
exported-mostly to countries producing their own anthracite-so universally is its supremacy recognized, only about 33 per cent being required for home use. However, Britain has grown wiser of late, and, thanks to a vigorous publicity campaign, organized to educate the people as to the merits and advantages of this wonderful fuel-rightly termed the "king of coals"the inland demand has grown enormously, far exceeding the supply at intervals, and the order of the percentages quoted above is now reversed!

In the Western Valleys of Wales informs us that one of the earliest records of digging for coal in South Wales appears in the charter granted by the Lord Marcher, William de Breosa, in 1305, to the burgesses of Swansea, giving permission to get "pit coal in Byllywasta" (believed to be Gellywastad, north-east of Swansea). In the reign of Queen Elizabeth, the Lord of Cemaes declared that the coal of the locality " may be number'd as one of the cheefe commodities of this country, and it is so necessary, as without it the country would be in great distress."

As to the methods of mining then in vogue, he says, "They used not engynes for lifting up the coal out of the pitt, but the people carried the coale up a slope and along stayers uppon their backes; whereas now they sinke their pitts downright four square, and with a wynlass turned by four men they draw upp the coals, a barrell full at once, by a rope."

Even so, they feared exhaustion of their resources, and imposed a tax on the coal " to stay the transporting," which "it is feared would in time wholly ware out the coale and soe leave the country destitute of fuell !"

It was not until 1850, however, that the modern coal industry really commenced, the first pit being opened at Aberdare, in the Cynon Valley Thereafter 
it became one of the big commercial activities of the country, pitshafts being sunk and mining villages springing into existence with great rapidity, until now every valley in South Wales contributes its quota of coal.

Notwithstanding the lead which America holds as regards output, and the potentialities of the German fields, we possess the advantage of holding (in normal times) almost the whole of the overseas coal trade of the world. The convenient proximity of the best seams to the South Wales ports is largely responsible for this satisfactory state of affairs.

There are forty companies working the South Wales anthracite coalfield, comprising seventy collieries; of which the most important are the veins, or " seams," known as the Big, Stanllyd, Brynlloi, Peacock, Gras, Green, Charcoal, Triquart, Pumpquart, and Lower Pumpquart veins. The largest colliery is New Cross Hands, owned, together with several other collieries, by Cleeves's Western Valleys Anthracite Collieries, Ltd., Swansea, pioneers of the industry. Over 200,000 men are engaged in the whole field, but only about 14,000 of them are in the anthracite collieries.

Mining experts calculate that the present output of over $45,000,000$ tons of Welsh coal a year can be maintained for another 600 years. The total estimated reserve is given as 28,000 million tons, of which $22 \cdot 27$ per cent is anthracite, 30.42 per cent is bituminous, and 47.31 per cent semi-bituminous and steam coal. In 1904, when the late Lord Merthyr prepared, for the Royal Commission on Coal Supplies, an estimate of unworked coals in South Wales and Monmouthshire, he calculated that, below St. Bride's and Carmarthen Bays respectively, there were $50,360,444$ tons and $329,664,000$ tons of anthracite-apart from the 
appreciable deposits known to exist under Swansea Bay. So we are in no immediate danger of the " anthracite famine" which certain hysterical sections of the Press occasionally threaten us with.

The demand for coal is, of course, an ever increasing one, consequently Britain must sternly discourage the continual resort to strikes; and next in importance to production is coal conservation-by the proper use, instead of abuse, reducing waste to a minimum. South Wales is paying more and more attention to this ; much is being done in the coking industry, in the recovery of valuable by-products, and in the manufacture of patent fuels. The greater use of anthracite contributes immensely to this desirable end, easing the drain upon bituminous coals which are rich in by-products.

Professor W. A. Bone says: "The world's demand for coal, which in 1863 amounted to some 130 million tons per annum only, had been by 1913 increased to nearly 1,250 million tons per annum. Such a tenfold increase in fifty years represents a ' compound interest rate' of practically 5 per cent per annum throughout the whole period. During the last ten years of it this rate of increase was fully maintained as follows-

"In 1903 the total demand was 800 million tons; in 1908, 1,000 millions, and in 1913, 1,250 millions, and it is hardly likely that the rate will diminish. . . . During the last decade these demands have been principally supplied by three countries, namely, the United States, Great Britain, and Germany, which have between them annually raised practically 83 per cent of the total coal consumed in the world. If now the average outputs of anthracite and bituminous coal from each of the three countries in question for the three periods since the year 1900 be examined, it will be found that the output of the United States has been increasing 
at a compound interest rate of 6 per cent per annum, that of Germany at a compound rate of 4 per cent per annum, whilst the British output has increased at a compound rate of only 2 per cent per annum. Assuming that these relative rates of increase are maintained, it may be predicted that Germany's output will overtake that of Great Britain about 20 years hence, when each country will be producing some 420 million tons per annum "

But an important point of interest to Wales is that America's output of anthracite (over 100,000,000 tons annually) has practically reached its height, and may soon be on the decline, whereas the output in South Wales will most certainly continue to rise, without making an appreciable inroad on the abundant reserve supplies.

The special nature of the coal produced and the position of the coalfield, have led to South Wales becoming the chief coal-exporting district of the country. The arrangements at the collieries, railways and docks have been made consistently with a view to export, and their equipment is in some respects unfavourable for inland trade.

That this coalfield appreciates the value of its small coal is apparent from the fact that it is the largest briquette-making district, producing over 90 per cent of the total output of the country.

Writing in the Herald of Wales (7th Jan., 1922) on the triumph and recent " boom " of Welsh anthracite. Mr. J. D. Morgan, J.P., the Miners' Agent, says-

"The position of the anthracite coal industry of West Wales to day is unique, and when I look back at the years which have rolled away since 1875 and 1876, and see the headway that has been made, I am inclined to describe the progress as almost romantic. Prices, 
the demand for the coal, comparison with the position, past and present, of the steam and bituminous coal markets, and the relative positions in regard to employment and unemployment, form a remarkable story. In the early days, anthracite was selling at $7 \mathrm{~s}$. $6 \mathrm{~d}$. to 8s. per ton f.o.b. Swansea. Now look at the change ! The price of anthracite had improved from 9s. 1d. per ton f.o.b. Swansea in the year 1888 to $18 \mathrm{~s}$. $4 \mathrm{~d}$. per ton f.o.b. in the year 1913, and the total production had increased from $1,550,154$ tons in 1894 to $4,833,159$ tons in 1913 (the year immediately preceding the war), whereas the total output of coal in the whole of the South Wales coalfield had only increased during the same period from $33,418,344$ tons to $56,830,072$ tons. The anthracite output for the period referred to had increased at the rate of over 200 per cent, whereas the total increase for the whole of South Wales coal was only at the rate of 70 per cent. The anthracite collieries are in a very unique position to-day. They work regularly, and the demand is far in excess of the supply, and the best large coal is selling at the present time, according to the prices quoted on the Swansea Exchange, at from 60 s. to $62 \mathrm{~s}$. per ton, f.o.b., whereas the best Admiralty steam coal at Cardiff is selling at from 25s. $6 \mathrm{~d}$. to $26 \mathrm{~s}$. 6d. per ton f.o.b., and the best bituminous is selling at from $27 \mathrm{~s}$. $6 \mathrm{~d}$. to $30 \mathrm{~s}$. per ton. The price for anthracite is more than twice as high, yet the demand is far greater than the supply.... There is no such anthracite in the world as ours.

"Do you remember Andrew Carnegie, in his Triumphant Democracy volume, in 1886 , boasting of the position and prospects of Pennsylvania? He pointed out that that State had deposits of anthracite covering an area of 470 miles, which were of greater value than the coal areas of other countries which might be ten 
times as large; that, in parts, those deposits varied from 50 to $700 \mathrm{ft}$. in thickness and averaged $70 \mathrm{ft}$. Well, I worked for a few years on the anthracite coal in the United States-in the years 1888-89-90-in the best anthracite seams in Pennsylvania, the most notable being the Baltimore Seam, in Wilkesbarre, and I can claim from experience that the best Welsh anthracite in West Wales is far superior in quality even to that coal .... and has secured such a position that no other coal can possibly compete with it or become a substitute for it."

The interesting figures $\mathrm{Mr}$. Morgan quotes as showing the enhanced value of anthracite to-day, refer only to prices for exported coal. He might have truthfully added that the enormously increased inland demand for anthracite during the year 1921 was so great that, not only did it seriously retard the sale of Welsh steam coals, but that anthracite was readily bought in London by domestic consumers even at the exorbitant prices of $95 \mathrm{~s}$. and 100s. per ton (due, of course, to the retail merchants' charges) !

The effect of educational propaganda during the last three years in this country has revolutionized public opinion regarding Welsh anthracite, establishing a big and permanent demand for home consumption. One of the large exporters, asked about the prospects of reviving the trade hitherto carried on so extensively with South America, said : "The demand for anthracite is such that we have all our work cut out to supply the orders we already have in hand ; there is no necessity for us to hanker after American markets."

Origin of Anthracite. If the production of anthracite were a question of pressure metamorphism, there would be some connection between the formation of anthracite and the effects of crushing by earth movements. But in 
South Wales there is no relation between the relative amount of disturbance of strata and the production of anthracite. It is usually found that in passing through the South Wales coalfield from east to west, the lower beds first exhibit the conversion into anthracite, the change being manifested at successively higher levels going west, until in Pembrokeshire all the seams are anthracite throughout.

Dr. Strahan, Director of the Geological Survey, from an exhaustive study of Welsh anthracites, formed the conclusion that the difference between these and the bituminous coals must be looked for in original differences in the nature and composition of the vegetable matter from which they were derived. Analyses of the individual seams of coal show great differences in their susceptibility to anthracitization, and he has been able to define certain iso-anthracitic lines for some of the more important seams on the South Wales map. These lines show no relation to any recognizable features in the topography of the district, nor to any lines of faulting or disturbance in the strata. Thus the "Red" vein becomes anthracitic in a region where seams hundreds of feet below it have not yet assumed that character. Dr. Strahan also calls particular attention to the very remarkable freedom from ash of the South Wales anthracites, and this diminution of ash apparently accompanies the production of anthracite. The Ras-las seam has about 7 per cent of ash in the bituminous area east of the coalfield, but when it becomes anthracite in the west its ash content falls to only 2 per cent. Thus the percentage of ash diminishes pari passu with the decrease of bituminous matter. If the anthracite had been formed merely by the loss of volatile matter from bituminous coal, the ash content would have increased, not decreased, and the conclusion seems to 


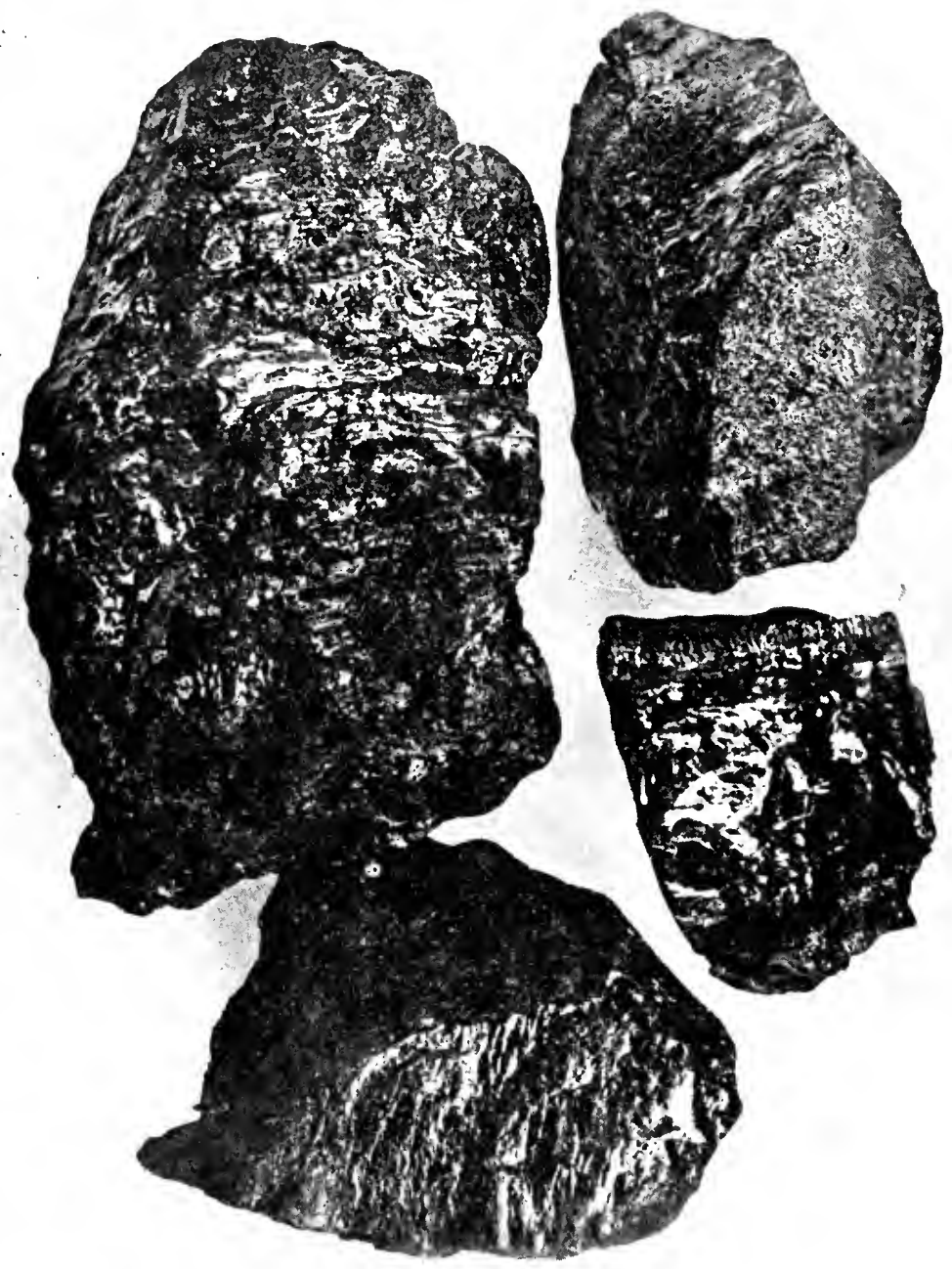

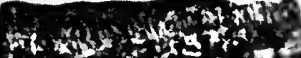

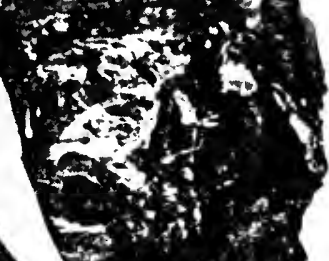
$x_{1}, x$ 
be that the South Wales anthracites were derived from a purer organic deposit more free from earthy matter than that from which the bituminous coals were formed.

In mining it is common to all coalfields that extraction is followed by subsidence, with the resulting crush and squeeze on the excavated areas, and on the roads through the areas. In most coalfields this effect is usually confined to the excavated areas and their close vicinity. Roads driven through the solid coal or in the undisturbed strata invariably remain intact. The feature of South Wales mining is that roads driven in the solid coal or in undisturbed strata do not usually stand intact, and are thus more difficult and expensive to maintain than roads through excavated areas. All the strata in the Welsh coalfield appears to be under compression, and an opening made therein soon begins to "squeeze" and close up. This renders Welsh mining different from that of other coalfields, and the result is shown by the higher cost of production due to the heavy cost of maintaining the mines, in repairing labour, and the pitwood necessary for safe working.

Three physical features in South Wales may account for this compression: (1) The mountain masses forming the surface, the weight of which is supported by the measures in which mining is carried on ; $(2)$ the friable nature of the strata associated with the coal seams chiefly worked; (3) the geological thrust from the south to which the coalfield is exposed.

In an interesting series of lectures on "The Origin of Anthracite," delivered by Mr. W. Galloway, D.Sc., before the South Wales Institute of Engineers, that gentleman referred to the decrease in volatile matter in the seams of coal which takes place between the southeast and north-west of the South Wales coalfield. In 
accounting for this decrease, he suggested that the change was probably due to the fact that the north-western end of the coalfield was at one time covered by a much thicker series of deposits than the south-eastern end, and that the deposits overlying the ground in the intervening space thinned gradually from north-north-west to south-south-east, with the result that the seams lying at greater depths under the surface would, while that condition obtained, be exposed to a higher temperature than those lying at a less depth, and that decomposition would proceed more rapidly in the former than in the latter. He mentioned that it is the universal experience in all coalfields that, other things being equal, the deeper seams are less bituminous than the shallower seams.

The lecturer said Sir Aubrey Strahan had questioned the validity of this explanation, so he cited some further information obtained from borings in Kent, and at Pembrey, near Kidwelly, which appeared to corroborate his views. He submitted five diagrams-three of the Kent boreholes, and two Pembrey boreholes, showing in each diagram the depths of the seams below the surface; the percentages of volatile matter, less ash and moisture; and the percentages of ash. The analyses of the seams found in these borings appeared to prove : (1) That there is a gradual and practically uniform decrease in volatile matter with depth; (2) that the proportion of ash has no special connection with the decrease in volatile matter ; (3) that, other things being equal, the deeper the seams lie under the surface the more nearly does their chemical composition approach to that of anthracite (88 to 95 per cent of carbon); and (4) that the casual occurrence here and there of a seam containing more volatile matter than one, or more than one, of those above it, does not invalidate the 
first of these four propositions, but must be attributed to causes into which it is not essential to inquire.

On the subject of deep mining Sir R. A. S. Redmayne, late Chief Inspector of Mines, says that the gradual exhaustion of the shallower fields of coal will necessitate the opening out of the " hidden" coalfields to an increasing extent. The deepest coal mine in the world is in Belgium, and is just about 4,000 ft. (metalliferous mining is carried on-e.g. in Michigan-at a depth of over $5,000 \mathrm{ft}$ ). In this country none of our mines attains this depth, though in some few cases they are not far from it. The Royal Commission on Coal Supplies in making their estimate of our coal resources took for their purpose a limit of $4,000 \mathrm{ft}$., though we know there is coal in the United Kingdom at a greater depth than that, it was not considered accessible for all practicable purposes. One of the chief obstacles to mining at great depth is the increased temperature. The first report, therefore, of the Institution of Mining Engineers' Committee appointed by the Department of Scientific and Industrial Research with the co-operation of the Doncaster Coal Owners' Committee, emphasizes certain aspects of the subject so far as the question of temperature is concerned. The Committee found that with a properly devised scheme of ventilation the wet-bulb temperature should be capable of such control as to allow of economical mining at a depth of at least $5,000 \mathrm{ft}$. 


\section{CHAPTER II}

THE BEAUTIFUL ANTHRACITE DISTRICT

The beautiful anthracite district-Unusual fertility-Absence of smoke-A picturesque panorama-Tourists' facilitiesWhat is anthracite?-Chemical analysis of the coal-Welsh supremacy-Labour and time saving-An artistic featSafety-Heat regulation-Rules for anthracite firesAnthracite and horticulture-.." Ca' canny" and underproduction-Output per man-Proportions of coal used industrially.

HIDDEN away among the mountains of South Wales, unknown and little suspected by the average tourist, is one of the most delightful bits of country Great Britain possesses, combining road, river, ravine, hill and valley, forestry and fertility rich and alluring as the Tyrol ; in fact, one instinctively wonders why it is necessary to go abroad for such scenes with these on our doorstep, as it were. But then, of course, the locality in question is unknown-the writer only accidentally discovered it through a business visit to the district, and was as much surprised by the artistic revelation as by the impressive grandeur of the scenery chanced upon. And it is actually the anthracite colliery areapositively beautiful!

North Wales, of course, as everyone knows, has long been famous for its beauty spots and health resorts, greatly lauded by the guide-books; but not so South Wales, which popular imagination associates only with coal mines and foundries. Hence, it follows that 
nobody would think of searching for the picturesque in the great coalfield; yet that is precisely where it exists !

In the Western Valleys of Wales graphically describes the district thus: "The Glamorganshire valleys of the anthracite area, known as the Swansea and Western valleys, are a delightful revelation to the surprised tourist. Ranges of impressive mountains on either side, green and fertile cornfields, pasture lands, and forests of trees here and there. Strange, you think, fertility can flourish so luxuriantly in a colliery district. True, all the same. Why? Because anthracite is a smokeless fuel, and consequently not injurious to plant life. Not a sign of smoke can be seen coming from any of the colliery chimneys, nor the chimneys of works using anthracite, in the whole district; and the uninitiated would not suspect the presence of collieries at all, so inconspicuous are they amongst the trees. In fact, some are not easy to locate, as the writer discovered when in search of them, excepting where their wastedump happens to occupy high ground. The views obtainable from certain of the more elevated collieries, such as New Cross Hands, Tirydail, and Llandebie, are magnificent. From these heights, on a fine day, one's vision can sweep the whole country, taking in a hundred hills ; and the panorama displayed around Pantyffynnon is particularly fine. Good roads, too, are the order almost everywhere, with many picturesque farmhouses and cottages by the wayside and in the villages to please the eye; and the well-built, substantial walls of Wales are a study in themselves." The housing accommodation of the miners in the anthracite district is particularly good, too ; there are no " dreadful hovels" to be seen, like those alleged to exist in some of the northern mining areas. On the contrary, their cottages 


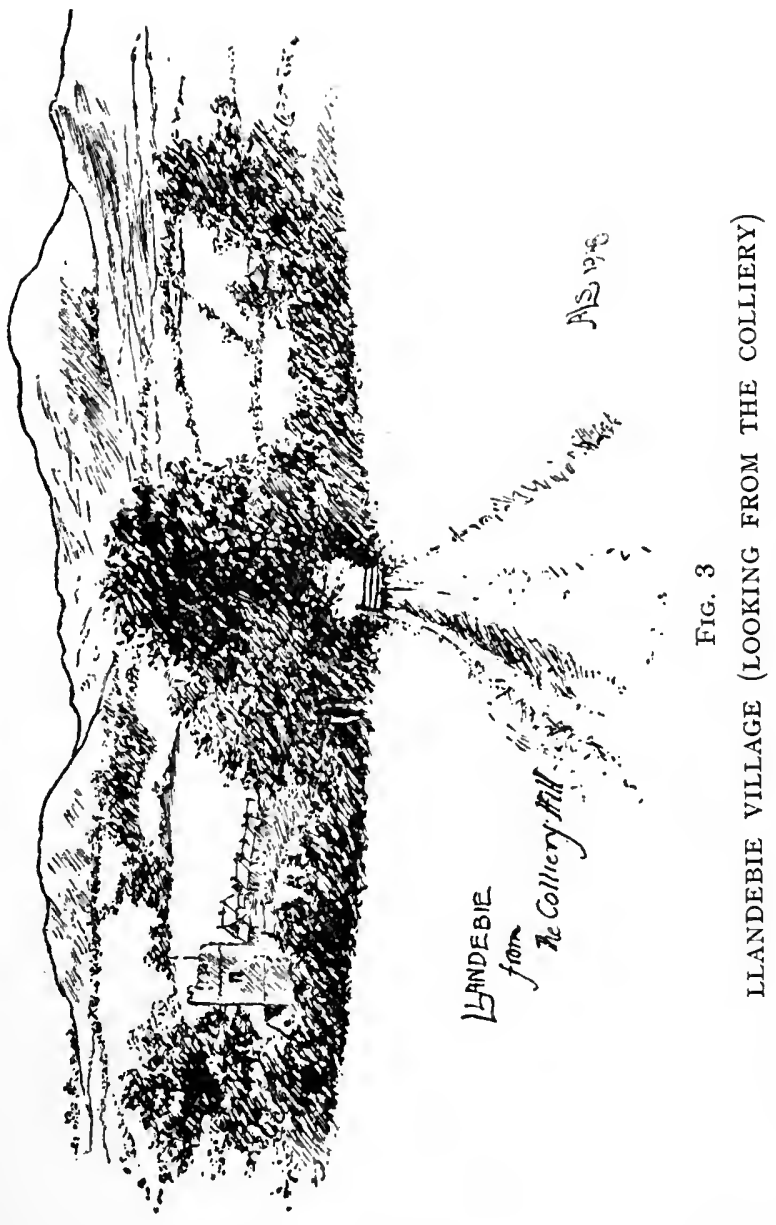


are well built, modern, clean, and wholesome generally, while some the writer has inspected were models of comfort and convenience, directly due to the personal interest of certain colliery proprietors in the welfare of their employees, and certainly not giving one that impression of the miner's hard life and "deplorable conditions" which some would have the public believe. Even the railway stations afford quite extensive views, as a glance at the illustration of Tirydail station shows.

The recent complaints of motorists as to the inadequate hotel accommodation and poor catering met with throughout England are, happily enough, not applicable to this charming locality, for there are plenty of good and comfortable old-fashioned inns, as well as a sprinkling of modern hotels, in the villages, where ample fare at reasonable charges is always available.

The whole district is well served by the Great Western and London and North Western Railways, and is conveniently reached by road from either Neath, Swansea, or Llanelly. The close proximity of the anthracite mines to the Bristol Channel ports (Swansea, Llanelly, Kidwelly, Briton Ferry, Port Talbot, etc.), has been of vital importance in the successful development of the export trade.

What is Anthracite? Being virtually pure carbon (the best quality containing quite 94 per cent), the calorific value of Welsh anthracite far exceeds that of all ordinary bituminous or " soft " coals, and it contains the least ash (less than 1 per cent in the higher grades) ; it is jet black, with a metallic lustre ; very hard, dense and slow-burning (therefore very economical); burns steadily with a bright red glow; gives intense heat, is clean to handle, continuous-burning, and absolutely smokeless. 


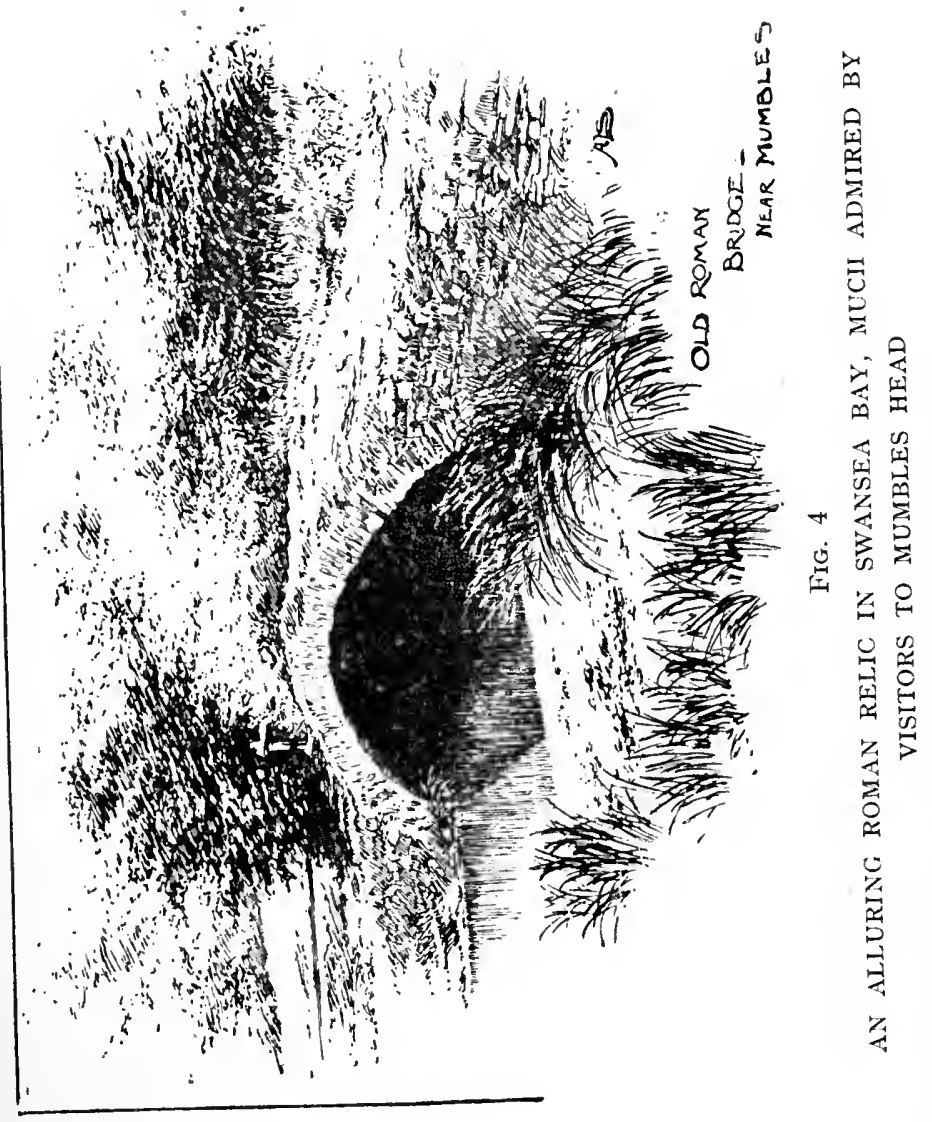


Below is a chemical analysis of best Welsh anthracite-

Carbon. Hydrogen. Oxygen. Sulphur. Nitrogen. Ash.

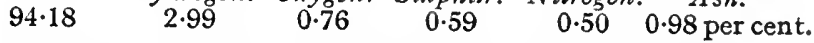

Several countries possess anthracite deposits of commercial value-some of which I shall deal with

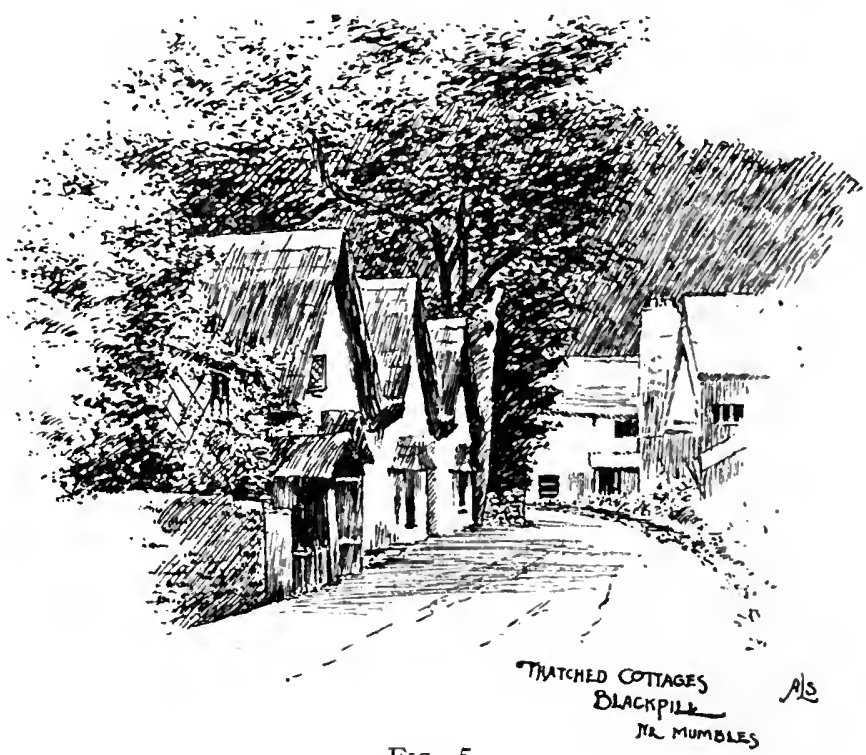

FIG. 5

BLACKPILL, ON THE IITTLE MUMBLES RAILWAY

later-but the quality of Welsh anthracite is supreme. Its economy is immense, apart from its other advantages, as will be obvious from the evidence in these pages; and not only does this coal burn so much slower and more regularly than other coal, but there is no waste. whatever involved with it, as the processes to which it is subjected, screening to sizes required, washing (to 
remove impurities), picking, etc., eliminate the dust, or " slack," associated with ordinary coals, which the consumer has to pay for and usually wastes. And it is pretty generally conceded that in domestic use one ton of good anthracite is equal to two tons of bituminous coal, or three tons of coke, which should compensate amply for its somewhat higher initial cost, necessitated

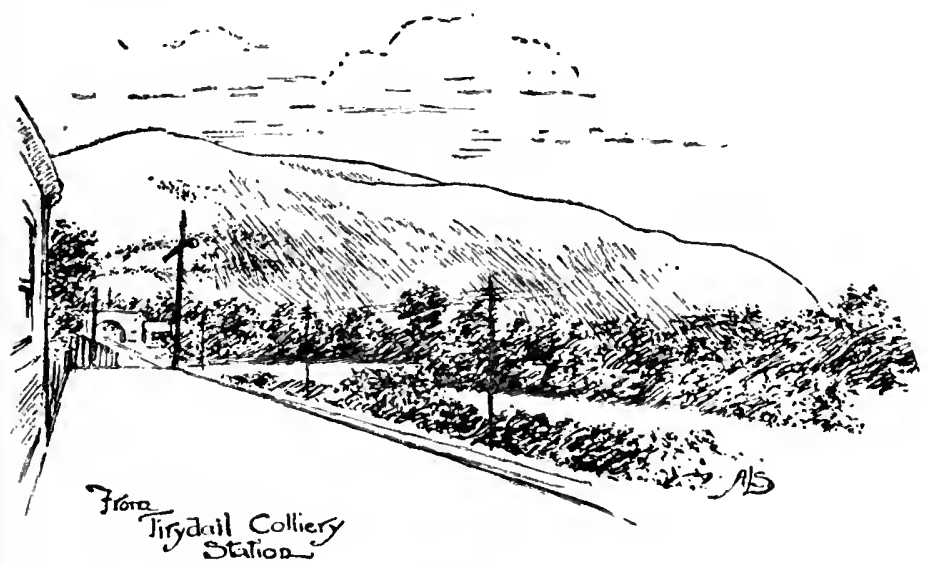

FIG. 6

MOUNTAIN VIEW FROM TIRYDAIL STATION

by its essentially elaborate preparation. I would emphasize the importance of this to consumers, industrial or domestic, who should appreciate the point when considering the question of comparative prices. It is undoubtedly the care and attention bestowed upon the preparatory processes which contribute in no small degree to the ultimate high efficiency and satisfactory results attained.

- In addition to the economies referred to with anthracite, must be mentioned the enormous saving of wood, 
paper, matches and such kindling materials, as, once lighted, an anthracite fire can be kept burning throughout the winter, or even continuously, if desired. In many Welsh households these fires have been burning for a lifetime! Again, there is the important consideration of time and labour saving. To lay and light a fresh

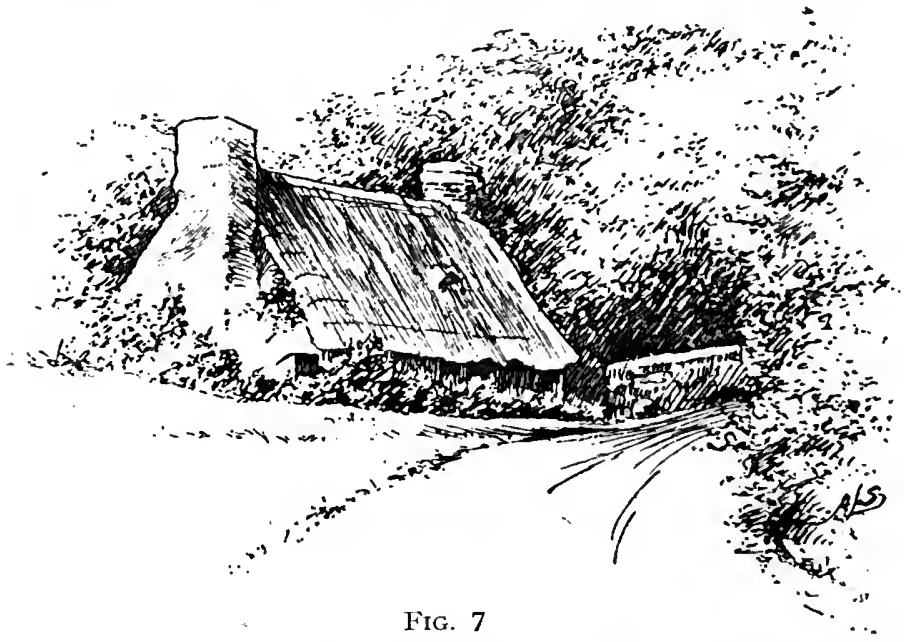

A PICTURESQUE SUNKEN COTTAGE BESIDE THE ROAD TO NEW CROSS HANDS

fire every day is a burden to be rid of - often very troublesome and irritating with a refractory grate and bituminous coal, filling the rooms with suffocating smoke from a backdraught. As an example of time and laboursaving, it may suffice to mention some business premises in which are installed seven stoves burning anthracite coal. It takes the housekeeper only 30 minutes a day to convey the replenishing coal from the cellar and attend to the seven stoves, whereas he requires 
fully 20 minutes daily to rake out, clean, relay, and light up two ordinary open fires.

Anthracite, being smokeless, causes no soot or dirt (obviating that unpleasant periodical visit of the chimney sweep) to spoil the pictures, walls, ornaments, furniture, etc.-hence, less work in dusting and cleaning. For these reasons anthracite stoves are being increasingly used in artists' studios, doctors' and dentists' consulting rooms, laboratories, etc. One enthusiastic and enterprising artist told the makers of a stove they installed : "In spite of the worst chimneys, stove is a perfect success and constant practical giver of solid comfortwarms not one centre, but every corner, and has turned an awfully damp studio room into a pleasant retreat, and has assured the safety of its contents-valuable drawing papers, sketches, books, etc. It has never been out, and so economical and efficient. I can toast, cook, boil water, etc., on the stove-grand!"

All this accomplished by the resourceful artist on an ordinary ornamental type stove, not intended for cooking! Of course, with one of the specially-constructed ranges for cooking, anthracite is simply perfection.

Anthracite requires much less attention than other coal, beyond replenishing and cleansing from residueabout once only in twenty-four hours in the case of large stoves, or once in twelve hours where small stoves or open grates are used. There is much less labour involved for servants in carrying coal, while the grates and hearths are more easily cleaned. And as this coal deposits no soot in the chimney, there is nothing to catch fire; nor does it crack, spark, or fly like other coal, which has so often caused serious fires and fatalities. The writer has had occasion to watch large anthracite furnaces, heating great $40-\mathrm{ft}$. boilers, for periods as long as six hours at a time, but never once saw a spark 
or splinter of burning coal fly out of the open doors, even while stoking. And there were flames $20 \mathrm{ft}$. long, for anthracite is by no means devoid of flame as some people suppose. Anthracite also meets a down-draught better than does ordinary coal.

The cinders burn equally as well as the coal itself, so nothing but the ash need be discarded.

Anthracite must on no account be disturbed by poking, or it will quickly lose its heat and pleasant glow. Leave it severely alone, and abolish the poker. The ash need only occasionally be raked out with a thin iron rod from the bars at the bottom of the grate, allowing the fire to settle itself down naturally when replenishing.

Many of the best kitchen ranges are capable of burning anthracite (there is one specially constructed for the purpose, and I shall have occasion to refer to it later), and those new consumers who are daily adopting it are astonished by the economy and other advantages effected, wondering why they have allowed themselves to be so long prevented by old-fashioned prejudices and ignorance from giving it a trial.

This coal is now used extensively in a large number of important public institutions, clubs, churches, railway stations, halls, and prominent London and country houses. It keeps well, and loses none of its calorific value in an open shed, or when exposed for a lengthy period to the open air.

Of course, the specially-designed stoves give the best results, reducing heating to a science. They regulate temperature as required, are kept burning day and night, consume a minimum amount of coal with a maximum of heat, and are highly ornamental and in great variety of design; but it must not be supposed that stoves are absolutely necessary to the proper burning of anthracite, for such is not the case. It will burn in any ordinary 


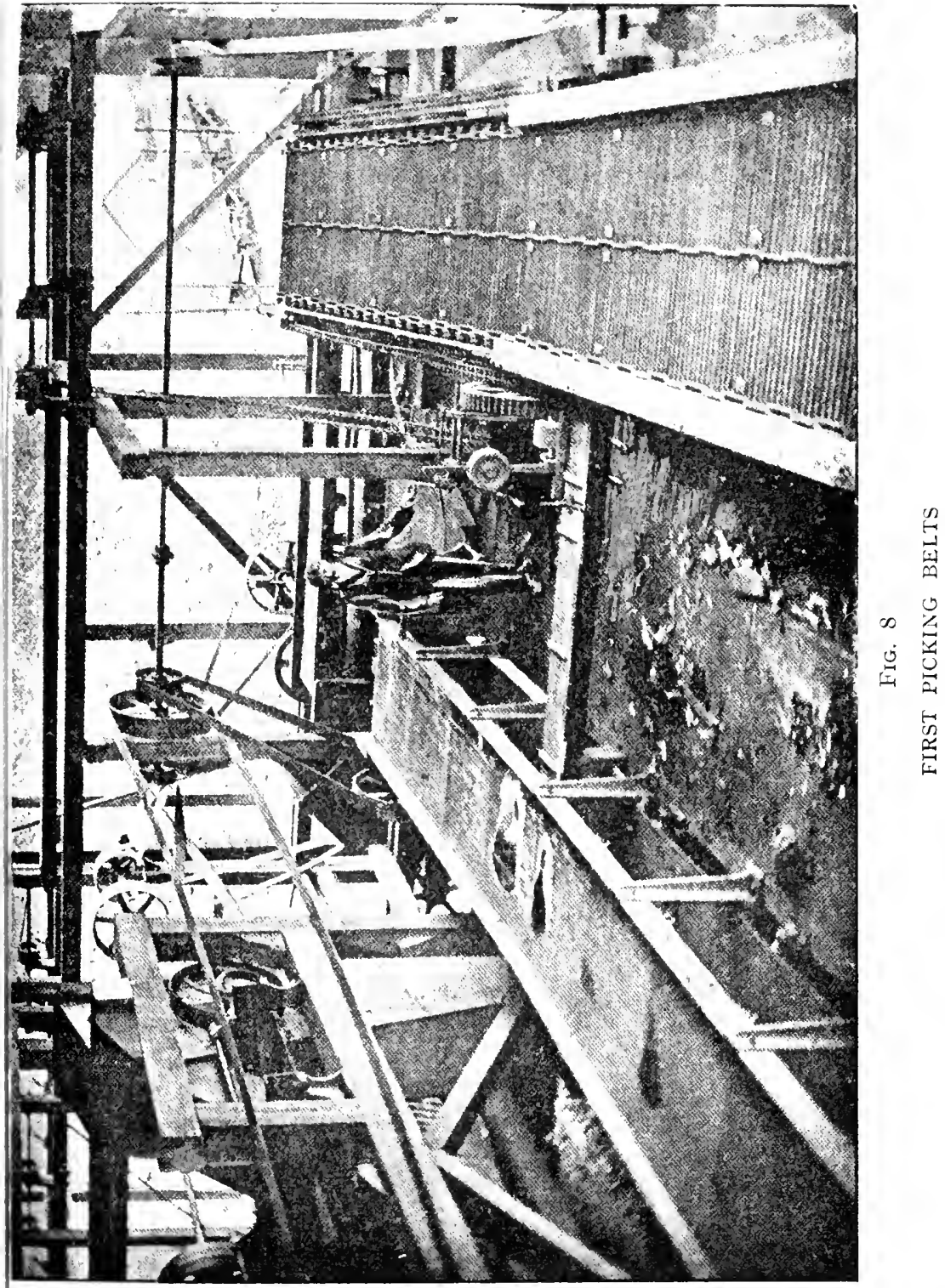


open grate, the only condition being that, anthracite being hard and slower of ignition, a little more wood than usual should be allowed for when starting the fire. I have seen careful comparative tests made with anthracite and ordinary coals in an open grate showing not only a 40 per cent saving of fuel on the part of anthracite, but a higher temperature maintained-even though windows were opened while the anthracite fire was in progress !

As a ventilator anthracite is unsurpassed, requiring as it does for perfect combustion proportionately three or four times the volume of air which a gas fire requires.

And instead of coming down to a room like an icechamber on winter mornings, as happens when using ordinary coal, we know that anthracite keeps alight all night, maintaining the same warmth and comfort for us to return to each morning as on leaving our rooms the previous night.

Practical rules for the domestic use of anthracite are given in In the Western Valleys of Wales, as follows-

(1) Kindling wood should be a little thicker-and preferably harder-than for ordinary coal. It should also be $d r y$, and there should be rather more of it than usual.

(2) Pack the anthracite closely on and about the sticks, and well fill the grate. Then light the paperwhich can be gently raked out when burnt to increase the draught, as the greater the draught the better when starting the fire.

(3) Once lit, leave the fire absolutely alone.

(4) Do not poke an anthracite fire.

(5) When replenishing the fire, take a thin iron rod, or wire, and thoroughly clear the ash from the bottom of the grate. Do not put on too much coal at a time. (6) Riddle all cinders and re-burn them. 
For horticultural purposes anthracite is ideal and in great demand. It is rapidly superseding coke for heating greenhouses, as it gives a more regular, uniform heat, and lasts longer without attention, dispensing altogether with the costly night labour. Less ash is made, so furnaces need less cleaning, and few clinkers require to be removed; and there are no poisonous fumes from the chimneys to injure vegetation or retard cultivation.

A serious drawback to the Welsh coalfield, as to other British coalfields, has been the disturbing "ca' canny" policy of the miners, the shortened hours of working, and the surplus men employed (condoned by the Miners' Federation), followed by disastrous strikes during 1921, as a direct result of which our outputs decreased to absurd proportions, we suffered the loss of our export trade, and many collieries were compelled to close down -permanently, it is feared. The following statistics by Mr. Thomas H. Watkins, President of the Pennsylvania Coal and Coke Co., given before the United States Chamber of Commerce, reveal the deplorable condition of affairs--

\section{United States-}

1918. Employees engaged in production of Bituminous Coal

Employees engaged in production of Anthracite Total production of Bituminous and Anthracite Coals Average output each man employed :

Great Britain-

1920. Employees engaged at the mines .

" Total production . Average output each man employed .

615,305 men.

147,121 ,

$678,211,000$ tons.

889 tons.

$1,185,000$ men. $229,000,000$ tons. 193 tons.

His ironic comment: "The regulation by the Union has reduced the output per man to what appears to us (Americans) to be an absurdly low figure." 
At a meeting of Consolidated Cambrian, Ltd., held in March, 1921, at the Great Western Hotel, Paddington, Sir Leonard W. Llewelyn, K.B.E., said that " in South Wales there are now far too many men employed, and more than necessary-27,679 more than pre-war-a burden on the industry. Many young men who would not fight for their country came to the collieries as protection against military service. These men ought, in fairness to the genuine miners, to be made to return to their pre-war occupations. South Wales coalowners were losing at the rate of $£ 25,000,000$ a year-or a little less than $£ 2$ per man per week."

And it is through these very unwanted young menthe "hotheads" and agitators-that the unrest and industrial strife have been fanned into flame! It serves to show what the industry is up against, of which it must be purged ere normal working can be resumed.

The Fuel Economy Reviezer of April, 1921 (issued by the Federation of British Industries), recorded the interesting result of a questionnaire sent to manufacturers, etc., in an endeavour to obtain the proportions of different coals used industrially in Britain. The statistics gathered were-set forth as follows-

\begin{tabular}{|c|c|c|}
\hline \multicolumn{2}{|c|}{$\begin{array}{l}\text { Tonnage used by consumers } \\
\text { replying to questionnaive }\end{array}$} & $\begin{array}{l}\text { Estimated output tonnage } \\
\text { during } 9 \text { months of } 1920 \text {. }\end{array}$ \\
\hline $\begin{array}{l}\text { Bituminous } \\
\text { Welsh Steam } \\
\text { Anthracite }\end{array}$ & $\begin{array}{r}37,507,000 \\
\quad 624,000 \\
: \quad 449,000\end{array}$ & $\begin{array}{r}107,450,000 \\
72,070,000 \\
3,234,000\end{array}$ \\
\hline
\end{tabular}

The table illustrates a preponderating tonnage of bituminous coal and the relatively small amount of steam and anthracite coals used in industry; and a comparison with the output figures seems to indicate that the class of coal which can be exported with the 
least detriment to industry is Welsh steam coal. Anthracite would appear to be regarded by industry as a luxury, and is used principally in gas-producing and steam-raising undertakings.

However, these figures are considerably discounted by their unsatisfactory incompleteness, as shown by the editorial memo: "In South Wales it was found that manufacturing interests were not disposed to give the information required, and the project had to be abandoned in that area."

"Of a total fuel consumption of $44,309,000$ tons, estimated to be 30 per cent of the total industrial requirements, it appears that as much as $39,644,000$ tons are used in the unwashed state, i.e. over 89 per cent."

Proportions of bituminous coal used as slack, to that used in the large grade, in various industries are here given-

$\begin{array}{cc}\text { Tons } & \text { Tons } \\ \text { Large. } & \text { Slack. }\end{array}$

1. For Steam raising, including electricity undertakings (nearly 3 times as much slack)

2. For Producers . $2,325,0006,411,000$

3. For the gas industry (nearly 30 times as much large as slack).

4. For coke ovens (nearly 3 times as much slack).

$553,400 \quad 432,000$ $10,060,000 \quad 395,000$ $1,238,0003,658,000$ 


\section{CHAPTER III}

LIFE AT THE ANTHRACITE COLLIERIES

Life at the anthracite collieries-Exploiters' difficultiesPower of anthracite-The pioneers-Preparation of anthracite-Sizing and washing coal--Standard sizes-Foreign buyers-The wonderful pit pony.

THE output of anthracite from the South Wales coalfield was for many years restricted to two trades-the brewing and hop-drying, and lime-burning trades, in both of which this quite smokeless fuel was found to be ideal. Practically none was required domestically, except in the form of what the Welsh people call " pele" (a mixture of anthracite dust and clay), because its merits and advantages were neither understood nor favoured, the average Britain preferring his blazing, smoky and wasteful fire to the closed stoves adopted on the Continent, and this splendid coal-the best in the worldwas marketed abroad in consequence, two-thirds of the total output continuing to be exported until up to about three years ago, when the eyes of the British public were at last opened and the situation rapidly changed. "The coal of the future," as writers of bygone generations described it, has now become the coal of to-day.

But it has not been an easy task to develop the anthracite coalfield, and many enterprising speculators in the past have lost more money than they got out of it, such are the risks incurred. Unlike other coalfields, where operations usually commence on a large scale, all anthracite colliery undertakings had modest beginnings, for this field is continually troubled by "faults"almost weekly occurrences-involving the companies 
in much trouble and financial strain, causing many of the properties to change hands again and again before success and stability are attained. Considerable courage as well as perseverance and special knowledge of local conditions are necessary to successfully develop an anthracite property, hence few outsiders entering the industry have succeeded.

The growth of the output and demand for anthracite from South Wales is traceable from the date of the introduction of the Dowson pressure power plant, the gas for which was generated from anthracite ; and with the introduction of the suction power plant to follow, the demand for anthracite became universal, especially when power users realized the important fact that one ton of anthracite will produce in a pressure or suction gas-engine power equal to ten tons of ordinary steam coal used under an ordinary steam boiler.

The trade in anthracite has steadily increased from about $1,780,000$ tons in 1896 to $4,800,000$ in 1913 , largely attributable to the activities of the real pioneers of the industry, Messrs. Cleeves's Western Valleys Anthracite Collieries, Ltd., of Swansea, the largest company in the field, owning some of the principal collieries working the best seams. To their initiative and enterprise is due the introduction of the most efficient electrical and other up-to-date equipment in modern mining development, always regardless of expense ; and the organization necessary to popularize anthracite and increase the output to the benefit of the whole industry must be credited to their energy and efforts. The company's London offices are at 120 Fenchurch Street, E.C., where helpful information or advice on the selection of anthracite for different purposes may be obtained.

The process of preparing anthracite before it is ready 
for the various markets is elaborate and very costly, entailing the use of intricate and delicate machinery, the wear and tear on which is considerable. When next comparing coal prices, perhaps the reader will not begrudge the necessary extra cost of his anthracite. I cannot do better than quote the interesting description of life at the collieries given in the instructive brochure, In the Western Valleys of Wales, issued by Messrs. Cleeves who employ nearly 3,000 men in normal times, and whose mineral area covers something like 2,580 acres-

"The mines are each approached by 'slants,' or inclined tunnels, but at the New Cross Hands Colliery (the largest and one of the older collieries) there is also a pit shaft. An elaborate system of tramlines links up the different parts of a mine, and small iron 'trams,' or trucks, are utilized to bring up the coal, hauled to the surface by powerful steel-wire ropes connected to electric and other winding engines. Usually about a dozen full trams at a time are hauled up and ingeniously diverted to their destination along separate routes, elevated where there is a hill to climb by means of a moving chain, or 'creeper,' as it is termed, which runs between the lines and carries hooks which attach themselves automatically to the trams.

"Trams containing the shale and other rubbish go direct to the waste-dump, while those filled with the good coal travel past the weighing-room, opposite which, on a weighbridge, each tram automatically registers the weight of its contents, recorded on an indicator inside the room. It then passes on to a rotary tippler, which turns the tram completely upside down, shooting the coal on to the declivity screens, from whence it travels on belts to the breaking and screening departments. The empty tram is then released, returning 


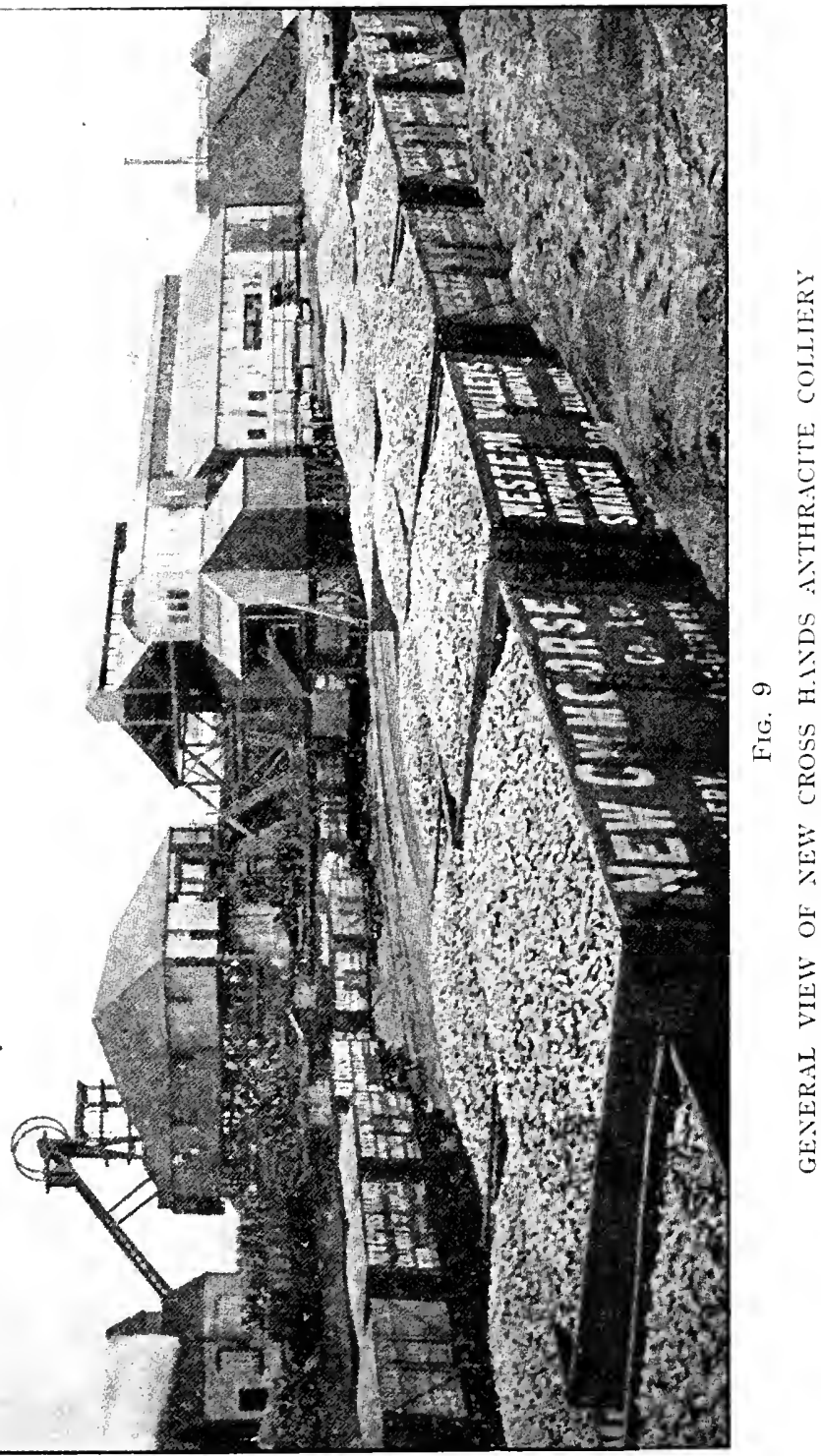


by itself to the mine, down a gentle gradient, propelled by its own weight.

"The revolving breaker having dealt with the large coal, this coal travels to the various ' screens' for sizing. These screens for sizing are placed one above another, sloping, and worked on a shaking principle, keeping the coal steadily on the move to obviate congestion. Some collieries do not break their coal, merely screening it to a few sizes, but Messrs. Cleeves break and screen their product into eleven different sizes, besides carefully washing several sizes. The screens are perforated with round holes, through or over which the coal passes in sizes from $2 \frac{1}{4}$ in. by 4 in. (the largest cobbles) to $\frac{1}{8}$ in. by $\frac{1}{4}$ in. ('grains ') ; and similar moving belts, but not perforated, convey the screened coal to the pickers who remove by hand whatever shale it contains. Impurities are picked from the cobbles and large coal prior to the coal going to the breaker. These picking belts also serve the purpose of loading the coal into the railway trucks, but on them only the larger sizes are dealt with, viz., machine-made cobbles and machinemade 'French' nuts. Sizes below the French nut cannot be conveniently picked and sorted by hand, and are therefore transferred to a washer.

" The 'washery' belts work with the same shaking movement, carrying the small coals, such as Stove Nuts, Peas, Beans, Pea Nuts, etc., through tanks of water to effectually remove the particles of stone. This is the sole reason for washing, not, as some suppose, to remove the fine coal-this being done by screening before washing. Notwithstanding this, however, it is, of course, impossible to prevent some fine coal made in the washing process adhering to the wet pieces; but Messrs. Cleeves have always made it their practice to place all their coal in the trucks in the best possible 


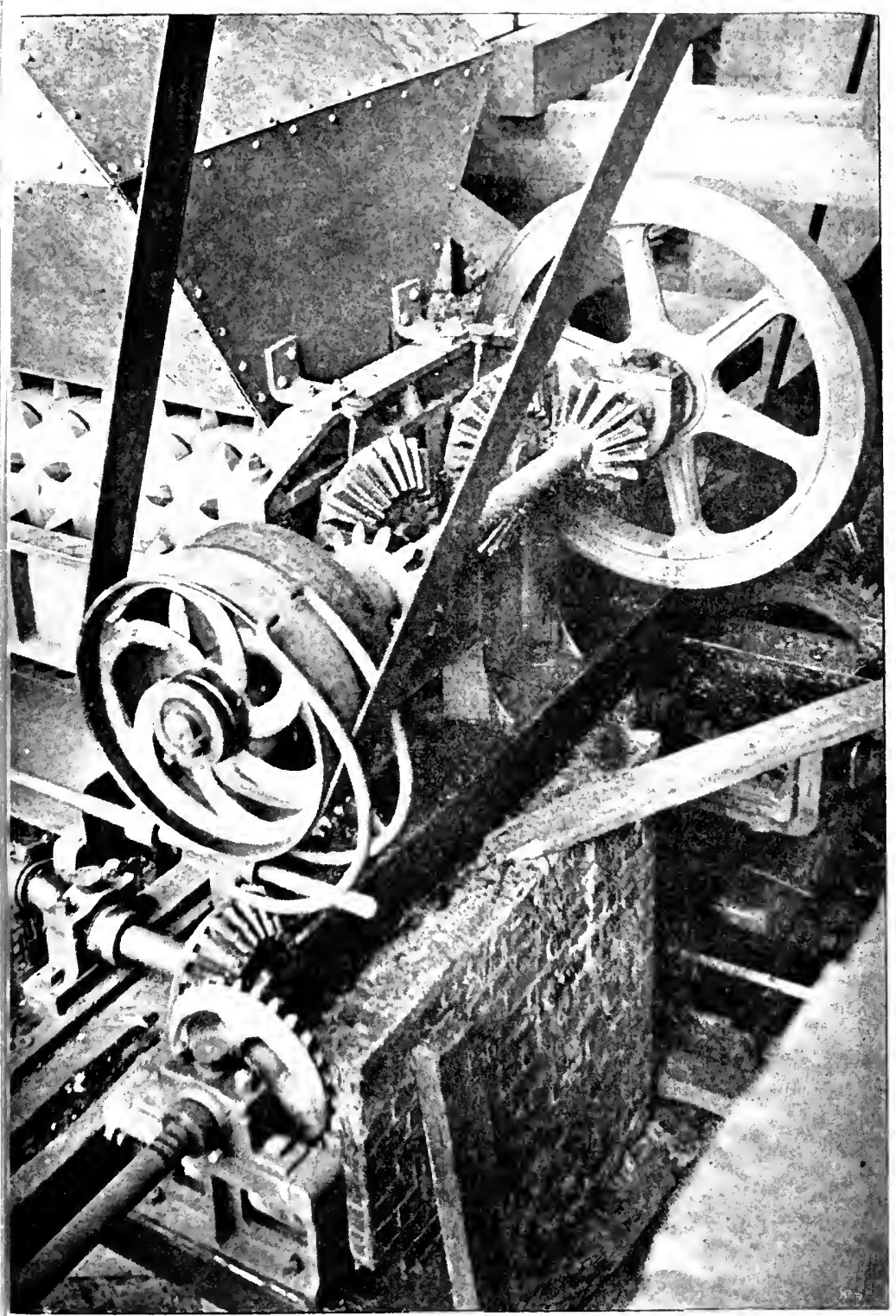

Fig. 10 
condition, which is important to the consumer. To ensure a maximum standard of quality being maintained, the firm's coal examiner twice daily takes and tests samples of coal from the screens and washery, and the percentage of waste material detected rarely reaches 1 per cent."

Below are the various descriptions and sizes into which Messrs. Cleeves divide their coal (the recognized British standard sizes), with their respective uses--

Selected large, for malting, hop-drying, and horticultural purposes.

Screened large, for export for breaking down into sized coals. Machine-made Cobbles $\left(2 \frac{1}{2}{ }^{\prime \prime} \times 4^{\prime \prime}\right)$, for central-heating apparatus, Dowson and pressure gas plants, household and various purposes.

Machine-made "French" nuts $\left(1 \frac{3}{4} " \times 2 \frac{1}{2}\right.$ "), for practically similar purposes as cobbles, and for open grates or large stoves.

Machine-made and washed Stove Nuts $\left(1^{\prime \prime} \times 1{ }^{\prime \prime}\right)$, for suction gas plants and the majority of domestic stoves.

Machine-made and washed "Pea-nuts" $\left(\frac{1}{2} " \times 1 \frac{1}{4}\right)$, for "Economic" stoves and suction gas plants.

Machine-made and washed "Beans" $\left(\frac{1}{2}{ }^{\prime \prime} \times \frac{3}{4}\right)$, for suction gas plants and domestic stoves.

Machine-made and washed "Peas" $\left(\frac{17}{4} \times \frac{5}{8}\right)$, for suction gas plants and steam raising.

Machine-made and washed "Grains" $\left(\frac{1}{8} " \times \frac{1 "}{4}\right)$, for speciallyconstructed suction gas plants and under steam boilers with forced draught.

"Duff" (the fine, small dust), for spelter and cement making, chiefly to a small extent mixed with steam coals for making patent fuel, including boulets for domestic stoves and fires.

"Rubbly Culm" (or the rough small coal passed between longitudinal bars $11^{\prime \prime}$ apart), principally used for lime burning and steam raising.

Anthracite, being free from arsenic, etc., is excellent for the brewing industry; and the high percentage of carbon contained in Welsh anthracite enables it to displace coke and charcoal for the manufacture of carbide of calcium in Norway, Sweden and Italy, which countries take large quantities in various sizes. 
The industry was built up on its export trade, the largest buyers before the war being France, Italy, Germany and Scandinavia ; but the market is a worldwide one, even as small a quantity as $\mathbf{5}$ tons is dispatched at intervals in bags (for mule, etc., transport) to the most remote and unexpected corners of the globe.

While producers prefer to cultivate the home market (likely in future to surpass the foreign demand), they are compelled to maintain their export connections for the purpose of disposing of certain descriptions of anthracite not required at home, and unless these descriptions are disposed of, the quantities worked would be restricted and the costs to the home consumer increased in consequence. Reduction in cost is dependent upon increasing the output per man employed, reducing the present heavy railway, dock, etc., charges, and the more profitable utilization of the small (duff) involved. Given these circumstances, anthracite will quickly resume its former moderate prices.

Much of the "life" at a colliery

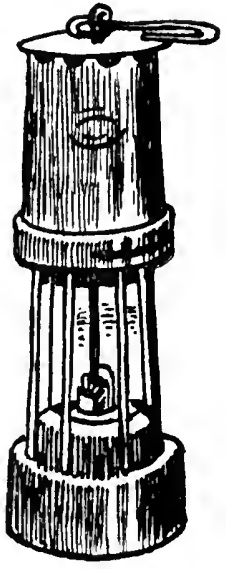

FIG. 11

A TYPICAL MINER'S IAMP Electric ignition, double gauge. Fitted with either magnetic, pneu matic, or lead lock, is, of course, below the surface, where the activity is none the less vigorous for being in the gloom of the pit. Anthracite mines are particularly lively and energetic concerns, with their signalling stations, electrical machinery, winding-cables, lights, bells, etc.; but one of the most interesting features of all mines, perhaps, is the wonderful pit 
pony, whose intelligence is quite extraordinary. These animals possess an uncanny sense of everything going on, and although their heads are usually covered, to afford protection for their eyes, they walk about and turn in awkward tunnels without injuring themselves, and can find their own way to the stables from any section of the mine! It is very important to the efficient working of a coal mine that suitable ponies for haulage are carefully selected, and such animals are a distinct class, selected for their weight, build and muscle-and they must be strong. They must also be short from nose to tail, to facilitate easy turning in the numerous narrow and cramped passages in a mine.

A colliery manager throws an interesting light on this subject : "No pony is allowed to work below ground until it is four years of age, and then only the best possible are of any value for colliery work. Given proper care and attention they are able to continue working in a pit until aged, and at the colliery with which I am associated there are animals which have been labouring below ground for sixteen years and are 'still going strong.' Nowadays, when so much controversy is raging as to the cost per ton of raising coal, it is surprising how often the factor of the maintenance of the ponies is ignored by the statisticians. The cost of a pony now varies between $£ 50$ and $£ 75$, as compared with anything from $£ 25$ to $£ 45$ before the war. During the war I paid as much as $£ 180$ for one. The cost of maintenance averages about 25s. a week, which is about double the pre-war figure. That they should be fed well is essential, for although the working day is one of only seven hours, it is a very strenuous one.

"When a horse goes blind it must no longer be worked underground. For that reason in nearly every colliery the stables are down in the mine, for unless brought 
daily to the surface-a difficult and costly procedurethe sight of the ponies is apt to be greatly affected by exposure to the sunlight after becoming accustomed to the darkness of colliery conditions. Ponies develop a most uncanny way of sensing a danger which is not apparent to the officials or the men. I have known not a few cases where a horse, without any apparent reason, has obstinately refused to pass a certain spot in the colliery ' roadway,' as the tunnel leading up to a 'stall' is called. Close scrutiny has revealed a piece of bad top which might at any moment cause a 'fall."

Hauliers generally form a strong attachment to their ponies, naturally, and one was amazed to learn that during the disorders of the great coal strike of 1921 there were men capable of the callous and inhuman attitude of abandoning such wonderful animals to their fate in the deserted pits. 


\section{CHAPTER IV}

\section{ECONOMICS AND EFFICIENCY}

Economics and efficiency-Anthracite in domestic serviceEducating the public-Official tests and demonstrations100 per cent economy-Increased efficiency from decreased consumption-Comparative costs of fuels-Dr. Fisherden's experiments-Fallacy of adding chemicals-Professor Barker's fuel tests-Comparative heating values-Chimneylosses-Consumers' reports of stoves-Pre-eminent economy of anthracite-Coalowners and costs-Kitchen conquestEnglish cookery-The " King of Ranges "--Immense saving of fuel-Importance of clean fires-Soot and Heat-lossesDomestic boilers-Anthracite versus gas-The "Therm" and B.T.U.-The " Florence" boiler-grate-Welwyn Garden City installations-Anthracite stoves and grates-Capacities of stoves-Dutch stoves and their capacities-Principal stove makers-Stove "scares"-Stove fuel costs-Expert opinions of anthracite-Gas-stove perils.

Anthracite in Domestic Service. During the past three years Welsh anthracite has made enormous strides towards its chief goal and ultimate destination-the British household-and, thanks to energetic educational propaganda, which swept aside the barriers of apathy and prejudice, has succeeded in winning by sheer merit the esteem and respect of many thousands of families hitherto not only unfamiliar with its advantages, but sceptical or indifferent, and may now lay claim to having captured the heart as well as the hearth of the enlightened householder.

Practical demonstration helped materially to convince the public of what anthracite can do, and at several of these exhibitions (in which the writer actively participated) certain popular fallacies-such as that which denied the possibility of burning anthracite in open grates-were effectually dispelled; and some very 
remarkable results were attained during these useful experiments. Numerous official records were duly reported in the Press from time to time; but one instance of the kind may be mentioned here (from the Coal and Iron and By-Products Journal, 23rd Nov., 1918)-

"At a private meeting of the Coal and Coke Supplies Committee for South Wales, a practical demonstration of anthracite large coal (broken by hand) in an ordinary grate was made on 7 th Nov. before the zone representatives for the distribution of coal under the zone scheme for Area 13 (south-western counties), held at the Royal Hotel, Bristol. A fire was lighted at 4.30 p.m. in a room measuring $31 \mathrm{ft}$. by $23 \mathrm{ft}$. $6 \mathrm{in}$., $15 \mathrm{ft}$. in height, the temperature of which was as low as $48^{\circ} \mathrm{F}$. at the start. Within half an hour the thermometer registered $55^{\circ}$ (with windores open), when the fire was built up with 'pele' (anthracite duff and clay balls), sufficient to last for at least twenty hours. These made a splendid glow, throwing off a fine heat, and shortly afterwards the temperature rose to $66^{\circ}$, which was maintained throughout the evening - a bitterly cold one, with a keen east wind blowing. The committee was highly satisfied with both the efficiency and economy-the total fuel consumed being only $10 \mathrm{lb}$. of coal and $12 \mathrm{lb}$. of 'pele.'

The accompanying illustration of the grate in question (Fig. 12) shows its exact dimensions, 24 in. wide in front, in which, burning ordinary coal to the full capacity (quite double the quantity) nothing like the temperatures mentioned could be obtained! With the substitution of anthracite the corners of the grate were enabled to be filled in with firebricks, reducing the actual size of the firebox to 16 ins. at the front, the same as the back. The newspapers have recorded several comparative 4-(1458H) 
trials of anthracite and ordinary coals in the open grate showing a clear saving of 40 per cent in fuel consumption (to say nothing of the wood, paper, matches, etc.), but here we see a far bigger economy-about 100 per cent-with superior efficiency and service.

Similar trials with anthracite in the conference chamber (a room nearly $40 \mathrm{ft}$. long) of the Institute of

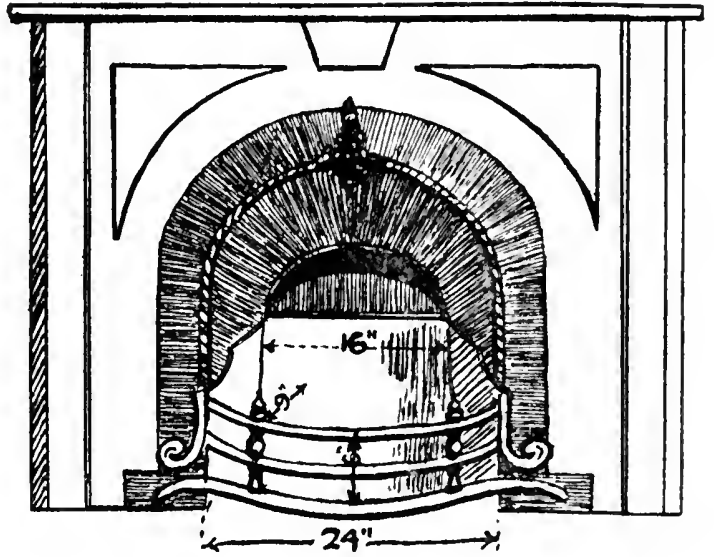

FIG. 12

GRATE AT ROYAL HOTEL, BRISTOL

Fire-box only 6 in. deep. Bars $1 \frac{1}{2}$ in. apart, 3 in. from hearth. Filled in with firebricks to 16 in. wide, the reduced dimensions being adequate with anthracite

South Wales Engineers, Cardiff, revealed that their large grate, wasting over $40 \mathrm{lb}$. of ordinary coal daily, could be fitted with firebricks reducing the capacity of the firebox by about 30 per cent, and yet ensure a more comfortably warm room when burning anthracite.

Domestic Engineering (November, 1920) quoted the following very interesting table of the comparative cost 
of fuels (from a paper read before the Institution of Heating and Ventilating Engineers), plainly showing that even in the matter of price anthracite beats all.

\begin{tabular}{|c|c|c|c|c|c|}
\hline \multirow[t]{2}{*}{ Fuel. } & \multirow{2}{*}{$\begin{array}{c}\text { Calorific } \\
\text { value } \\
\text { B.T.U. }\end{array}$} & \multirow{2}{*}{$\begin{array}{l}\text { Specific } \\
\text { gravity. }\end{array}$} & \multirow[t]{2}{*}{ Current Price. } & \multicolumn{2}{|c|}{$\begin{array}{l}\text { ACtual Cost (for } \\
100 \% \text { efficiency) } \\
\text { IN PENCE. }\end{array}$} \\
\hline & & & & $\begin{array}{l}100,000 \\
\text { B.T.U. }\end{array}$ & 1 H.P. hr. \\
\hline $\begin{array}{l}\text { Coal } \\
\text { Brown coal } \\
\text { Anthracite. } \\
\text { Coke } \\
\text { Logs : } \\
\text { Petrol : } \\
\text { Gas tar : } \\
\text { Heavy fueloil } \\
\text { Methylated spirit } \\
\text { Paraffin : } \\
\text { Coal gas : } \\
\text { Electricity }\end{array}$ & 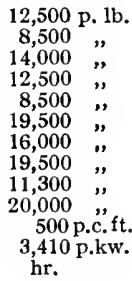 & $\begin{array}{l}0 \cdot 75 \\
1 \cdot 1 \\
0 \cdot 9 \\
0 \cdot 82 \\
0 \cdot 85\end{array}$ & 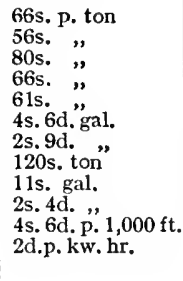 & 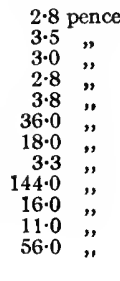 & $\begin{array}{l}0 \cdot 07 \\
0 \cdot 09 \\
0 \cdot 075 \\
0 \cdot 07 \\
0 \cdot 095 \\
0 \cdot 90 \\
0 \cdot 45 \\
0 \cdot 085 \\
3 \cdot 70 \\
0 \cdot 40 \\
0 \cdot 28 \\
1.40\end{array}$ \\
\hline
\end{tabular}

Even at the high price of 80 s. a ton (due to abnormal circumstances) calculated, the economy of anthracite is apparent ; but based on the usual price of anthracitewhich is nearer to $60 \mathrm{~s}$. a ton under normal conditionsthe figure $3 \mathrm{~d}$. would be only about $2 \mathrm{~d}$. And the statistics do not take into consideration the further important question of costs of installation, upkeep, or extra expense attributable to convenience, comfort, appearance, etc., which in connection with some fuels would be heavy.

A number of tests of the efficiency of the coal fire were published in the report of the research work carried out by Dr. Margaret Fisherden for the Manchester Corporation Air Pollution Advisory Board in 1920. It was assumed that the heat generated from coal fires goes in three directions: (1) Heat radiated into the room. (2) Heat carried up the flue by the warm air, and gases, part of which escapes through the chimney, 
whilst part, heating the walls of the flue on its passage, is conducted through the walls to the outside or to adjacent rooms. (3) Heat given up to the walls and connected from them into the room, or conducted elsewhere. The heat completely wasted from a heating point of view is : (a) That which escapes from the top of the chimney, though even this is doing useful work in causing ventilation. (b) That which is conducted through the walls at the back of the fire to the outside. Where the chimney is an inside wall, part of $(b)$ is utilized in heating adjoining rooms. In the case of an inside chimney, the only final loss is the heat in the gas escaping from the top of the chimney.

Various grates were tested, and working with ordinary bituminous coal, the radiant efficiency was in all cases between 20 and 24 per cent. A Welsh anthracite of the calorific value of 14,400 B.T.U. per lb. gave a radiant efficiency of 27 per cent in a grate which only showed 24 per cent radiant efficiency for coal fires. I am inclined to think that this was (in error) considerably underestimated, however. Other fires tested included gas-coke, wet and dry; low-temperature carbonization coke; briquette, and electric fires, and the conclusions arrived at were that the aggregate efficiency of the coal fire in heating a room is generally at least 30 per cent, even for grates of supposedly inferior design; that of the better modern gas fires is in the neighbourhood of 60 per cent, whilst the efficiency of electric fires, in which there is no flue egress of heat, may be taken as 100 per cent. Adopting these values, it was calculated that, with coal at, say, 45s. a ton, gas at $4 \mathrm{~s}$. $6 \mathrm{~d}$. a thousand cubic feet, and electricity at 1d. per unit, the cost of a coal fire for continuous heating is only about one-third that of a good gas-fire, and one-fifth that of an electric fire of equal heating capacity. Of course, the economy 
is much greater even than this in the case of anthracite burned in a closed stove of modern design, when the heat radiation and convection are about 85 per cent.

On the subject of salts, the report states: "We have tested several of the preparations that are so widely advertised as doubling the value of a ton of coal. They consist generally of common salt, with a small percentage of other chemicals added. In every case we have found, as was to be expected, that they had no effect whatever on the quantity of heat given out to the room from a given weight of coal."

In the Western Valleys of Wales gives the following fuel costs, compiled by Professor Barker for his lectures at University College, London-

\begin{tabular}{|c|c|c|c|}
\hline Fuel Tested. & Cost. & $\begin{array}{l}\text { Pence } \\
\text { per Hour. }\end{array}$ & $\begin{array}{c}\text { Cost } \\
\text { for Season }\end{array}$ \\
\hline Coal grate & 45s. ton & .455 & $\underbrace{}_{16} s . d$ \\
\hline Gas fire. & $4 \mathrm{~s} .1,000 \mathrm{cub} . \mathrm{ft}$. & 1.28 & 1014 \\
\hline Gas radiator. & & .383 & $\begin{array}{lll}3 & 4\end{array}$ \\
\hline Naked gas flames & & .21 & 115 \\
\hline Anthracite stove . & 60s. ton & .21 & 115 \\
\hline $\begin{array}{l}\text { (Burned continuously } \\
24 \text { hours day) }\end{array}$ & " & 一 & 310 \\
\hline Electricity & 8d. unit. & $9 \cdot 4$ & 7810 \\
\hline Hot-water radiators & $\begin{array}{l}2 \frac{1}{2} \mathrm{~d} . \text { unit. } \\
42 \mathrm{~s} \text {. ton (coke) }\end{array}$ & $\begin{array}{r}2 \cdot 95 \\
\cdot 15\end{array}$ & $\begin{array}{rrr}24 & 12 \\
1 & 5\end{array}$ \\
\hline $\begin{array}{l}\text { (Burned continuously } \\
24 \text { hours day) }\end{array}$ & \} & - & $2-$ \\
\hline
\end{tabular}

The above calculations are based on tests of heating a room of 2,000 cubic feet during a period of 200 days of ten hours each, and the prices were those ruling several years ago. Were these tests made to-day, they would place anthracite in a still more favourable position, - far eclipsing coke, as, of course, the post-war price of coke has been practically equal to that of anthracite 
for lengthy periods, whilst the prices of gas and electricity have advanced considerably.

Another instructive point in Professor Barker's lectures was this table of comparative heating values-

\begin{tabular}{|c|c|c|c|c|}
\hline Heat by & Coal Fire. & Gas Fire. & $\begin{array}{l}\text { Anthracite } \\
\text { Stove. }\end{array}$ & $\begin{array}{l}\text { Hot-water } \\
\text { Radiator. }\end{array}$ \\
\hline $\begin{array}{l}\text { Radiation } \\
\text { Convection } \\
\text { Conduction } \\
\text { (Walls, etc.) } \\
\text { Chimney loss }\end{array}$ & $\begin{array}{l}25 \% \\
5 \\
15 \\
\frac{55}{100}\end{array}$ & $\begin{array}{l}50 \% \\
\frac{15}{35} \\
\frac{100}{100}\end{array}$ & $\begin{array}{l}35 \% \\
\frac{15}{50} \\
\frac{100}{5}\end{array}$ & $\begin{array}{l}88 \% \\
12 \\
- \\
- \\
100\end{array}$ \\
\hline
\end{tabular}

But I fear I must disagree entirely with Professor Barker's estimated 50 per cent chimney loss on an anthracite stove! Either the stove he tested was defective somewhere, or his figures are confused, I think, for the opinions of stove makers, after a lifetime's practical experience, is that the chimney loss of an efficient, properly-fitted, modern anthracite stove is only about 15 per cent, which I should vote correct. Obviously the Professor's figures prove themselves wrong, for they show only an additional 5 per cent chimney-loss in the case of an open fire. If he had put the latter's chimney-loss at 85 per cent, most investigators would agree therewith, for that is nearer the true mark. However, even professors are liable to make little mistakes occasionally, so I trust Professor Barker-whose scientific tests are of great value to the nation and have our utmost respect-will not mind my venturing a slight correction.

A writer in Our Homes and Gardens (February, 1920) says, "The continuous-burning closed anthracite stoves are excellent. The fire seen through the mica door presents a cheerful glow, and there is only need to stoke 
twice a day, night and morning. I had two going all last winter, and the cost worked out at $6 \mathrm{~d}$. per day each, with anthracite at the high price of $65 \mathrm{~s}$. per ton. A judicious mixture of coke can be made which lessens the cost somewhat, but it burns quicker and the stoves required filling more often in consequence; coke also makes more ash than anthracite."

For the information of those who like to see the fire itself preferably to seeing the glow "through the mica door," I may mention in passing that there are certain stoves-such as the "Home Comfort," a well-known British stove-which can be used either closed or with the door open, like an ordinary fire.

The contributor of an important article on anthracite stoves to Country Life (3rd Dec., 1921) writes: "The anthracite stove is a boon in a house where some room must be left untended, perhaps, for the best part of the day, for the fire will still be alight and the room cosy and warm after this long interval, whereas a coal fire would have burnt itself out and the heat be all lost by way of chimney and door and window, leaving the room cold and cheerless. Quite a remarkable degree of control is possible with the back and front dampers, according to climatic conditions. Obviously, when the weather is dry and there is a high wind, the dampers need to be closed far more than when the air is still and moist. And apart from these conditions of weather one's personal wishes can be met very completely. Thus, an anthracite fire can be kept going hour after hour at minimum intensity by closing the dampers to their fullest extent. This is normally done when retiring for the night. Then, in the morning, the dampers can be opened full, the ash shaken down into the tray, and very soon the fire will be seen fully aglow through the mica front, a delightful radiation coming from it. 
"With regard to the cost of running anthracite stoves, the writer has proved from personal tests that with anthracite even at the present extortionate price of $£ 5$ per ton a stove sufficient to heat a room about $15 \mathrm{ft}$. square costs less than 8d. for twenty-four hours, burning continuously, whereas a test made at the same time, under similar conditions, showed that with an ordinary hearth fire burning best household coal the cost was practically the same for 12 hours! The open fire, of course, had the cheerier appearance, but against this had to be set the trouble entailed by it, and the fact that its running cost was twice that of the anthracite stove."

After so many protests that anthracite was such an "expensive" coal, and the prolonged attempts of coal merchants (from interested motives) to keep the public in ignorance of its possibilities, it is quite a refreshing change to find an enlightened consumer, speaking from practical experience, able to prove convincingly that, even at an "extortionate" price, anthracite's running cost was only half that of ordinary coal in an open fire! It shows how necessary it is for people to give more serious attention to this question.

During the autumn of 1921, as a result of the prolonged coal strike, miners' high wages, inflated railway and other charges, lost exports, etc., the price of anthracite for household purposes necessarily soared to an alarming height. Yet, notwithstanding the high figure attained, it still remained the most economical fuel to use; and The Ironmonger pointed out that a first-rate anthracite stove would save tenpence where it saved a penny in 1913 , as the figures (on page 47) for a day's run show.

And I might here take the opportunity to mention something in defence of the much-abused coalowner, who the public was led to believe extorted such swollen profits that anthracite became dear. In the preparation 
Comparison in Cost FOR a DAy's RuN

Ordinary coal fire 1913

1921

burning $30 \mathrm{lb}$. in

15 hours at

Anthracite stove

burning $15 \mathrm{lb}$. in

24 hours at

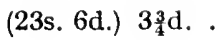

- at (63s.) $10 \mathrm{~d}$.

(42s. 6d.) $3 \frac{1}{2} \mathrm{~d}$

at $(95 \mathrm{~s}) .7 \frac{1}{2} \mathrm{~d}$.

$\frac{1}{4} \mathrm{~d}$.

$2 \frac{1}{2} \mathrm{~d}$.

of sized coal there is necessarily much wastage, and the more regular the size of the coal the greater the expense and wastage involved in preparing it. Now, while the high price prevailed I happened to receive this piece of private information direct from the South Wales anthracite colliery owners: "To day as much as 20 per cent of the output of collieries where they break coal is actually being sent away for less than the cost price, railway carriage, and wagon hire; and 10 per cent consists of 'Peas' which have to be sold in competition with steam coal and realise less than the actual wages paid. This explains why a high price has to be asked for the Nut coal." From which one gathers that, when circumstances arise necessitating an increased price for coals, it is not safe to so readily condemn the colliery proprietors.

Kitchen Conquest. Although the fact is by no means generally realized, the most important room in every household is the kitchen-whilst the predominant feature of that room is unquestionably the cooking range! The kitchen range is of primary importance and the foundation of most of our comfort, and, if properly constituted, brings peace and quietude, or, if otherwise, wrangling, disquietude and friction between mistress and servants. Where this is not recognized, there can be no smooth working and harmony, no efficiency 
in the culinary department, and not infrequently waste, muddle and confusion are the inevitable results. It is wise, therefore, to admit one's obligation at once, and bestow even more attention upon the kitchen than the drawing-room.

Given a light, roomy, airy, cheerful kitchen, equipped with an up-to-date range, constructed on scientific principles to ensure fuel economy and the minimum of labour, the cook's daily task becomes a really interesting, healthy occupation instead of-as so often happens-a dark, gloomy, stifling, unhealthy furnace of drudgery and dreariness. A congenial atmosphere for the cook means all the difference between contentment and discontentment among the staff, and is probably the true solution of the troublesome servant problem.

Most of the ordinary, old-fashioned open and closed fire ranges conduce to fuel wastage, and give unsatisfactory results. Such ranges are utterly opposed to economy, the chief reason being that a large percentage of the heat generated is wasted by passing up the chimney - the serious defect accompanying the majority of English fireplaces. Another portion of the heat is by radiation wafted into the kitchen, making that domain intolerably hot and unwholesome-a severe trial to the health, strength and temper of the unfortunate cook, who wonders why she or he feels so unaccountably irritable throughout the day.

All this, of course, has tended to bring English cooking into bad repute, and earned the reproachful sneers of our cynics in the Press and elsewhere. For instance, the following are specimens of paragraphs one is constantly reading in the newspapers-

A wife was asked at Old Street Police Court if she were a very good cook. " Yes, I am," she replied. 


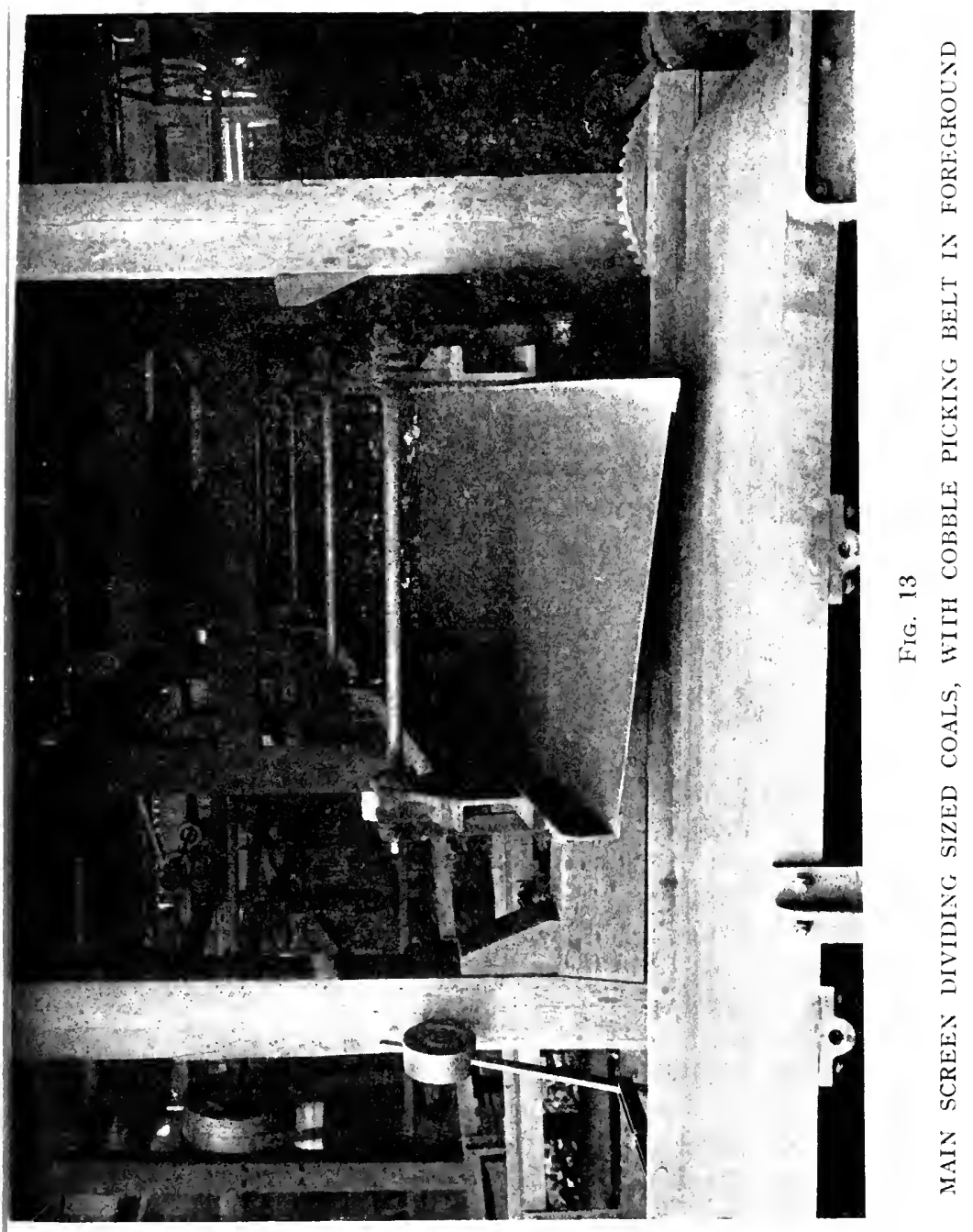


" She is the first Englishwoman I know who is !" commented Mr. Clarke Hall, the magistrate.

A country housewife, full of good intentions, but possessing little culinary knowledge, decided to try her hand at cake-making (says the Morning Post). The result was somewhat on the heavy side, and, after offering it to the various members of her household, she threw it to the ducks in disgust. A short time afterwards two urchins tapped at her door.

"I say, missus," they shouted gleefully, " your ducks 'ave sunk!'

Even generations back we trace the slurs cast upon English cookery, for David Garrick is credited with the unkind remark, "Heaven sends us good meat, but the devil sends cooks !"

Now, there is really no need for a continuance of this sarcasm to-day. As a contemporary observes, "It is not too much to say that the cook holds the secret of the nation's happiness because he or she holds the secret of good health. Ill-cooked and ill-served food provoke bitterness of soul and uncharitableness. The man whose potatoes are half-glue, half-stone, whose steak is white and tough, whose bed is ill-made, gets up in the morning in the evil temper of indigestion, which makes him ready for war and battle."

Sir James Crichton-Browne has truthfully asserted, " nothing has brought more grist to the medical mill than indigestion and dyspepsia; and nothing has contributed more to these than ignorance and neglect in the kitchen."

What to have for dinner will always be the most important question of the day, hence the preparation of the meal is of equal importance. "It is not the quantity of the meat, but the cheerfulness of the guests, which makes the feast," said Lord Clarendon. 
"The proper cooking of potatoes is the great test of a cook," declared a London magistrate; but he hardly went far enough, though it is certainly better to cook a potato well than to play a piano badly.

However, to be conscious that one is ignorant is the first step to knowledge, so I admire the lady who recently made this frank admission in a newspaper-

" At first I hadn't got a mincer, a pair of scales, an electric iron, a polish-mop, nor a long-handled scrubber. But the drawing-room was a dream! Nowadays I'd rather have a set of rustless knives than an etching, and a washing and ironing machine than a baby grand ! Anthracite stoves, too, I'd have. Consider the worksaving of fires that burn continuously, need little cleaning, and attention at rare intervals, and, after getting up shivering on a cold winter's morning, try to picture the joy of-finding a delightfully warm kitchen to cook the breakfast in, and a dining-room at just the right temperature! Isn't it worth the sacrifice of some of the fal-lals to achieve real, solid comfort ?"

The foregoing confirms my contention that the kitchen is of supreme importance, as they class it on the Continent. There the kitchen is the bright, cheerful apartment it ought to be. The stoves, smaller than ours, consume much less fuel while retaining greater efficiency. Usually, as in America, the range stands clear of the wall, to permit of easy access all round it, obviating the irksome strain of leaning forward to see how things are progressing. It is precisely these seemingly small conveniences for the cook which help materially towards unison between mistress and servant. Make the kitchen a comfortable place instead of an insanitary inferno, and there will be far less discontent among its tenants.

Quite the best designed British made kitchen range 
is that known as the "Kooksjoie" (Florence patent), rightly called the "King of Ranges," and admitted even by the trade to be the most scientific on the market. At exhibitions it becomes the centre of attraction, and has secured several highest awards, including the gold medal of the City of Leicester Bakers, Confectioners and Caterers, and the first-prize medal of the Royal Sanitary Institute.

With this range-specially constructed to burn anthracite-the consumption of fuel is considerably lower than with any other range, while the wear and tear are reduced, hence it is rapidly superseding oldfashioned, ponderous ranges, many of which swallow up four times the amount of coal and give less efficient service. Its flues are completely under control; the heat goes first to the boiler, then passes all round and over the oven, and by the time it reaches the flue it has exhausted itself. All kinds of fuel may be used, of course, but the best results are obtained with anthracite, which ensures continuous burning and constant hot-water supply, besides abolishing smoke and soot, saving labour and time. So little deposit from anthracite accumulates in the flues, that they need only be swept once in six months, and the chimney only once in as many years!

Some thousands of this remarkable range have already been sold, and its makers furnish me with exceedingly interesting particulars of the work it is accomplishing in evolutionizing the British kitchen.

For instance, an average size "Kooksjoie" range (it is made in twelve different sizes, from a mansion to a cottage), such as would be required to cook the meals of a family of from twelve to twenty persons, only consumes, under proper regulation and conditions, about $1 \frac{1}{2} \mathrm{lb}$. of anthracite an hour, working continuously 
twenty-four hours, representing a running cost, with coal even at 80s. per ton, of a fraction over a halfpenny per hour! And here are the amazing figures forthcoming from an independent official test of one of the large-size "Kooksjoie" ranges, such as used in hotels or clubs-

\begin{tabular}{c|c|c|c|c} 
Fire lighted. & $\begin{array}{c}\text { Meals } \\
\text { served. }\end{array}$ & $\begin{array}{c}\text { Actual weight } \\
\text { of food cooked. }\end{array}$ & $\begin{array}{c}\text { Anthracite } \\
\text { consumed. }\end{array}$ & $\begin{array}{c}\text { Total cost of } \\
\text { cooking for } \\
300 \text { persons. }\end{array}$ \\
\hline 7.30 a.m. & $\begin{array}{l}\text { Between } \\
12.30 \& \\
1.30 \text { p.m. }\end{array}$ & $527 \mathrm{lb}$. & $45 \mathrm{lb}$. & 2s. 7d. \\
\hline
\end{tabular}

These large " communal" ranges only consume on an average about $20 \mathrm{cwt}$. of anthracite per monthwhich some large ranges of much less capacity would burn in a week! The above test was a truly astonishing performance-a record, I believe-for, besides cooking the food, the range provided ample hot water for washing up and for teas.

In basing the average fuel consumption by the "Kooksjoie " range on the figure of $30 \mathrm{lb}$. per twenty-four-hour day (or $10 \mathrm{cwt}$. per month), the makers really allow a liberal margin for the possible careless regulation of flues and other contingencies, as the range when burning anthracite can actually be run on less. One report says : "We kept the range working day and night for 14 days, using $380 \mathrm{lb}$. of anthracite nuts, cooking and baking for five people-27 lb. of coal per day." And some customers, employing experienced and careful cooks, write that their fuel consumption is even lower than that. Sir Courtney Bennett wrote to the makers as follows regarding his extraordinary experience with coke-

"During the war and afterwards anthracite was only with difficulty to be obtained for use in the 
“ Kooksjoie' range which I purchased from you three years ago, and I had to use ordinary gas coke to eke out the anthracite This succeeded so well that I gradually decreased the anthracite used to zero, and still the results were good For the last twelve months I have used nothing but broken coke from the local gas company, and am more than pleased with the result. The 'Kooksjoie' does all that it should do, and with less expense than when I used anthracite. I find that, using coke, the range consumes just under half a ton per month."

This evidence, of course, proves that, burning anthracite under proper regulation, the range can be run on the still smaller quantities of fuel quoted by some users.

Few people realize the importance of clean flues and fires in the kitchener-possibly because that desirable condition is not possible with ordinary ranges burning ordinary coals. With anthracite, of course, fouling of flues, and other nuisances, automatically disappear; and if that were the only advantage claimed for anthracite, it would be considerable.

But, apart from the question of labour and inconvenience accompanying soot-laden flues, let us look at another and more important aspect. The dirty firesurface causes great loss of heat, acts as an insulator, and prevents the heat from getting to work effectually. A special investigation by the Institute of Marine Engineers disclosed the startling fact that soot on heating surfaces decreases the efficiency of heat-absorbing surfaces in the following ratio-

Soot thickness

inches.

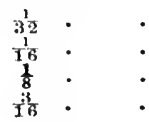

Efficiency loss per cent.

$9 \cdot 5$

$26 \cdot 2$

$45 \cdot 2$

$69 \cdot 0$ 
Now, marine engineers know that marine engines and boilers must always maintain the highest state of efficiency, hence frequent tests are made for the purpose of ascertaining the true state and ensuring perfect running; therefore the above conclusions, surprising as they may appear, are absolutely trustworthy

Domestic Boilers : Anthracite versus Gas. There are at least two distinct kinds of gas boilers, but the one most commonly fixed and used, known as a "circulator," is merely an independent boiler, using gas as fuel instead of coke, said that authority, The Ironmonger, in a recent instructive article. It is smaller in size and of less power than the average coke-burning boiler, but it is used in much the same way; that is connected with an ordinary hot-water apparatus of circulating pipes and storage tank, for tap supply, to heat the water in conjunction with a range boiler, or alone.

A gas boiler requires an effective flue, and a little experience makes the fitter seek to carry his flue pipe into the kitchen chimney. To carry the flue pipe through an outer wall and fit it with a conical cap outside is almost always a failure. A flue pipe from a gas boiler merely carried through a wall would be successful if there was no wind, but down-blow or wind pressure, when the wind is in certain quarters, will cause the burning gas to " light back," or perhaps be extinguished. When the flue pipe from a gas boiler must go through an outer wall it has to be carried up a few feet inside the house and then through the wall with a conical cap outside.

The power of a gas boiler is best based on the amount of water it will heat to dish-washing temperature, say $140^{\circ} \mathrm{F}$. A boiler which does not yield water hot enough for the scullery sink is a failure, whatever else it may do. Experience teaches that for domestic hot-water 
requirements the first necessity is to satisfy those who use the sink.

Ignoring laboratory figures, which are seldom correct in practice, calculations must be based on allowing three cubic feet of gas per gallon of water heated from average cold to dish-washing temperature. This allowance is not always correct, but it is a figure that may be used with the certainty that no one can say it is false or misleading. If it comes out badly, which it rarely does, it will be due to abnormally bad conditions. A consumption of three cubic feet of gas per gallon does not claim a high efficiency for the boiler. A gallon of water, $10 \mathrm{lb}$., raised from 50 to $140^{\circ} \mathrm{F}$., has $900 \mathrm{~B}$.Th.U. Gas now averages about 480 B.Th.U. per cubic foot, or 1,440 for three cubic feet. This shows nearly 63 per cent efficiency for the boiler. Considering the claims made for gas boilers, this may be thought low, but it is not wise to calculate on a better yield than this if we take the temperature of the water obtained from the average domestic tap. In residential installations there are many losses between the gas burner and the hotwater taps. There are plenty of instances of better results than this, but they are not the majority by any means. Two common sizes of circulators consume, the one 40 cubic feet, the other 80 cubic feet of gas per hour when full on. This means that, according to the foregoing, they yield $13 \frac{1}{2}$ and $26_{3}^{2}$ gallons of dish-washing water per hour-rather less in winter, more in summer.

It will be found that three feet of gas per gallon is a useful figure to remember in relation to the duties that gas boilers will do. Given the gas consumption, the amount of heated water per hour can be readily calculated. Gas at, say, 5s. (60d.) per 1,000 cubic feet costs $\frac{1}{2} \mathrm{~d}$. for $10 \mathrm{ft}$. At $6 \mathrm{~s}$. (72d.) it is $7 \cdot 2 \mathrm{~d}$. per 100 , .72d. for $10 \mathrm{fcet}, \cdot 072 \mathrm{~d}$. per foot. Calculated in this way 


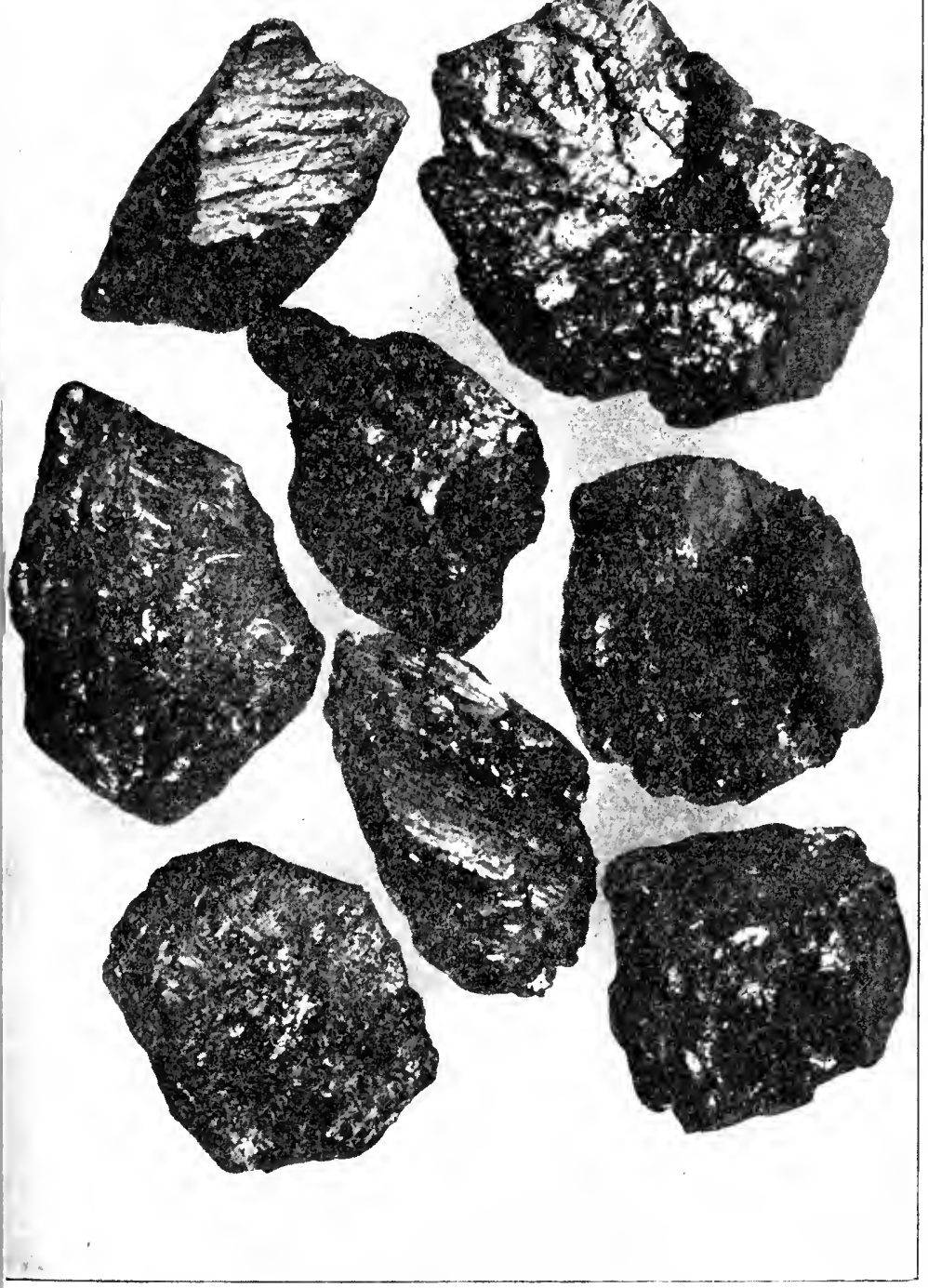

FIG. 14

ANTHRACITE MACHINE-MADE AND WASHED " STOVE NUTS" 
a close cost for any quantity can be found in a moment.

The one duty for which everyone wants to know the time and cost is the warm bath. Baths vary in size, and people have different ideas as to what the temperature of the water should be, but, say, 25 gallons at $100^{\circ} \mathrm{F}$. in the bath. This will require, taking an average over the year, $13 \frac{1}{2}$ gallons of water at $140^{\circ}$, the remainder being cold water. $13 \frac{1}{2}$ gallons $\times 3=40 \frac{1}{2}$ cubic feet of gas, cost about $2 \frac{1}{2} \mathrm{~d}$. to $3 \mathrm{~d}$. (it used to be 1d. to $1 \frac{1}{2} \mathrm{~d}$.) ; time taken, boiler burning 40 cubic feet per hour, one hour ; boiler burning 80 cubic feet, halfhour. In practice the results are often better than this.

The full-on gas consumption should always be adjusted not to exceed the maker's figures on the card of directions Excessive consumption defeats itself.

So much for the case of gas. Now let us examine figures of exhaustive and reliable tests in this connection made with anthracite as the fuel-and this is where anthracite triumphs magnificently once more !

Above calculations assume the price of gas to be the medium one of 5 s. per 1,000 cubic feet $=$

900 B.Th.U. cost $\cdot 2 \mathrm{~d}$.

Now, burning anthracite in the "Kooksjoie" range previously referred to, and assuming the price of anthracite to be the very high one of 90 s. per ton $(\cdot 482 \mathrm{~d}$. per lb.), prolonged trials have proved that $3 \frac{1}{2} \mathrm{lb}$. of anthracite gives-

$$
\text { 22,000 B.Th.U. }=\text { cost } 1 \cdot 7 \mathrm{~d} . \quad\left(1 \frac{3}{4} \mathrm{~d} .\right) .
$$

Therefore the equivalent efficiency in gas would cost approximately $4 \frac{1}{2} \mathrm{~d}$.- - minus the extra culinary service simultaneously accompanying the said range!

The question of what exactly is a British Thermal 
Unit so frequently arising, it might be as well here to define it.

When gas was first introduced, over a hundred years ago, consumers were charged so much per burner, an obviously unfair way. Then followed the gas meter, which ticks off the gas used in hundreds and thousands of cubic feet. Gas was valued more for its lighting qualities in those days, whereas now it is primarily valued for its heating capacity, hence the recentlyintroduced and fairer method of charging for so many heat units instead of so many cubic feet, although the meters still register in cubic feet.

A "therm" is 100,000 British Thermal Units ; and a British Thermal Unit (B.Th.U.) is the amount of heat required to raise the temperature of $1 \mathrm{lb}$. of water 1 degree Fahrenheit. To calculate the therms consumed, multiply the cubic feet by calorific value and divide by 100,000 , thus-

8,000 cubic feet $\times 475=3,800,000$, which divided by $100,000=38$ therms.

One Fire to Heat a Whole House! The economics of anthracite in conjunction with scientific modern appliances become almost incredible. Who of the uninitiated would suppose it were possible comfortably to heat a whole house with a single anthracite fire ? Yet that is fait accompli-and by means of an open fire, not the usual closed stove!

Such is known as the "Florence" Patent Boiler-grate, an open grate ingeniously constructed with a boiler at the back, and made in sizes with heating capacities of from 2,500 cubic feet to 3,500 cubic feet, and a radiation of from 30 to 150 square feet. This burns anthracite to perfection, and affords an ideal fire for any drawingroom, a brilliant, steady glow, a splendid warmth, and a most alluring appearance unequalled by any other 
open fire. The boiler serving radiators in hall, bedrooms etc., is connected with a hot-water cylinder in the bathroom, and in the majority of cases a single pipe carried round the skirting of the rooms is sufficient, so that the installation itself need not be at all complicated or unduly expensive The saving in fuel effected by this grate is a remarkable feature, considering its enhanced services; and, burning anthracite, it needs practically no attention, being fed only night and morning and keeping alight continuously. In severe, official tests along with other grates, the "Florence" Patent Boiler-grate has not only come out supreme in the matter of smoke-abatement qualities, but eclipsed all others as regards heat radiation and fuel economy.

It was this particular grate which won the prize of $£ 50$ offered by the Daily Mail for the best labour-saving device, in connection with the "Ideal Homes" Exhibition, London. That journal announced that the Committee of the Designs and Industries Association, acting as judges, awarded the prize to Mr. A. Bate, "Fairydene," Shoreham-by-Sea, for the following-

"I have installed in my 60-year-old house in Richmond, Surrey, rent $£ 36$ per annum-

" Floors: Linoleum, with rugs. Light: electric. Heating: whole house-including double drawing-room, dining-room, bathroom, three bedrooms, hall, kitchen, and linen cupboard-heated from one open fire (not a stove), burning anthracite nut coal, which never goes out from autumn to spring; consumption, 3 tons for the whole period. Six radiators are in operation in a simple way from the one fire."

A later issue of the Daily Mail (2nd Jan., 1920), explained-

Mr. Bate has had a flood of questions and says-

"I should like to say that the open fireplace is fitted 
with a "Florence" grate (not a stove), the back of which consists of a special hot-water circulating boiler about 36 in. by 16 in. by 8 in., with an ingenious flue under control. The anthracite nut coal burns in the open grate with a beautiful glow, and will keep alight for 12 or 14 hours without attention. The circulation is simplicity itself, there being only a $1 \frac{1}{4}$ in.

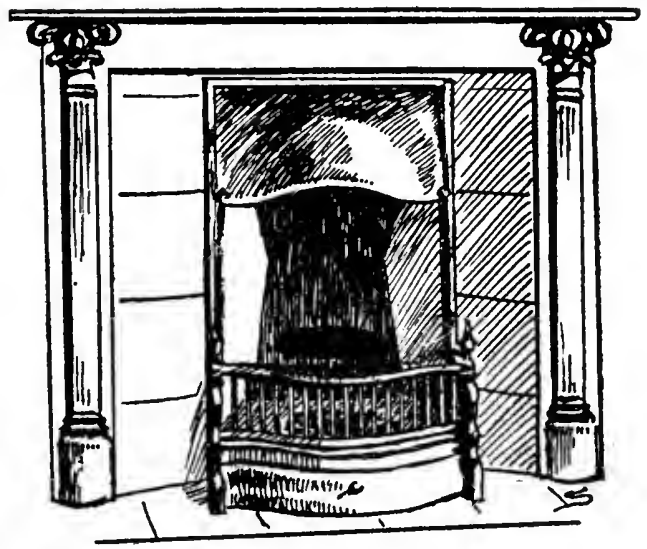

FIG. 15

THE “ FLORENCE” PATENT BOILER-GRATE

pipe throughout connecting the radiators. This pipe is run mainly beneath the floors. It has been working now for about ten years, with not a penny for repairs."

At the showroom of the makers (The London Warming Co., Ltd.) the "Florence" Patent Boiler-grate may be seen actually working during the autumn and winter seasons, serving radiators to heat the company's offices. "Kooksjoie" anthracite ranges and "Florence" boiler-grates have been installed in about thirty of the houses erected in the Welwyn Garden City (Herts), and 
it is of interest to note the report from the Clerk of Works, who very carefully tested both outfits and worked out the following figures-

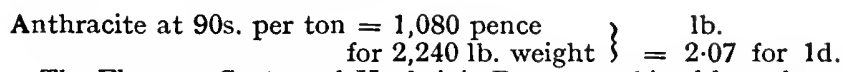

The Florence Grate and Kooksjoie Range combined have been run for 24 hours at $10 \mathrm{~d}$. for fuel $=20.7 \mathrm{lb}$. fuel.

Say $10.35 \mathrm{lb}$. fuel for Florence Grate in 24 hours

$=.43 \mathrm{lb}$. fuel per hour

$=.21 \mathrm{~d}$. ( $4 \mathrm{~d}$.) cost per hour.

Say $10.35 \mathrm{lb}$. fuel for Kooksjoie Range in 24 hours

$$
\begin{aligned}
& =.43 \mathrm{lb} \text {. fuel per hour } \\
& =.21 \mathrm{~d} \text {. (td.) cost per hour. }
\end{aligned}
$$

The Clerk of Works also reported that the whole installation was found to be very satisfactory in operation.

In these times of enforced economies details of this description cannot be too widely known, both in the interests of individual economists and coal conservation ; and for that reason I have deemed it important to dwell at some length upon the outstanding merits of the above two labour-saving and efficient appliances.

Anthracite Stoves and Grates. As I have previously explained, anthracite can be burnt quite well in any ordinary open grate, although, of course, some grates would be more suitable and give better results than others-particularly if affording good draught, as anthracite requires plenty of draught. A fire, when lighting up, requires more than four times the volume of air necessary when the fuel has become incandescent, therefore good grates are as important as good coal. It is calculated that old-fashioned open fireplaces, or iron grates, waste 70 to 80 per cent of the potential heat of the coal ; but such grates converted to scientific principles would only waste $\mathbf{3 5}$ per cent, while a thoroughly efficient modern grate wastes less than 10 per cent of the heat. Perhaps the best form of grate for anthracite is that possessing thin perpendicular bars, 
about 2 in. apart, and the fireplate on which the coal rests about 3 in. above the hearth. The front should be double the size of the back, and the depth from front to rear equal to the width of the back. The back and sides should be of fire-brick, not metal The most suitable coal would be "French" nuts

That no one need be dubious of burning anthracite in an open grate, will easily be gathered from a report, in the Evening Standard (26th Jan., 1920), of an interview with a member of the firm of Giddy \& Giddy, the well-known London estate agents-

"We know one lady, the owner of collieries, who burns anthracite, not in stoves but in open grates, in all her houses. She has an old farmhouse, in Wales, with an old-fashioned open hearth; she even burns anthracite there-says she gets a steady glow."

The writer can quite understand this, having seen such hearth-fires; and very probably they are kept burning continuously, like the Welsh people's grate fires, which are never allowed to go out. According to local tradition, the kitchen fire (anthracite) at a farmhouse on Gwrhyd Mountain, above the Swansea Valley, has been kept alight for over 300 years. When repairs to the fireplace were necessary, the fire was carefully removed and replaced on completion of the work !

The modern, scientific anthracite stove, however, regulates the heating to any required temperature, eliminates waste of heat up the chimney, besides saving fuel, time and labour. These also ensure cleanliness and safety, for they can be left alone in a room at any hour of the day or night without danger. The cost for given results is far less than that of gas, electricity, or any other fuel.

A very large variety of designs in stoves has grown up with modern demands, to suit all purposes, and 
many are quite artistic and ornamental accessories for the home, so that there is no longer the old complaint that stoves were unsightly objects. Indeed, the general admission is that a really smart stove enhances the appearance of a room.

Some of the more popular anthracite stoves, by the best British and other makers, are named below, with their respective heating capacities-

\begin{tabular}{|c|c|c|c|c|c|c|}
\hline "Calesco" & ${ }^{\circ}$ & . & • & • & & $2,800-5,000$ \\
\hline "Unique" & $\theta^{\circ}$ & . & . & 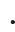 & & $5,000-6,000$ \\
\hline "Lustrous" & & & . & t. & • & 4,500 \\
\hline "British Cott & age " & - & - & & • & 6,000 \\
\hline "Jewel" & & . & . & . & . & $5,000-6,000$ \\
\hline "Dainty Dot & & . & 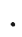 & & • & 2,500 \\
\hline "Classic" & . & . & - & re & . & 7,000 \\
\hline "Cygnum " & . & . & . & . & . & 6,500 \\
\hline "Cora". & . & . & • & . & . & $3,000-7,000$ \\
\hline "Argus" & . & . & . & . & . & $2,500-4,500$ \\
\hline " Hygiene" & r & . & . & re & . & $15,000-35,000$ \\
\hline "Phoenix" & • & . & . & . & . & 15,000 \\
\hline "Lion" & & . & . & & . & 5,000 \\
\hline Home Comf & fort" & . & . & . & . & 3,000 \\
\hline Hestia" & . & . & . & . & . & 5,000 \\
\hline "Tortoise" & $\cdot$ & . & . & & . & $1,000-120,000$ \\
\hline "Pallas" & & . & . & . & 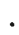 & 3,000 \\
\hline Pompadour & & - & . & . & • & 4,500 \\
\hline Taurus" & . & . & . & & • & 5,000 \\
\hline Neptune" & . & . & . & 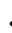 & 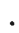 & 2,100 \\
\hline Defiance" & & . & . & . & . & 3,500 \\
\hline Economic" & & . & • & . & • & $1,000-3,000$ \\
\hline Anthra-Reco & ord " & . & • & & • & $5,000-20,000$ \\
\hline Isel " . & . & . & . & & . & 10,000 \\
\hline Canum" & - & - & • & 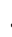 & . & 4,200 \\
\hline Centaur" & & • & . & & & $14,000-17,000$ \\
\hline Salamandre & & • & & & & 5,000 \\
\hline Glycine" & . & . & - & . & - & 5,000 \\
\hline Perseus" & & • & • & & •• & $7,000-10,000$ \\
\hline Chantecler" & & . & . & & • & $2,000-2,500$ \\
\hline Vesta" & . & . & $\bullet$ & & & 5,000 \\
\hline Canis" & $\theta$ & . & ${ }^{\circ}$ & & • & $2,100-4,200$ \\
\hline Ceres" & 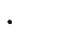 & . & 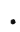 & & & 4,500 \\
\hline Orion" & . & 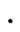 & . & & & 3,000 \\
\hline Orinis" & & • & . & 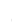 & . & 5,000 \\
\hline
\end{tabular}


The majority of the anthracite stoves on the market are of Continental make, the Dutch being particularly good, both as regards design and durability, good finish and appearance I append a list of these, and might mention that the sole agent for Great Britain is The London Warming Co., Ltd., at whose showroom the stoves are on view.

The principal and latest models of anthracite stoves manufactured in Holland, and their respective heating capacities-

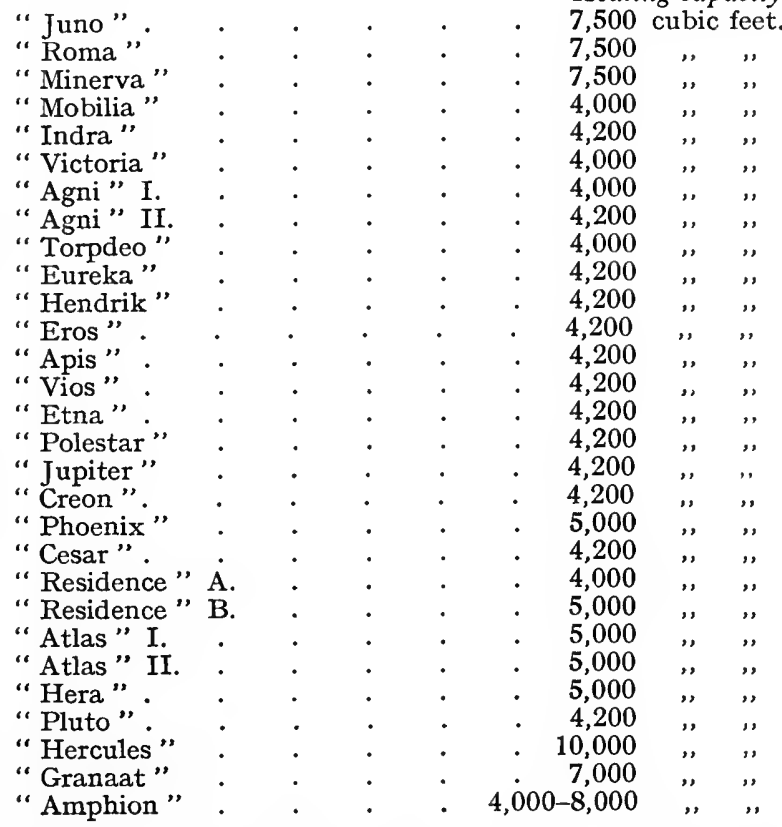

Fitted with circulation tubes, many of these stoves have an increased capacity of from 2,000 to 3,000 cubic feet. 
As a great many people do not know where they can purchase anthracite stoves, it will be a convenience to the reader if $I$ mention the names and addresses of the principal makers and their agents in different parts of the kingdom, as follows-

Adams \& Sons, 63 and 65 Shandwick Place, Edinburgh.

Bratt, Colbrau \& Co., and The Heaped Fire Co., Ltd., 10 Mortimer Street, London, W.1.

Briffault Range Co., 13 Leicester Street, London, W.C.2.

Burnie \& Sons, A., Nelsonia Works, North Road, Preston.

Carron Company, 50 Berners Street, London, W.1, and Falkirk Foundry, Furnace Hill, Sheffield.

Falkirk Iron Co., Ltd., Craven House, Kingsway, London, W.C.2. George Wright, Ltd., 155 Queen Victoria Street, London, E.C.4, and Rotherham.

Hardware Trading Co., 12 New Oxford Street, London, W.C.1. Hygienic Stove Co., Ltd., Hygienic Works, Huddersfield.

Jones \& Campbell, Ltd., Torwood Foundry, Larbert, Stirlingshire. Lane \& Girvan, Caledonia Works, Bonnybridge, near Galsgow. London Warming Co., Ltd., 20 Newman Street, Oxford Street, London, W.1.

Mills, English \& Co., Wind Street, Swansea.

Nautilus Fire Co., Ltd., 60 Oxford Street, London, W.1, and Luton.

O'Brien, Thomas \& Co., 17 and 18 Upper Thames Street, London, E.C.4.

Pither's Radiant Stoves, Ltd., 36 and 38 Mortimer Street, London, W.1.

Planet Foundry Co., Ltd., Guide Bridge, near Manchester.

Portway \& Sons, Chas., "Tortoise" Works, Halstead, Essex ; London-57 Farringdon Street, E.C.4.

Salamandre Stove Co., 255 Tottenham Court Road, London, W.C. Standard Range and Foundry Co., Watford, Herts.

Webster, G. M., 71 Upper Parliament Street, Nottingham. Williams \& Co., E., 4 and 16 Heathfield Street, Swansea.

Yates, Haywood \& $\mathrm{Co}$., and Rotherham Foundry Co., Effingham Works, Rotherham.

Some especially popular anthracite stoves-because they can be used either as closed or open fires-are the "Home Comfort," which will burn all fuels, the "Glycine" (cadé stoves), and Pither's "Radiant" Series. The makers claim for the "Glycine" (a quickcombustion stove) that it gives for each $1 \mathrm{lb}$. of coal 
burnt three times more heat than a slow-combustion stove; that it causes a strong draught, preventing all back draughts; that it completely consumes the gases ; and that it produces a constant renewal of air, which ensures a purified instead of a vitiated almosphere. This stove is simple in construction, requiring little attention, cannot produce carbon monoxide (which in some circumstances will cause headaches and enervation), and is of small capacity, only holding a little coal subjected to incandescence. Hence, although quick combustion is combined with maximum heat, fuel consumption is minimized.

I might here refute the untrue statement sometimes made that anthracite coal in stoves gives off noxious fumes and gases. There are no more fumes, etc., emanating from anthracite than from any other coal, as the Coal Mines Department official published tests effectively proved.

At rare intervals one may read in the "stunt" papers, revelling in sensational "copy," some such headlines as "Explosion in an Anthracite Stove," but there is nothing in it to be alarmed about. On investigation it will be found that the scare is mostly in the newspaper office! I personally investigated two cases of the kind and discovered that one accident was due to a thoughtless person heating something explosive in the stove, and the other was due to the presence of some foreign substance in the coal-a quite common occurrence. In the latter case, the owner expressed entire confidence in his stove, and ordered another similar one !

Accidents of this kind, while not, of course, outside the bounds of possibility with the most careful management of stoves, are exceedingly rare-not one in a million, in fact. 
Anthracite stoves consume from one to two cwt. of fuel per week of seven days, burning day and night. varying, of course, according to size and heating capacity; but their real economy can be judged by the following comparative estimates quoted by a scientist, Mr. J. D. Hamilton Dickson, in the Times Engineering Supplement, as the result of extended tests of heating by various methods, the costs being based on periods of a week of seven days, of twelve hours each-

Gas Fire

Open Fireplace

Anthracite Stove . . . . . 1s. 2d.

The table below shows the comparative results of tests (made at a private house near London) of three fires heating separate rooms-two of the fires burning bituminous coal in ordinary open grates, and one burning anthracite in a modern stove-

\begin{tabular}{|c|c|c|c|c|c|}
\hline Dimensions of Room. & Fire. & Fuel. & $\begin{array}{l}\text { Duration } \\
\text { of Test. }\end{array}$ & $\begin{array}{c}\text { Temperature } \\
\text { Raised. }\end{array}$ & $\begin{array}{l}\text { Total Fuel } \\
\text { Consumed. }\end{array}$ \\
\hline $16 \mathrm{ft.} \times 10 \mathrm{ft} .6 \mathrm{in}$. & $\begin{array}{c}\text { Modern } \\
\text { grate } \\
12 \text { in. }\end{array}$ & $\begin{array}{c}\text { Bitu- } \\
\text { minous } \\
\text { coal. }\end{array}$ & $\begin{array}{c}20 \\
\text { hours. }\end{array}$ & $\begin{array}{c}\text { Steadily } \\
\text { from } \\
55 \text { to } 63^{\circ} \mathrm{F} \text {. }\end{array}$ & $28 \mathrm{lb}$. \\
\hline $15 \mathrm{ft} .3$ in. $\times 10 \mathrm{ft} .6$ in & $\begin{array}{l}\text { Old } \\
\text { Register } \\
\text { Grate, } \\
12 \mathrm{in.}\end{array}$ & $\begin{array}{l}\text { Bitu- } \\
\text { minous } \\
\text { coal. }\end{array}$ & $\begin{array}{c}15 \\
\text { hours. }\end{array}$ & $\begin{array}{l}55 \text { to } 57^{\circ} \mathrm{F} \text {. } \\
\text { in } 3 \text { hours, } \\
\text { reaching } \\
62^{\circ} \text { in } 5 \mathrm{hrs} .\end{array}$ & $18 \mathrm{lb}$. \\
\hline $16 \mathrm{ft} .9$ in. $\times 14 \mathrm{ft} .0$ in & $\begin{array}{c}\text { Anthracite } \\
\text { stove. }\end{array}$ & $\begin{array}{l}\text { Anthra- } \\
\text { cite. }\end{array}$ & $\begin{array}{c}26 \\
\text { hours. }\end{array}$ & $\begin{array}{l}51^{\circ} \text { to } 69^{\circ} \mathrm{F} \text {. } \\
\text { (rose } 7 \mathrm{deg} \text {. } \\
\text { first hour). }\end{array}$ & $26 \mathrm{lb} .1$ \\
\hline
\end{tabular}

$11 \mathrm{lb}$. of anthracite per hour-with a good reserve of coal still in the stove. The stove was a "Home Comfort," one of the flat-fronted type, with mica door, which was opened at frequent intervals. Not only was the fuel consumption far more economical than that of the grates, but it heated the largest rocm rapidly from the lowest starting temperature to a much higher temperature than the grates were capable of attaining.

The published testimony of those who have practically tested the coal cannot fail to be of interest-

The Cambria Leader: "Those who, like the writer, 
have for years been accustomed to the bright heat. without smoke, of anthracite coal, would not willingly exchange it even for the brisk consuming scorch of Rhondda steam coal, nor would they give up the 'pele' of small coal and clay which enables the wives and daughters of the miners to keep fires 'banked up' night after night-weeks, months, years-without dust, soot, smoke, or cinders."

South Wales Daily Post: "A prominent gentleman burning anthracite continually, tells us that though he has changed houses several times during the last twenty years, he has never burnt anything else, and has burnt it in the grates existing without any alteration. This gentleman's experience could be multiplied by hundreds of similar instances."

The late Sir Guy Calthrop (when coal controller) : "I am personally using anthracite, and find it lasts nearly three times as long as coke."

Coal, Iron, and By-Products Journal: "Anthracite coal has no equal for domestic purposes. Householders who have adopted anthracite stoves never return to the use of other fuels."

A writer of wide pràctical experience in a scientific journal : "One ton of good anthracite goes at least as far as two of bituminous coal."

Professor Stanfield, of the Heriot-Watt College : "Its much slower combustion is one of its advantages. ... The Welsh anthracite is virtually pure carbon, and smokeless."

Gas-stove Perils. The present-day need of anthracite stoves in preference to gas stoves is strongly emphasized by the frequent and alarming reports of domestic tragedies resulting from the scandalously inferior and injurious gas permitted to be supplied to domestic consumers-containing nearly 15 per cent of carbon 
monoxide, in some cases! This gas is so deadly that I believe as little as 1 per cent is sufficient to cause death in a few minutes in certain circumstances; yet, despite comments and warnings, authorities seem unperturbed by this grave menace to the public health. Following certain of these gas fatalities, an analysis was made of gas from an ordinary domestic supply to premises in the West End of London on 31st January, 1922, and below are the figures obtained by the analyst-

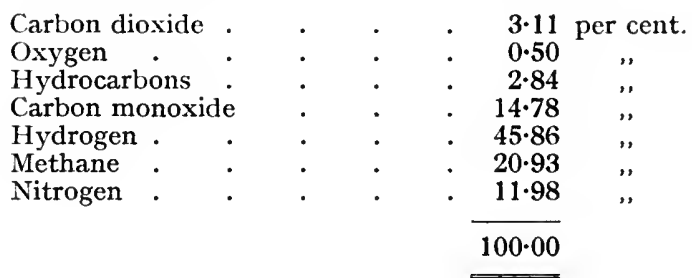

The percentage of carbon monoxide here shown is about double the percentage usually found in an unadulterated purified coal gas. Large quantities of this insidious poison might be filling a room before the occupants of the room realized their peril, because this gas is odourless! At the inquest on four persons killed by carbon monoxide in Liverpool, the coroner stated : "So long as this poisonous substance is allowed to remain in the supply of gas it is dangerous to have a gas fire in a bedroom."

Gas-fittings which were safe when gas was pure are quite unsafe to-day, as even the smallest leak is dangerous-experts declare that carbon monoxide will escape in dangerous quantities through the walls of iron pipes.

At the Royal Society of Arts, Professor Armstrong claimed that it was the notoriety obtained by the poisonous properties of our coal gas that had set the 
fashion in oven suicides. The public tolerated inferior gas as a war-time economy, but there is no necessity for its continuance now, especially as the gas companies really secure a much higher price from consumers under the new "therm" calculations.

The Board of Trade, after scores of gas fatalities throughout the country, have just issued an order that gas companies shall not supply gas containing carbon monoxide unless it possesses the distinctive pungent smell of coal gas, but this will not remove the danger. The proper remedy is to reduce the permitted proportion of carbon monoxide, and on this the public should insist. 


\section{CHAPTER V}

\section{THE INDUSTRIAL WORLD}

THE industrial world-Prolific gas-yield of Welsh anthraciteBaking by anthracite-Economic motor-transport-New gas-producer-Anthracite and electrodes-Steam raisingSome remarkable economies-Mixed coals-Irish anthracite -Output and resources-Development prospects-Official reports-Outputs and employees (1918)-Analysis of Irish anthracite-Scotch anthracite-An analysis-American anthracite-Comparative outputs-Canadian anthraciteWorld's largest field-Government's interest-Other anthracites-Anthracite compounds and patent fuels-Spontaneous ignition.

ANTHRACITE is making itself felt appreciably in industries generally, particularly as regards steam raising-for which purpose there is no better fuel-and power-gas production, being prolific in this direction, one ton of Welsh anthracite yielding from 170,000 to 220,000 cubic feet of gas for power purposes. The internal-combustion engine and pressure and suction gas-power plants alone have created a widespread demand for anthracite; but new uses are gradually being found for it as progress and developments occur in the industrial arena.

One of the latest industries to discover the advantages of anthracite is the baking. Bakers were induced to try anthracite during the period in which they were short of coke (owing to the prolonged coal strike), when the clean, smokeless coal quickly found favour among them.

"We believe anthracite will revolutionize the bakeries," declared a master baker in Swansea. "We find that when it is judiciously used it is cleaner and gives a brighter heat than coke, and it is likely that when this coal crisis 
is over there will be very little necessity for bakers to revert to the use of coke again."

Experiments in connection with the development of economic motor transport will undoubtedly disclose the value of anthracite in the near future. The solid natural fuels now used involve loss of the by-products, except

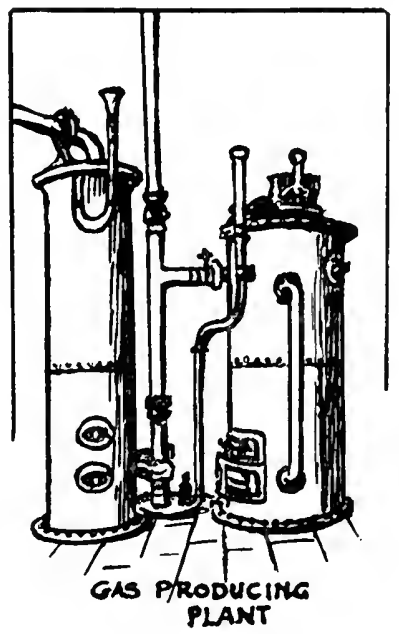

FIG. 16

in the case of anthracite. Some very interesting comparisons of solid and gas fuel were communicated by Mr. D. J. Smith to the Institution of Automobile Engineers-and his calculations appear to be based upon the gas-yield of ordinary coal, not anthracite, which, of course, produces a far greater volume of power gas.

According to Mr. Smith, 1 ton of ordinary coal would propel a 5-ton steam wagon about 160 miles, involving the complete destruction of the fuel. Subjected to 
distillation, 1 ton of coal yields 13,000 cubic feet of coal gas, and, taking 250 cubic feet of this gas as the equivalent of one gallon of petrol, this would propel a 5-ton internal-combustion engined vehicle 312 miles, still leaving $10 \mathrm{cwt}$. of coke, which, at the rate of $3 \mathrm{lb}$. coke per mile, would run a 5-ton vehicle, operated by producer gas from a self-contained unit, a further distance of 373 miles, making 685 miles in all, as compared with 160 miles by the steam wagon, and still leaving a full complement of by-products !

Mr. Smith has devoted considerable attention to the question of a gas-producer suitable for vehicular propulsion, and has succeeded in evolving a design which has great possibilities in motor traction. His estimate of comparative costs of similar vehicles propalled by steam, petrol, and producer gas, shows that, taking coal at 50s. per ton, the cost per net ton mile is $\mathbf{7 5} \mathrm{d}$. With petrol at $3 \mathrm{~s}$. per gallon the comparative figure is 1.2d. With the price of coke at 55s. per ton, the cost of fuel converted into producer-gas as propellant is only 091d. Therefore, taking equivalent values of each and compared with the price of a gallon of petrol at 3s., the steam, petrol, and producer-gas vehicles stand in the proportions of 1 s. 6 d., 3s., and $2 \cdot 6$ pence respectively.

The Electrical Review mentions the utility of anthracite in connection with the manufacture of electrodes-now on such a scale that the larger manufacturing firms require plants comparable in size to the largest ceramic kiln installations. The raw materials considered suitable for making electrodes include all varieties of carbon found in sufficient purity and in a form which can be used industrially. One maker quotes the following details of the physical and chemical qualities of his electrodes: Specific weight, 1.50 to 1.55 ; specific 
resistance at cross sections of from 30 to 3,000 sq. em. 45 to 100 ohms; electric co-efficient, at temperatures from 25 to $900^{\circ} \mathrm{C}$., 0.18 to 0.22 ; compressive strength, 230 to $410 \mathrm{~kg}$. per sq. em. ; bending strength, 51 to $81 \mathrm{~kg}$. per sq. em. ; ash content, 2.5 to 3.0 per cent ; phosphorus, 0.45 to 0.53 per cent; sulphur, 0.93 to 1.10 per cent. The principal raw materials used in the process are retort carbon, petroleum, coke, and anthracite, pitch forming the binding medium. These materials are used either separately or mixed in proportions depending upon the cost of production. Suitable anthracite usually selected shows this approximate analysis : Ash, 2.77 per cent ; volatiles, 6.30 ; sulphur, 0.79 ; phosphorus, 0.032 ; iron oxide, 0.27 . After the volatile matter has been removed by distillation, the material is passed through a crushing and grinding plant and broken into grains of a size between 2 and 3 mm. It is then packed into sacks and weighed, when it is ready for use. The tar, which serves as a binding medium, is a mixture of pitch and tar oil, the quantity ratio of which must be strictly maintained. It usually contains these percentages of composition: Ash, $0 \cdot 15$; volatiles, $43 \cdot 0$; carbon, $56 \cdot 85$.

After removal from the kiln, the electrodes are brushed clean and examined. They should show no cracks, and when tapped with a hammer should give out a ringing sound.

Steam power users everywhere now acknowledge the advantages of anthracite for steam raising, given the right conditions. With anthracite in use an evaporation of from $\mathbf{8 . 5}$ to $10 \mathrm{lb}$. of water per $\mathrm{lb}$. of coal can be obtained, as compared with an evaporation of from 6 to $8 \mathrm{lb}$. of water per lb. with North Country, Midland, and other coals. Two boilers running on Welsh anthracite accomplish the work of three boilers 
using English coal. Engineers who have not yet contemplated making a change are recommended to give the question their earnest consideration.

Remarkable instances of the economies effected with anthracite are mentioned in In the Western Valleys of Wales, including that of an electrical concern, supplying a town with light and power, whose gas engines were run on anthracite peas at 38s. per ton, or $\frac{1}{2} d$. per h.p. per hour, as compared with a previous running cost of $2 \frac{1}{2} \mathrm{~d}$. per h.p. per hour, when using steam coal at $23 \mathrm{~s}$. per ton.

"One ton of anthracite did the work of $30 \mathrm{cwt}$. of Somerset coal," the manager of the Tin Mines, Cornwall, readily admitted.

At another works-a gas plant of 300 h.p. capacityusing best anthracite nuts, about $13 \frac{3}{4}$ tons per week, the cost of running is less than 1d. per h.p. per hour ; whilst the introduction of anthracite on a steam engine plant at these works has effected a saving of about $£ 20$ per week !

Good reports reach me of two recent boiler tests in London, in which the fuel used was anthracite " peas," obtaining evaporations of $12.2 \mathrm{lbs}$. of water per $\mathrm{lb}$. of coal, and $11.3 \mathrm{lbs}$. of water per $\mathrm{lb}$. of coal respectively.

The mixing of anthracite and other coals for steam raising is found advantageous at some works where their ordinary firing may not be proving satisfactory. Instances of the kind are intimated in the following extracts from the reports of an anthracite colliery stoker who visited several works-

"A Dyeworks. Three boilers-mechanical stokers. Started by mixing half Yorkshire coal and half anthracite. Kept going easily. Then two of anthracite and one of Yorkshire, similar results. Then three of anthracite and one of Yorkshire. Kept all in good order. 
“Dyeworks. One boiler-hand stoking. Half each of anthracite and Yorkshire coals. It would not take any further mixing. Kept going.

"Ammunition Works. Four boilers in one place, four in another. Took to the four boilers. Half each of anthracite and Yorkshire coals. Kept all in proper working order. Next took to three other boilers. Same result.

"Dyeworks. Two boilers (separate). Boiler working the dye machinery hand-stoked. Anthracite only used. Kept going first rate.

"Dyeworks. One boiler-hand stoking. Hard pressed for steam. Half each of anthracite and Yorkshire. Everything in good order when I left.

"Dyeworks. Four boilers. Sprinkler's patent. Took to three boilers. When I arrived all machines were on stop. Pressure falling. Half each of anthracite and Yorkshire. Got steam up in short time, and kept in good going order all the time.

"Memo.-Anthracite should have sufficient boiler room, a very thin fire, and even stoking."

Users of anthracite-particularly industrial usersshould exercise care to keep their supplies free from dirt or other impurities. One colliery company, in urging the necessity of this, issues these instructions to suction gas-plant customers-

"It is of the utmost importance that anthracite coal on arrival be discharged into a perfectly clean conveyance, and if allowed to run out of the truck on to the ground in the station yard, the ground should first be swept clean.

"The anthracite, when finally in store, should be kept apart from any foreign matter, especially coal of a smoky nature. The latter, if allowed to get mixed with the anthracite, will seriously interfere with the quality of the gas. 
"To obtain the best results in a plant, it is recommended that any dead small in transit, etc., be screened out of the bulk before charging the hopper."

Irish Anthracite. The coal industry in Ireland has in the past suffered from undevelopment, owing to various circumstances, chiefly, perhaps, the unsettled condition of the country ; but from recent investigations and reports it would seem that there are great possibilities of development in the future, particularly as regards the production of native anthracite.

The total amount of coal raised in Ireland in 1918 was only 92,000 tons, while the coal imported amounted to something like $4,500,000$ tons. Even these figures are not so good as formerly, according to evidence given by Mr. L. Kettle, Electrical Engineer, Dublin Corporation, before the Irish Industrial Commission in April, 1920. In 1866, he said, the Irish coal mines produced 127,000 tons of coal, of which 73,000 tons represented anthracite and 54,000 tons bituminous, the latter coming from Ulster. But improved transport facilities are expected to improve matters considerably. Ballycastle mine is to be re-opened, also the Tyrone field, in the near future. Practically all the Leinster and Munster coal is anthracite, and the witness quoted said he had received the best sample of anthracite he had ever seen from county Tipperary.

There is an aggregate of 40,000 to 50,000 h.p. working on power-gas in Ireland, nearly all using anthracite, the bulk of which is imported from Wales or Scotland; but Irish anthracite, claimed to be eminently suitable for these plants, should make such imports unnecessary. For steam-raising special furnaces and appliances are generally requisite to enable Irish anthracite to be used satisfactorily. In closed stoves it is found very economical; and insistence is placed on the point that 
anthracite needs careful preparation-overlooking which has caused a lot of the prejudice against Irish anthracite.

In his evidence before the Coal Committee, Mr. St. John Lyburn, Geologist to the Irish Department of Agriculture, stated that there was an estimated reserve of 180,506,000 tons of coal in the Irish coalfields, made up to $171,800,000$ tons of anthracite in Leinster and Tipperary, and $8,696,000$ tons of semi-bituminous in Connaught. When fully prospected, the Tyrone and north-east Ulster coalfields are anticipated to greatly augment the resources.

Mr. J. P. M'Knight, past president of the Dublin Industrial Development Association, informed the Committee that they obtained anthracite from Castlecomer, but not in sufficient quantities. It was used for gas-producing plant, and "stood comparison with ordinary Welsh anthracite."

Another witness claimed that Irish anthracite was " equal to any anthracite that he knew in the world." $\mathrm{He}$ added that certain experiments were being carried out which would convert anthracite into a very quick and effective fuel, giving results equal to oil. Ireland's anthracite deposits were most valuable; it was merely a question of scientifically treating the coal with a proper mixture of oxygen to produce most perfect combustion.

There is a theory that a big coal trough extends from Fifeshire, in Scotland, across the Channel to Lough Neagh, in Ireland, and that this trough, which contains coal measures of great value in Scotland, probably contains similar measures of value to Ireland. Mining has only been spasmodic hitherto, in the district of Coalisland, with not very satisfactory results, but working has been on too inadequate a scale to furnish a test 
of reliability. By direction of the Government, boring was started in December, 1918, at Washing Bay, Lough Neagh, and continued until September, 1919, when the boring was abandoned, after reaching a depth of 1,766 ft. The Committee recommended that the boring (which had cost $f 15,000$ ) should be continued to a depth of $3,700 \mathrm{ft}$., assuming that the borings were just approaching the coal measures. In other areas the real difficulty was the thinness of the seams.

The Committee conclude that the industry should show considerable future growth-

"Our estimate of its probable increase under these circumstances is that the output and labour employed could be quintupled; in other words, we would estimate that the output should reach about 500,000 tons, and that the industry should employ about 4,000 hands. Apart from the possibilities of the Coalisland region and the development of existing mines, it is difficult to say whether an influx of much additional capital in Irish coal mining is to be expected, because the thinness of the seams prevents such big possibilities as are usually required to tempt capital into an industry which, to some extent, is in the nature of a gamble."

It is interesting to note an official Committee's candid admission that the highly-speculative coal industry is one "in the nature of a gamble" (quite ignored in the volume of abuse hurled at the coalowners in England), and that they very wisely decided that " there should be no statutory restriction on owners' profits." Otherwise it is, of course, foolish to expect any great rush of capital for developments!

The annual output of the various Irish mines during 1918 is shown by the following table, also the number of men employed above and below ground. 
Output. Employees.

Mine.

Tons. Under. Above.

Arigna Mining Co. (Roscommon) • • $\quad \begin{array}{llll}7,434 & 65 & 24\end{array}$

Castlecomer Collieries, Ltd. (Kilkenny) $\quad$. $63,675 \quad 364 \quad 162$

$\begin{array}{llll}\text { Michael Layden (Roscommon and Leitrim) } & 6,367 & 35 & 6\end{array}$

$\begin{array}{llll}\text { New Irish Mining Company (Queen's Co.) } & 7,086 & 60 & 33\end{array}$

$\begin{array}{lllll}\text { Slievcardagh Collieries (Tipperary) } & 3,945 & 25 & 12\end{array}$

$\begin{array}{llllll}\text { Various small mines } & \text {. } & 3,494 & 68 & 39\end{array}$

Total $\overline{92,001} \overline{617} \overline{276}$

Opinions differ as to the quality of Irish anthracite. A former official of the Ordnance Survey, writes to the Irish Independent (3rd May, 1920), thus-" The high quality is purely imaginary and untrue. Its utility for iron and steel manufacture is vitiated by the quantity of sulphur and phosphorus it contains, and as to the other uses, a railway witness told the committee, that ' though we gave it every chance, it was a failure.'

On the other hand, below are details of analyses I have received of their coal (anthracite) from the New Irish Mining Co., Wolfhill-

Calorific value $\quad 8206 \cdot 7$ calories $=14,772$ B.T.U. per lb. Moisture at 105 degrees Cent. $\quad .0 .90$ per cent.

Carbon on dried coal . $\quad . \quad . \quad$. 91.49 ".

Hydrogen . . . . . . . $\quad . \quad 3.21$

Ash . . . . . . . . 2.54

Sulphur in ash . . . . . . none

Volatile sulphur . . . . . . 1.00

Nitrogen . . . . . . . $\quad .1 .27$

Arsenic . . . . . . none

Carbon calculated on pure coal . . $94 \cdot 85$

Hydrogen . . . . . . 3.33

Nitrogen $. \quad . \quad . \quad . \quad . \quad . \quad 1.32$

Oxygen $. \quad . \quad . \quad . \quad . \quad .0 .50$

Carbon

Hydrogen

Ash

Nitrogen

Sulphur

$93 \cdot 75$

$2 \cdot 85$

$2 \cdot 15$

0.90

0.35

Calorific value Fah. units 14,650 B.T.U. per lb.

The latter certainly represents a high-class anthracite. 
And here is an earlier opinion, expressed in an interesting letter by Dean Swift to the Dublin Weekly Journal, bearing date 16th Aug., 1729-

"I sent for 1 cwt. of Kilkenny coal and weighed $\frac{1}{2}$ cwt. and $\frac{1}{4}$ cwt. Whitehaven coal. The Whitehaven coal lasted between 4 and 5 hours, and left a small heap of cinclers. I found it to abound with slatesa very slaty coal - that flies and cackles in the fire. The Kilkenny coal held good for about 9 hours, with a great heat. Afterwards, my fire-maker made a good fire (of the cinders) as before, and which continued the same, which convinces me of the extraordinary goodness of Kilkenny coal-preferable for many uses to any coal I ever saw-the most beneficial I have ever read of in these countries-or in all Europe! Can any sensible man say we are in our senses to encourage and send abroad for coal, when we have so excellent a coal of our own at home?"

Scotch Anthracite. The Scottish coalfields contain very little anthracite-in scattered areas round Stirling -utilized principally in making briquettes. Its qualities are much below either Welsh or Irish anthracites, though, on account of its higher volatiles, some people like it for domestic purposes. Quantities are sent as far in England as Sheffield, but railway charges no doubt preclude its travelling any farther south than there.

Results in a test of Scotch and Irish anthracites by the Vulcan Boiler Company, for the Dublin Corporation, showed that the Scotch coal burnt much quicker, and the evaporation figures showed that under the conditions existing at the time of the test $1 \mathrm{lb}$. of Irish coal evaporated 51 lb. more water than Scotch coal, which was equivalent to over 7 per cent difference in favour of the Irish coal. The trials were made on a large Babcock and Wilcox boiler, and on a Lancashire boiler. 
Messrs. Archibald Russell, Ltd., Glasgow, send me the latest analysis of their coal, as follows-

Fixed carbon .

Volatile matter

Ash

Moisture

Sulphur .

Calories .

B.T.U.

Evaporative power:

lbs. of water at $60^{\circ} \mathrm{F}$. evaporated per lb. of fuel, $13 \cdot 2$
86.58 per cent.

$8 \cdot 16$

$2 \cdot 00$

$2 \cdot 26$

$100 \cdot 00$

.66 per cent.

8302

14943

American Anthracite. The anthracite coalfield of America covers an area of some 480 square miles, in the eastern-central portion of Pennsylvania, and what the product may lack in quality-it is certainly not equal to Welsh anthracite-is made up for in quantity, the annual output being about 100,000,000 tons-and practically all utilized in the United States.

Two vital factors determining the degrees and method of anthracite preparation are: the character of the beds and the methods by which they are mined, the equipment used and practice followed burning the coal, states Mr. D. C. Ashmead, in a paper read before the American Institute of Mining Engineers. In 1830, by means of rakes, the large lumps of coal were separated from the small and sent to the surface; the smaller sizes were left in the mine. At the surface, the coal was dumped upon perforated cast-iron plates and broken to commercial sizes with hammers! In 1844, the roll crusher was invented, and installed at Philadelphia. Then followed the breaker, with circular screens. The first one was equipped to break 200 tons of coal daily. About 1876, a roll having a cast-iron shell into which steel teeth were driven was introduced; 
but a picking table was in use some six years earlier. The shaker and mechanical picker were invented in $\mathbf{1 8 7 2}$.

On the kind of rolls used and their operation largely depends the percentage of prepared sizes. An excess production of the smaller sizes reduces the sum realizable from the output as a whole. The total breakage in handling coal from shakers to the lip screen at the loading pocket is from 10 to 12 per cent.

In American mining the Hudson Coal Co. has installed chutes made of a high silicon iron, known as Corros iron; and the anthracite spiral picker is in everyday use. It separates the coal from the slate by centrifugal action. A device for the mechanical cleaning of coal that has recently been introduced might be called an air washer, or concentrating table; and the Hudson Coal Co. has just developed an experimental plant for testing the Conklin separator. This process is based on the principle of introducing a mixture of coal with its impurities.

Dealing with the preparation of anthracite, Mr. D. C. Ashmead thus describes the American method of separating the coal from the slate, etc.-

For the separation of coal from slate and bone, ocean beach sand has been used in sizes ranging from 20 to 30 mesh down to 100 to 200 mesh and even finer. The specific gravities of from 1.20 to 1.75 may be maintained for any period.

The inverted cone type of washer has been used in the most recent of these experiments, the washed coal and refuse both being removed from the apparatus without the use of complex devices or conveyors. A slow-moving rotary stirrer within the cone will keep the sand agitated and prevent its forming into banks on the walls. This fine granular material virtually forms a stratum of quicksand in the lower half of the cone, 
which the stirrer maintains at a uniform density. As the flow of water is reduced to a minimum, a high fluid density is maintained. The cleaned coal usually is discharged through an overflow weir along with the water, but in some cases it is removed with a conveyor or a raking wheel. The coal is discharged on to a stationary screen, where the sand particles that adhere are rinsed off and the coal is recovered. In treating the finer sizes, a shaker screen probably will be more efficient.

If the average specific gravity of the coal to be washed is $\mathbf{1 . 5}$, and the average density of the ash is such as to produce an increase in density of 0.01 per cent for each per cent of ash content, a specific gravity of the fluid of 1.6 will produce washed coal no piece of which can contain more than 10 per cent of ash. The coal that floats is a high-grade product. The material that sinks can be passed to a second washer, in which the fluid mass is maintained at a specific gravity slightly higher than the first, and graded into middlings and tailings. The middlings will contain most of the bone, which can be crushed so as to separate the coal and the rock; it can then be returned to the first washer for cleaning. Pyrites can be practically equal to that of the large pieces of clean coal, and will therefore be discharged with the washed product. With the Chance process, no difficulty has been found in maintaining such a fluid density that no individual piece of coal is discharged that contains more than 3 per cent of pyritic sulphur.

Highly satisfactory results have been obtained in treating No. 1 buckwheat, rice, and barley coals. It has been possible to reduce the impurity so that practically only the inherent ash remains. As a commercial proposition, however, this would result in too great a rejection of boney coal, and hence in too low a recovery. 
As a result, the percentages in the table given below have usually been found to represent the best practice.

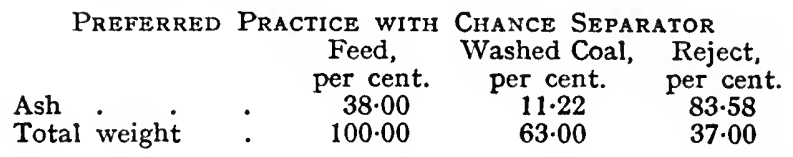

Little sand is lost in the operation. When rice coal has travelled less than $1 \mathrm{ft}$. over a $\frac{1}{8}$ in. mesh screen, the washed coal contains less than 0.6 per cent of residual sand. A further journey of $1 \mathrm{ft}$., with the addition of fresh water, reduces this final sand content to approximately $0 \cdot 1$ per cent, or $2 \mathrm{lb}$. per ton of coal. The sand is washed from the coal by the agitation water after it is discharged over the weir at the top of the cone. It is possible to use this water several times by employing a screen built in a number of steps, the sand washed out in one portion being given an opportunity to settle before the water is used in the next.

In a paper recently read before the American Institute of Mining Engineers, Mr. J. Griffen mentioned that their modern coal breaker uses approximately 1 gallon of water per minute per ton of production daily. As this water leaves the breaker it contains from 4 to 15 per cent solids, by weight, and is then known as "slush." None of the solids is larger than $\frac{3}{32}$ in. in diameter. Despite the efforts of the operators, these solids have found their way into the streams, causing, in some instances, pollution to a serious extent. In consequence, several slush-recovery plants containing Dorr thickeners and classifiers have been lately introduced. One plant is recovering the granular solids from 2,200 gallons per minute of slush made through a $1 \frac{1}{16}$ in. round-mesh screen. After this plant had been working a few weeks, the bed of the stream for some miles below the breaker 
had become freed from the solids, and after seven months no signs of deposit were apparent in the stream.

Based on breaker shipments, the cost of preventing pollution is slightly under 1 per cent per ton shipped, if the recovered coal is considered of no value. The coal recovered from breakers slush may be made into briquettes for about 3 dollars per short ton, and it has been successfully adopted as a steam fuel. Complete prevention of stream pollution, except under unusual conditions, may be obtained at a cost of one or two cents per ton of breaker shipments, if no value is placed on the recovered coal. If the recoverable coal is valued at, say, 35 cents per ton, the coal recovered will pay the cost of recovery and of preventing stream pollution by the slush solids that, at present, have no commercial value.

The remarkable superiority of coal-production per worker in America is ascribed to the fact that the United States possess thick seams of coal near the surface, which are blasted or scooped out by mechanical excavators, coal-cutting machines, etc. While this may be true of the bituminous coal, the position in America as regards anthracite mines-largely waterlogged-is very similar to that in the older mines of Britain. Anthracite seams are mostly thin and irregular, preventing the use of coal-cutting machinery in many cases, hence the coal can only be mined by pick and shovel. Notwithstanding this, the American miner-producing on an average about 4 tons of coal per working daymanages to send up about three times as much coal as the British miner, who is aided by a good deal of coalcutting machinery where such can with advantage be used. Production per worker has steadily increased in American mines, but correspondingly decreased in our own mines, as the statistics on page 88 show. 


\begin{tabular}{|c|c|c|c|c|c|c|}
\hline \multirow[b]{2}{*}{1890} & \multicolumn{4}{|c|}{ OUTPUT PER MAN PER } & \\
\hline & & 1.08 & tons & r & & \\
\hline & & $1 \cdot 18$ & & . & $2 \cdot 07$ & \\
\hline $1 \mathrm{~s}$ & & $1 \cdot 10$ & ," & . & $2 \cdot 40$ & ", \\
\hline & & 1.08 & " & . & $2 \cdot 18$ & \\
\hline & & $1 \cdot 00$ & 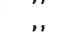 & . & $2 \cdot 17$ & \\
\hline & & 0.98 & & . & $2 \cdot 19$ & \\
\hline & & . 0.80 & ", & . & $2 \cdot 29$ & \\
\hline
\end{tabular}

Thus a single anthracite miner in America now produces per day almost as much coal as three British miners-and figures for 1920 revealed still greater contrasts !

According to the Coal Age (5th Jan., 1922), in a review of the American coal trade, the production of bituminous coal in 1921 was 408,000,000 tons-the lowest annual production since 1911. The labour cost of producing anthracite coal increased from 1.59 dollars per ton in 1913 , to 3.85 dollars per ton under the present wage scale, according to a bulletin issued by the General Policies Committee of Anthracite Operators. In 1913 there was produced $71,046,816$ tons of anthracite, at a labour cost of $113,320,000$ dollars, or about 1.59 dollars a ton. The production in 1920 was $65,458,673$ tons, and the labour cost was $252,179,000$ dollars, or 3.85 dollars a ton-an increase of 141 per cent. These figures are based on commercial fresh mined coal exclusively. The coal consumed at collieries and the washery or dredge product is not included. This wage agreement, which was based on the award of the United States Anthracite Coal Commission, expired on 31st March, 1922.

Canadian Anthracite. What is reported to be the world's largest coal deposit exists in British Columbia, where an anthracite coalfield, with an area of about 2,000 square miles, is situated on the Upper Skeena. 
north-east of Prince Rupert. The quality of this coal, according to Mr. J. G. Scott, of Quebec, is " anthracite and semi-anthracite, similar to Welsh coal."

Negotiations for the purchase of a large portion of this property were, in 1912, opened by Mr. R. C. Campbell-Johnson, the well-known mining authority of Western Canada, who, associated with a Quebec Company, opened the Groundhog Mountain district. The late Lord Rhondda inspected the property in 1914, deciding to purchase subject to his engineers' approval; but about that time his duties as Food Controller intervened, and he died before matters could be completed. Since then Lord Jellicoe has visited Vancouver and resumed negotiations on behalf of the British Admiralty, mining engineers believing the coal to be especially suitable for Admiralty requirements.

Mr. Campbell-Johnson, who fully expects that the British Admiralty will become the possessor of the property, considers that the discovery of the coalfields of Groundhog Mountain "marks an epoch greater and more far-reaching than even the historical gold discovery of Klondyke; for when the last ounce of gold has been wrested from the frozen vaults of the treasure house of the Great North, millions of tons of coal will yet await the pick of the miner and his children's children."

The quantity of coal estimated on the 47 miles controlled by the Skeena Company is 1,100 million tons; and the construction of 100-180 miles of railway would afford the coal an outlet to the Portland Canal, to Hazelton, or to the mouth of the Naas River. By any of these routes coal could be delivered for bunkering purposes to Prince Rupert, which being some hundreds of miles nearer to Japan than Vancouver, might become the great bunkering station for ships in the Pacific trade. 
And if eventually, as is expected, the Canadian Pacific Railway Company extends and links up its system to this great coalfield, the possibilities of rapid and successful development are assured. But, after all, the chief factor of success or otherwise must be the quality of the coal itself.

Other Anthracites. Of the other known sources of anthracite supplies, we must take into account the field discovered in 1918 and exploited by the Northern Exploration Co., Ltd. Situated in Western Spitsbergen, large coal seams, both anthracite and bituminous, are included in this property.

According to the latest information $I$ have received as this book goes to press, the Norwegian Spitsbergen Coal Company has displayed great activity during the past winter, which activity will be continued throughout the present year. The output has been over 3,000 tons weekly, and about 300 men have been employed. Shipping will go on during this season both to North Norway and Christiania. It is expected that the season's exports will amount to about 150,000 tons of anthracite and bituminous coals.

And China, which has begun to export coal to Europe, is believed to possess about one-seventh of the world's coal reserves, and it is stated that something like 40 per cent of her coal consists of " high-class anthracites." However, all these are mostly in the "glowing report" stage. So far, I know of no anthracite anywhere in the whole globe equal to that from South Wales; that, doubtless, explains the universal demand for it.

Anthracite Compounds. In 1918, when preparing my previous book, All About Anthracite (Technical Publishing Co.), I referred to the vast quantities of anthracite dust lying dormant in very unsightly waste dumps at the collieries, pointing out the possibilities awaiting 


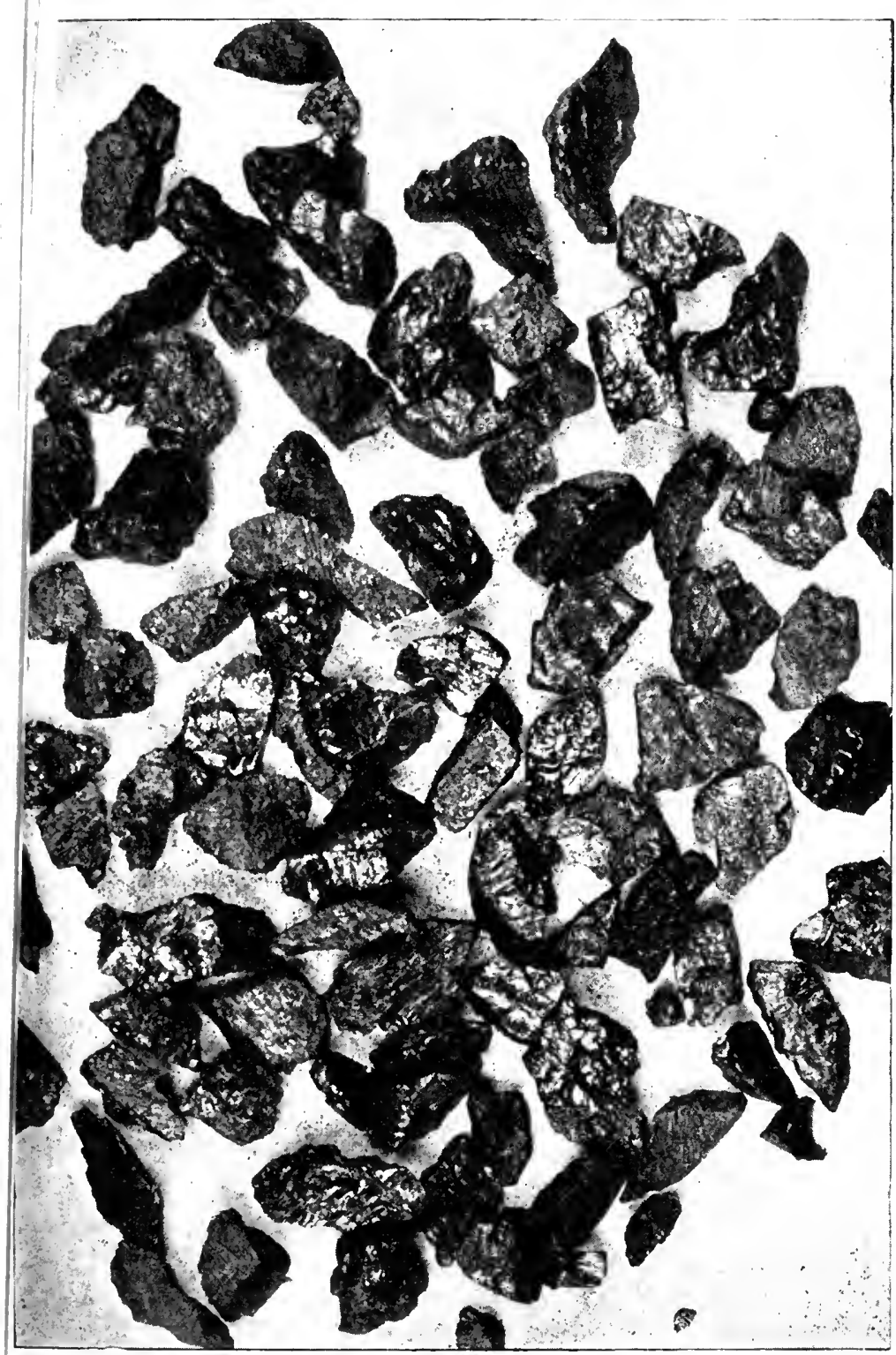

FIG. 17

ANTHRACITE MACHINE-MADE AND WASHED "PEAS" 
the utilization of this material, advantageous to coalowners and consumers generally; and it is gratifying to observe the progress made in this direction since the suggestion was made. Various enterprising companies have been formed for the purpose of taking the business in hand seriously, and some excellent synthetic fuels are now an established fact, and proving a commercial success in the market.

Knowing the qualifications of anthracite "duff" so well, and having personally submitted it to practical tests in the form known in Wales as " pele" (anthracite dust mixed with common clay and water), I never had the slightest doubt as to its efficiency and ultimate popularity. Likc anthracite coal itself, it merely need be known to be appreciated, as manufacturers of such fuel are quickly discovering. Anthracite coal dust usually contains about 82 per cent of carbonaceous matter and 6 to 7 per cent of volatiles, hence a really good fuel can be formed therefrom, given the right kind of binding ingredients-more particularly those which are hard-setting and capable of resisting water.

"Anti-waste" Fuel. Such appears to have been accomplished by a new company, called The Patent Fuel Marketing Co., Ltd., London, recently introducing their " anti-waste" fuel, made from anthracite duff with a small proportion of pitch, as a binder (and additional volatile). In the usual "ovoid," or oval, form, this fuel is giving satisfaction and found to be economical in domestic use, both in stoves and ranges, for heating or cooking purposes.

The Press report of a test of this fuel, on 11th January, 1922, shows that a good temperature was attained and well maintained. A fire was lighted at 10 a.m. in a room $18 \mathrm{ft}$. by $14 \mathrm{ft}$., having an ordinary grate with horizontal bars and an area of 108 square inches. 
Temperature readings were recorded by a thermometer suspended at $8 \mathrm{ft}$. from the fire. The initial temperature of the room, $47 \cdot 8^{\circ} \mathrm{F}$., rising at about 10.45 to $64^{\circ} \mathrm{F}$., and maintaining a comfortable average temperature of $61.4^{\circ} \mathrm{F}$. The weight of coal consumed was $14 \mathrm{lb}$., the fire lasting over ten hours, the weight of ash resulting being $1.65 \mathrm{lb}$. Next day a comparative test, in the same grate and under similar conditions, was made with best household coal (Derby Brights), and it is instructive to note that $14 \mathrm{lb}$. of this coal only maintained an average temperature of $59 \cdot 3^{\circ} \mathrm{F}$., and the fire only lasted 6 hours 15 minutes!

The Patent Fuel Marketing Co. originated what is known as " coal blending" and "reconstructed coal," now operating under eminent technical supervision.

Another compound fuel, in ovoid form, has been placed on the British market by the South Wales Fuel Co., Ltd. Following is the analytical report thereon"The sample received [tested in a "Hygiene" stove] was proved to contain 4.08 moisture, 9.15 volatile, ash $5 \cdot 58$, and fixed carbon $81 \cdot 19$. This compares very favourably with ordinary anthracite, and is much superior to anthracite which I am receiving at present. There are, of course, no shale or clinker pieces, and the ash is so fine that it very readily passes through the shaking bars or grid of the stove. The binding material showed no tendency to separate and run, and although the 'Hygiene' stove has a very large cooling area in the fuel supply end, there were no signs of condensation of tarry or sticky deposits as has been the case with other patent fuels."

Several leading stove-makers also report that they have tested this fuel and found it very satisfactory, and the writer has seen it give excellent results in an open grate. 
These useful compounds are certainly to be encouraged, for various reasons. Not only do they afford the means of utilizing material which would otherwise be wasted, but they help to a substantial degree to conserve the more valuable coals for the nation, to say nothing of the convenience of such stocks to fall back upon in times of " coal shortage," due to the interminable strikes, etc., to which this country seems so prone!

A patent fuel said to be finding favour in America consists of a mixture of 95 per cent of anthracite coaldust screenings with about 5 per cent of water-gas tar. This burns without smoke, and from a boiler-room standpoint is considered quite a satisfactory fuel, having a calorific value of from 12,000 to 14,000 B.T.U. to the $\mathrm{lb}$., according to the quality of screenings used. In one test a boiler was run for a day upon ordinary coal, and for one day on the patent fuel, and with the latter the boiler developed well in excess of its rated capacity, and about one-and-a-third times the capacity developed under coal firing ! The record is interesting in considering the assertion of some that the efficiency of patent fuels is from 10 per cent to 30 per cent higher than that of ordinary coal for steam raising ; but there is the question of whether the extra efficiency attained in the experiment was sufficient to cover the probable higher cost.

Germany produces more than $25,000,000$ tons of patent fuel yearly, against Britain's modest 2,000,000 tons, so there is obviously great scope for expansion here in this industry. South Wales collieries are, however, concentrating more and more on the subject lately, for it is realized that the proper development of composite fuels could save at least $50,000,000$ tons of our present annual consumption of coal-and probably 50 per cent per annum on the domestic coal bill. 
Patent fuel is found to be an efficient substitute for large coal at high rates of combustion, the average approximate analysis (mixed coals) showing-fixed carbon, 73.25 per cent; volatiles, 17 per cent; ash, 8.50 per cent ; moisture, 1.25 per cent, with a calorific value of 7,724 calories. The regular shape of briquettes ensures easy stacking, and it occupies less space than ordinary coal, the number of cubic feet to the ton being about 36 as against 45 , while it does not break down so readily under rough handling to which shipped goods are all subjected, the percentage of " small " on discharge after shipment being usually 5 per cent, as compared with 20-30 per cent in the case of large coal These advantages commend it specially to overseas buyersas also its freedom from the risk of spontaneous combustion.

As far back as the time of the Great Fire of London, we find interest displayed in the subject of composite fuel, for that discriminating man, John Evelyn, referring in his famous Diary to "My New Fuel," says, under date 2nd July, 1667-

“ Call'd upon my Ld. Arlington as from his Majesty about the new fuell. The occasion why I was mention'd was from what I had said in my Sylva three years before, about a sort of fuell, for a neede, which obstructed a patent of Lord Carlingford, who had been seeking for it himselfe; he was endeavouring to bring me into the project, and proffered me a share. I met my Lord ; and on the 9th by an order of council went to my Lord Maior to be assisting. In the mean time they had made an experiment of my receipt of houllies, which I mention in my booke to be made at Maestricht ${ }^{1}$ with a mixture of charcoal dust and loame, ${ }^{2}$ and which was

1 In the Dutch province of Limburg.

2 Very similar to what is known as "Pele" in Wales to-day. 
tried with successe at Gresham Colledge (then being the exchange for meeting of the merchants since the Fire) for every body to see. This done, I went to the Treasury for $£ 12,000$ for the sick and wounded still on my hands.

"Next day we met againe about the fuell at Sir James Armorer's in the Mewes.

“ 8. July. My Lord Brereton and others din'd at my house, where I shewed them proofe of my new fuell, which was very glowing and without smoke or ill smell."

It is a great pity that Evelyn's desirable " new fuell " did not survive along with his excellent Diary. However, if it gave as good a fire as the Welsh people are nowadays obtaining from their anthracite duff-and-clay mixture, I feel sure the diners enjoyed a warm reception and right comfortable time! The cost of Evelyn's fuel is not recorded, but interesting facts are available regarding the costs of fires with the modern similar fuel before mentioned ("pele"). Some two years ago I was present at a six-day trial of this fine fuel, conducted at the Hotel Metropole, Swansea. Three splendid fires were maintained in the building's public rooms, and the cost, on a basis of 12 hours per day, worked out thus-

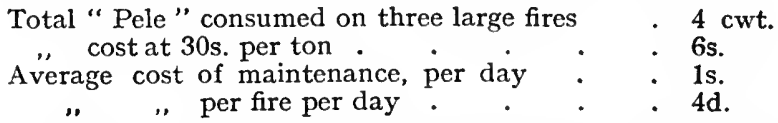

Patent fuel seems to have performed a conspicuous service at the big political meeting held at Devonshire House, Piccadilly, in January, 1922. In the society notes of a Sunday journal an observer writes-

"All Hot.-The throng of Coalition-Liberals at Devonshire House was thoroughly ' het up.' Those in authority were afraid that the great house would be cold, and, since there were no provisions for heating, 
they installed ten great stoves filled with a new patent fuel. That did the trick. One lady said that the lead fittings of her jewellery had begun to melt and were trickling down her shoulder. A good advertisement for the patent fuel.'

Temperatures of Spontaneous Ignition in Coals. In the spring of 1920, a very interesting and instructive paper by Messrs. F. S. Sinnatt and Burrows Moore was read before the Manchester Society of Chemical Engineers, quoting results of their investigation of the spontaneous inflammabilities of fincly-divided fuels (including anthracite), and the influence of physical and chemical variations of the fuels upon the temperature of ignition. The object of the experiments was to determine (1) the relative tendencies to spontaneous ignition in oxygen of various finely-powdered fuels; (2) to examine the influence of the degrees of fineness of the particles on the recorded temperature ; and (3) to examine the influence of the volatile matter upon the recorded temperature. The temperature of spontaneous ignition in oxygen was defined as the temperature to which a fuel must be raised for ignition to occur without the aid of external agents of inflammation; and the apparatus used for the experiments was similar to the ignition meter designed by Mr. Harold Moore to ascertain the relative ignition temperatures of liquid fuels.

The coals tested were Wigan Arley coal, Wigan Yard, Anthracite, Hoo cannel (25 per cent ash), and two coals liable to produce gob fires (numbered 1 and 2). The coals were pulverized to pass through a 1-200 mesh sieve and were air-dried. Excepting the Hoo cannel, the coals were freshly mined (within three weeks). The authors arrived at the following conclusions-

In all cases, except at the higher temperatures, 
glowing in the mass of coal commences before ignition takes place, and the time interval before the former occurs decreases with the rise in temperature. The variation of the " time intervals" before ignition takes place, compared with the intervals for glowing to appear, are somewhat irregular. There is a well-defined temperature below which no glowing occurs within a time limit of four minutes, and, with the exception of Hoo cannel, this also applies to the ignition. In the case of Hoo cannel an intermediate range of temperatures exist, at which no active ignition occurs.

In the coals examined, with the exception of the two which are known to be liable to gob fires, there appear to be zones of temperature at which spontaneous ignition occurs after a much longer interval, and it would appear that coal yields volatile compounds at these ranges of temperature, which compounds have a higher temperature of ignition. It is suggested that such coals may possess the property at these temperatures of tending to extinguish any heating which may be taking place, especially where the coal is in masses, and the oxygen only in contact with the surface. Where, however, coal does not evolve such compounds, no such self-damping action is possible, and the result of the oxidation would be an additive one consisting of glowing of the solid substances and ignition of the volatile constituents. Further experiments will be made in this connection.

In the case of the two coals liable to gob fires, the curves of spontaneous glowing and ignition were practically parallel, but there were very clear evidences of the spontaneous ignition occurring practically at the same interval at which the glow was visible; the volatile compounds produced from these coals were more easily inflammable than was the case with the other coals. 


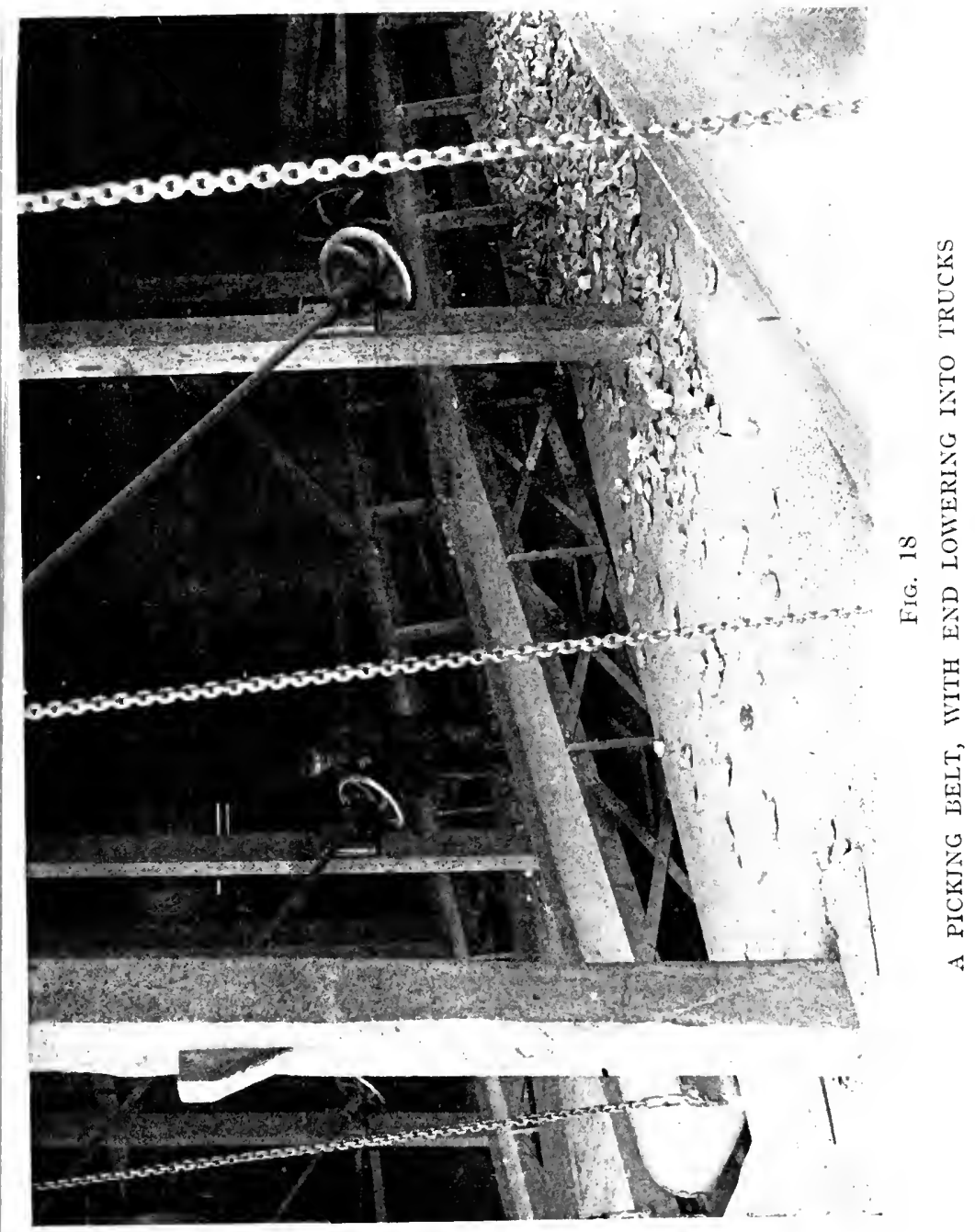


To obtain an idea of the minimum temperature at which substances would either glow or ignite, a time limit of four minutes was adopted, and the lowest temperature at which substances would glow or ignite within this period was taken as the temperature of glowing or ignition. The time interval was decided upon as being sufficiently long for most practical purposes. Early in the course of the experiments it was found that the degree of fineness of the fuel had a considerable influence upon the minimum temperature at which spontaneous glowing would occur, and preliminary observations have been made to ascertain broadly the influence of the degree of fineness of the fuels examined. The results, though not final, were held by the authors to show that the degree of fineness is a most potent factor, and worthy of prompt recordance.

The values obtained for the different substances tested are shown below-

\begin{tabular}{l|c|c|c|c}
\hline \multicolumn{1}{c|}{ Substance. } & \multicolumn{2}{|c|}{ Minimum Temperatures in Oxygen, deg. C. } \\
\cline { 2 - 5 } & Glowing. & lgnition. & $\begin{array}{c}\text { Holm's } \\
\text { figures. }\end{array}$ & $\begin{array}{c}\text { Brame's } \\
\text { figures. }\end{array}$ \\
\hline Anthracite coal & 250 & 258 & 440 & 500 \\
Hoo cannel coal & 225 & 230 & & 370 \\
Wigan Arley coal & 184 & 188 & & to \\
Wigan yard coal & 219 & 219 & & \\
Inclian coal & 242 & 242 & & \\
Coal liable to gob & 228 & 228 & & \\
$\quad$ fires, No. 1 & & & & \\
Coal liable to gob & 228 & 228 & & \\
fires, No. 2 & Above 398 & Above 398 & & \\
Gas coke , & Above 396 & Above 396 & & \\
"Coalite" & 248 & 248 & & \\
Wood charcoal & 300 & 300 & & \\
Irish peat & 324 & 324 & 360 & \\
Cellulose & 367 & 367 & & \\
Fusain & & 246 & 310 & \\
Paraffin wax & & &
\end{tabular}




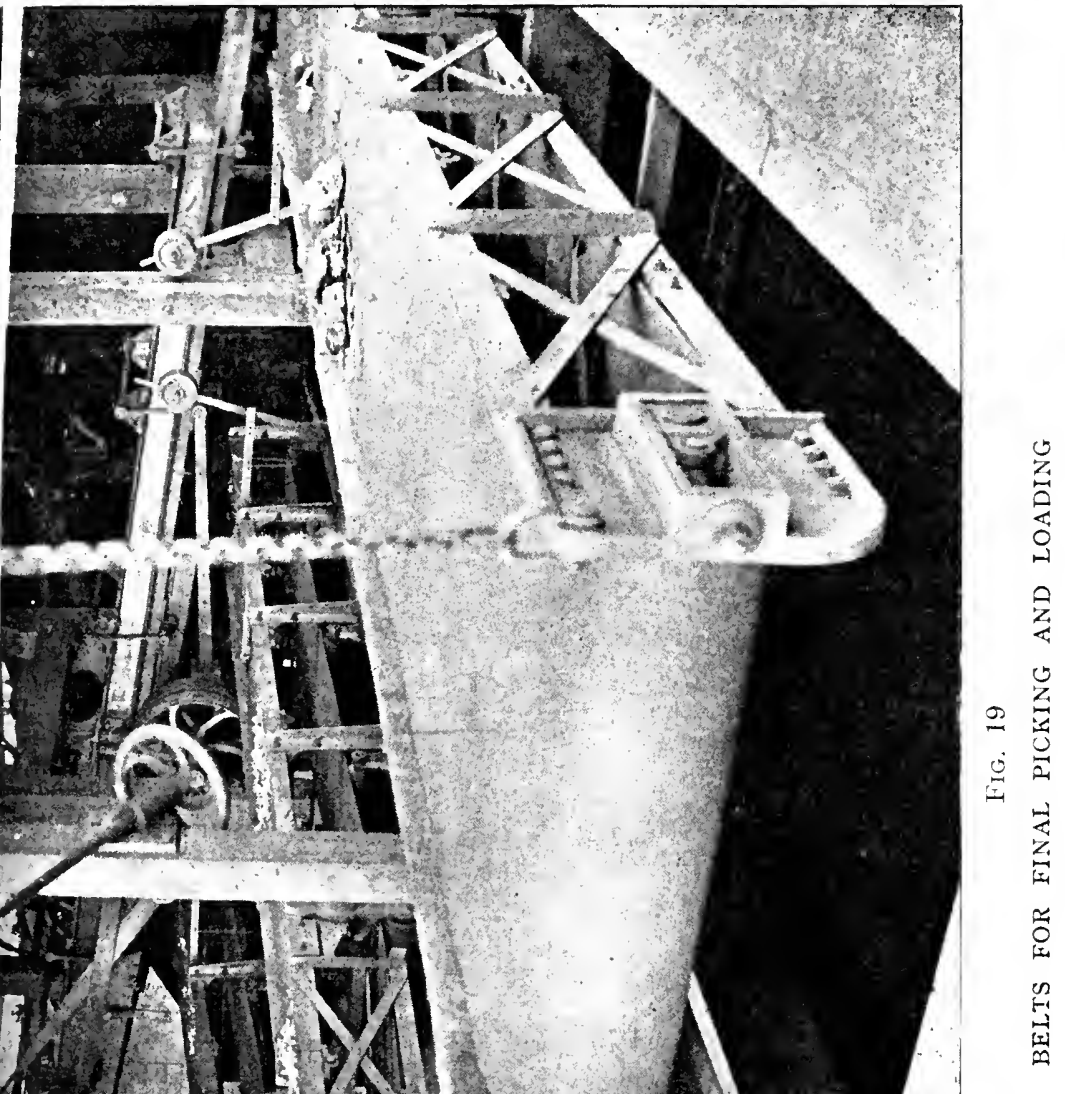

15. 15 H IIIM

- val Luta me
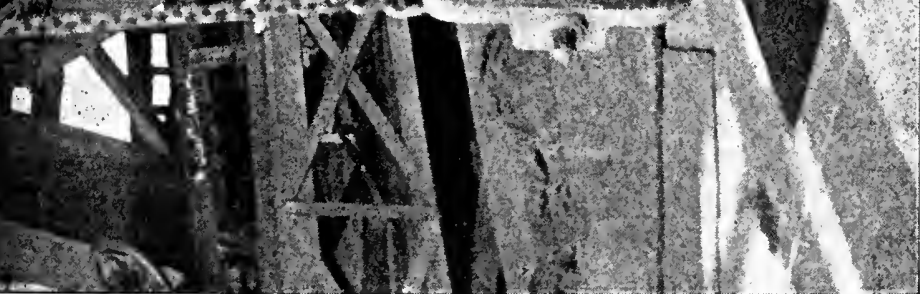
Mr. Hood, chief mechanical engineer of the United States Bureau of Mines, in an address before the Pennsylvania Electric Association on "Coal Storage," stated that the whole problem of coal storage rested on spontaneous combustion. Heating rarely occurred in coal piles of only a few tons. Anthracite coal never ignited spontaneously, and only rarely did the domestic consumer of bituminous coal experience trouble in this connection. The main interest in the subject lay in the large piles kept in reserve by public bodies or industrial concerns.

If a ton of bituminous coal could be delivered in a single cube, each dimension would be about $2 \cdot 8 \mathrm{ft}$. If such a cube, having originally about $47 \mathrm{sq}$. $\mathrm{ft}$. of exposed area, be continuously sub-divided, the rate of increase in the exposed surface is very rapid. If the size of each particle is reduced until it will pass a 16-mesh screen, the ton of coal will have an acre of exposed surface. From this it is obvious why trouble from spontaneous combustion originates in fine coal, because the great increase in extent of surface does not begin until we get below $1 \frac{1}{4}$ in. nut size If fine coal is kept out of the pile, the heating surface is so relatively small that no cause exists for spontaneous combustion. 


\section{CHAPTER VI}

\section{SMOKE ABATEMENT AND COAL CONSERVATION}

SMoke abatement and coal conservation-Coal-smoke and public health-Coal statistics-Concentrated poisons-Medical indictments-Atmospheric pollution reports-Analysis of polluted atmosphere-What constitutes injurious fogLondon's canopy of coaldust-The terrible toll of cancerFinancial cost of fogs-Important recommendation of Lord Newton's Committee-Public control committee-John Evelyn and the smoke nuisance-Fog paralysis of LondonHealthy prosecutions-Conserving Britain's coal-Electrical generation-Oil versus coal-Anthracite the remedy-Byproducts of soft coals-Stupendous annual waste of coal and energy-Low-temperature carbonization-Electricity wasteful.

DURING the past three years I have, through the medium of the Press, strenuously supported the movement organized in the interests of the public health in this country to abolish the coal-smoke nuisance, to the dangers of which I am glad to find that our lethargic authorities are at last awakening. In the course of many articles, etc., I have, too, endeavoured to impress upon the community the fact that our neglect of this important problem is responsible for enormous waste of good coal-two unnecessary evils incidental to the same state of national apathy. Moreover, I have shown conclusively that anthracite is waiting to prove its national importance as the simultaneous remedy for both defects! I have even asserted-and I do so again emphatically - that the health of our citizens should be safeguarded here, as it is in the principal American and Continental cities, by making the domestic use of anthracite compulsory; and in view of the alarming ,reports of scientists, medical men and engineers on the injurious effects of coal-smoke, and the wickedly wasteful 
manner in which our bituminous coals are being misused, we can no longer afford to ignore these serious problems.

Dealing first with the smoke evil, I will briefly set forth concrete evidence showing why we are a physically "C3" population, and overwhelmingly in favour of immediate reform.

We raise in this country something like $250,000,000$ tons of coal per annum, of which, say, 190,000,000 tons are consumed at home, 18,000,000 tons used for making town's gas, and 20,000,000 tons in coke ovens, the remaining $152,000,000$ tons being utilized in the raw state, including $90,000,000$ tons for steam raising and $35,000,000$ tons for domestic fires. London households alone normally require between 5 and 6 million tons a year.

Now, consider for a moment the dense volume of smoke constantly issuing from the accumulated fires of a great city like London, and you will not be surprised at the medical statement that the average Londoner's lungs are black, and that the cloud of coal-dust, soot, gases, arsenic, and other poisonous substances he breathes very often approximate to a hundred tons per day! Eminent physicians declare that when these poisons concentrate into a dense mass, causing a thick fog, they are responsible for the untimely death of thousands of citizens !

The average man consumes as much as $30 \mathrm{lb}$. to $50 \mathrm{lb}$. of air per day, $2 \mathrm{lb}$. to $3 \mathrm{lb}$. of food, and $4 \mathrm{lb}$. to $5 \mathrm{lb}$. of water-or more than four times as much air as food and water combined, hence we perceive the necessity for keeping the air as pure as possible.

Professor Leonard Hill, F.R.S., assures us that the smoke greatly increases the dampness of our English climate, thus aggravating another enemy of health. 
Dr. J. S. Owens, chief of the Advisory Committee on Atmospheric Pollution, who has worked energetically to open the public's eyes to the grave menace, declares that the average coal-smoke deposit over London for the year ending 31st March, 1920, amounted to 40,000 tons ! His scientific tests and data, collected from thirty observation stations throughout the country, are unquestionable. When analysed, the deposit was found to consist approximately of-

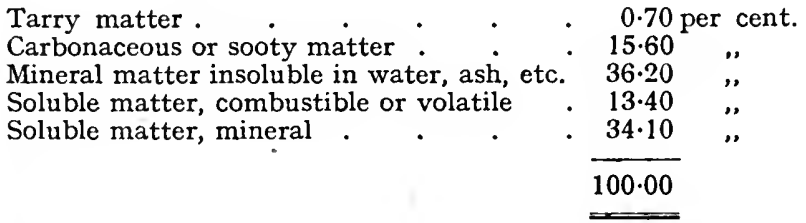

In addition, there is the suspended matter. To produce a dense fog, about 4 milligrams of soot per cubic metre of air are all that are requisite. One milligram produces the ordinary haze prevalent most of the winter in London. These quantities correspond to about $7 \mathrm{lb}$. and $1.7 \mathrm{lb}$. respectively per million cubic yards. If a dense fog extends over the whole of London and up to a height of $400 \mathrm{ft}$., something under 200 tons of soot are present. Dr. Owens estimates that the domestic fires of London, during the hours from 6 a.m. to 9 a.m., produce over 200 tons of soot. He has a new apparatus by which he calculated that during the fog of 26th October, 1921, the average Londoner's fog ration consisted of 252 thousand million particles of solid matter! These particles inhaled by each person, if placed side by side, would reach 130 miles, he pleasantly announced. The dragons of ancient times were truly insignificant compared with this foe.

The terrible toll of cancer is constantly increasing- 
there were over 42,000 victims died therefrom in England and Wales in 1919 - and one of the causes is attributed by the Imperial Cancer Research Society to smoky chimneys.

And the financial cost of these fogs is colossal-about $£ 8,000,000$ a year in London, made up by way of damage to stone, metal work, paint, cleaning, lighting, spoiled merchandise, etc. A thick fog all over the country is estimated to cost the railway companies about $f 5,000$ an hour; and Lord Newton's Committee on Smoke and Noxious Vapours Abatement estimated that in Manchester the depreciation to property through smoke and soot amounts to $£ 3,000,000$ a year.

Few people realize the prodigiousness of the coal consumption on Britain's railways. The figures computed by a railway statistician recently were surprising. The Great Eastern Railway uses coal at the rate of $3 \frac{1}{2}$ tons per minute, for instance! This means about 210 tons an hour, or 5,000 tons a day. As much as $1 \frac{1}{2}$ tons of coal per minute are consumed on the Great Northern Railway, too ; and the Underground Railway, London, working 100 miles of electric railways and tramways, etc., consumes 700 tons of coal daily, or about 250,000 tons a year. These three railways between them account for nearly $3,000,000$ tons of coal yearly, so it is probable that the coal consumed by all our railways exceeds $10,000,000$ tons a year, or more than double the weekly output of all our coalfields (about. 4,700,000 tons). In other words, the collieries must give two full working weeks, or over 5 per cent of their time to keeping the railways supplied with coal!

One notes with satisfaction the main recommendation in the report of Lord Newton's Committee-

"The Central Housing Authority should decline to sanction any scheme unless provision is made in the plans 
for the adoption of smokeless methods for supplying the required heat."

The Committee are satisfied that " the present housing situation affords a unique opportunity for constructive reform with regard to heating, cooking and hot-water supply arrangements in domestic dwellings," and that " domestic smoke produced by the burning of raw coal causes serious danger to health and damage to property, and is from the national point of view a wasteful proceeding. Even in industrial areas domestic chimneys contribute at least half of the total smoke nuisance. Six per cent of the coal used in domestic fireplaces escapes unconsumed as soot. Taking 40,500,000 tons as the amount annually burnt in Great Britain, the loss represents $2,430,000$ tons, or more than half the total of fuel required to heat the metropolitan area for a whole year."

It is interesting to note that heading the list of substitutes for ordinary raw coal recommended by the committee is - anthracite.

Another influential body, the Public Control Committee, state, in a report to the London County Council, that they have decided to take "such action as is necessary to abate the smoke nuisance."

In Chicago the Mellon Institute reported that from 600 to 2,000 tons of smoke-soot to the square mile fall in Pittsburg every year, and estimated that the smoke nuisance costs Chicago $£ 12,000,000$ annually.

Apparently London was plagued with this nuisance even in Evelyn's day, for the diarist records this quaint indictment-

"That hellish and dismall cloud of sea-coal is not oniy perpetually imminent overhead, but so universally mixed with the otherwise wholesome and excellent aer, that her inhabitants breathe nothing but an impure 
and thick mist, accompanied with a fuliginous and filthy vapour, which renders them obnoxious-corrupting the lungs, and disordering the entire habits of the bodies, so that Catharrs, Phthsicks, Coughs and Consumptions rage more in this city than in the whole earth besides."

This in 1670 ; but evidently they were less tolerant in the reign of Edward the First, when the use of coal was made a capital offence, and it is on record that a man was actually tried, condemned, and hanged for burning it in London.

Illustrative of the devastating effect of a London fog is this typical report from a daily paper dated 23rd Jan., 1922- " London yesterday was the sport of the densest fog that has been experienced. Omnibus services had to be withdrawn, the streets were empty of taxicabs, pedestrians carried lanterns and bicycle lamps at midday, railway services were disorganized, and there was a long list of street accidents. Tramcars were telescoped in three different accidents at New Cross, and many people injured . . . . a yellow, heavy, stinging, cough-compelling, real old-fashioned 'particular.' Even a walk along the pavement was a peril, and the negotiation of cross-roads a dangerous adventure. Several persons walked into the Round Pond, Kensington Gardens, and at Baker-street station on the Underground it was difficult for passengers to find their way about the platform-one man accidentally stepped off the edge and fell on the metals. . . . A tramcar journey from Norwood to Blackfriars occupied two and a half hours instead of the usual thirty-five minutes, and from Balham to Blackfriars took an hour and forty minutes instead of half an hour. Hundreds of pedestrians became hopelessly lost ; and the police were unable to obtain the help of the London County Council ambulance to carry injured people to the Miller Hospital, as the 
fog was too thick for the ambulance to proceed! Street lights were kept going all day, but they made little difference, being invisible at a distance of three or four yards."

Could there be anything more deplorably chaoticand ridiculously unnecessary-than this confused condition of suspended animation in the greatest city in the world (alleged) in the twentieth century? London loves to adhere steadfastly to its customs of the Middle Ages, I am aware, but it is high time that this particular nuisance of the "muddle" ages were dispensed with.

In the same paper I am pleased to read this recommendation by the Public Control Committee-

"That subject to the sanction of the Ministry of Health legal proceedings under the Public Health (London) Act, 1891, be instituted against the Hammersmith and the Islington Borough Councils in respect of smoke nuisance from the Hammersmith electricity works, Fulham Palace Road, and the electricity works, Eden-grove, Holloway."

That is good for a beginning. Extend these prosecutions generally, and you have the remedy.

His Majesty the King has recently given his subjects an excellent lead by ordering the exclusive use of smokeless fuel at Buckingham Palace, and all sensible people will applaud his wise decision. Government offices, too, are to be similarly reformed, I hea- - and the Government's coal bill is something like $£ 2,000,000$ annually-so we are certainly progressing gradually.

Having established a strong case in favour of smoke abatement, we will consider the essential points bearing upon the question of coal conservation.

Professor Barker, in his lectures on "Fuel Economy," at the Royal Society of Arts, gave it as his opinion that by application of the best known appliances in place 
of existing ones, the present domestic consumption of coal in this country could be reduced by four-fifths.

The Coal Conservation Sub-Commitee, under the chairmanship of Lord Haldane, reported that, of the $80,000,000$ tons of coal consumed in this country every year for power production (including railways), only $25,000,000$ tons would be required if existing steam engines were replaced by a general system of electrical generation; but perhaps this is more fantastic than practicable. And the economics are questionable, as Sir Dugald Clerk stated at a meeting of the Institute of Civil Engineers. Sir Dugald gave a detailed comparison of gas and electricity for domestic heating showing that electricity generated at $1.56 \mathrm{lb}$. of coal per electrical horse-power hour gave a thermal efficiency of production of 13 per cent. The efficiency of transmission for short distances was 90 per cent, so that the consumer received at his premises 11.7 per cent of the potential heat. The efficiency of electrical apparatus was estimated at 59 per cent. Eventually the consumer used 6.9 per cent of the heat units in the coal. Thus, for equal heat work, electricity consumed 2.65 times as much coal as gas.

On the assumption of the complete displacement of coal in houses by gas, a saving of 17.5 million tons was ultimately possible. Again, in the boiler house an average efficiency of $\mathbf{7 5}$ per cent instead of 60 per cent, as at present, which might lead to a saving of $4,000,000$ tons per annum in plant for manufacturing purposes (other than motive power); and in collieries which consumed about 17,000,000 tons of coal yearly on boiler furnaces for motive power an increase in efficiency from 55.5 per cent to 75 per cent might likewise save $4,000,000$ tons annually. But Sir Dugald considered that any attempt to crush out the smaller power units by a great 
Government scheme of general power production would act against the best interests of the country, both as to coal conservation and economy in cost.

Oil was "boomed" as the real substitute for coal during the great coal stoppage in 1921, but although the engines of ships, railways, etc., were temporarily converted for its use, they were soon converted back to the use of coal. Oil fuel is, of course, much more convenient to handle, store, and burn in boiler furnaces than coal, but the question is whether the saving in labour compensates for its extra cost-apart from the cost of the additional plant it necessitates.

The calorific value of oil is about 19,000 B.T.U. for the boiler furnace variety and 19,500 for the Diesel engine type. Its calorific value, like that of coal, varies considerably. That of good anthracite is nearer 15,000 B.T.U., but, assuming the average calorific value of coal to be only 12,500 B.T.U., the cost of fuel for producing a "therm" $(100,000$ B.Th.U.) by turning the oil fuel has been found to be two and one-third times the cost of producing it by turning coal at the corresponding market prices of the two fuels. In many cases it is very doubtful whether any economical advantage would be obtained by substituting fuel oil for coal.

In industrial undertakings steam-raising probably forms the most prominent of fuel-consuming processes, but it is seldom the requisite amount of attention is given to such important considerations as the correct proportioning of heating surfaces, combustion spaces, and grate areas. An extensive examination of Lancashire boilers carried out by Mr. D. Brownlie showed that, while an efficiency of nearly 80 per cent is possible in steady practice, a large number of plants are yielding only from 50 to 60 per cent. The influence of this indifferent working is exemplified by the fact that if 
an overall increase of 10 per cent in efficiency could be obtained, the annual saving of coal in this country would amount to about 7,500,000 tons.

It amounts to this, then : the most satisfactory way to effect the truest economy is to conserve the bituminous coal itself as much as possible. And this is where anthracite helps materially, its more general use relieving the demands upon soft coals, which contain so many valuable constituents needed for drugs, dyes, foods, fertilizers, etc. For this important reason alone, apart from other considerations, anthracite should be the only coal permitted to be used in the domestic household.

Let us glance at a few of the by-products of soft coal which are daily wasted-up our chimneys.

1 ton of coal yields about $30 \mathrm{lb}$. ammonium sulphate.

1 ton of coal yields about $100 \mathrm{lb}$. tar-giving enough fuel oil to drive a petrol boat 10 miles. The tar also contains chemicals, such as carbolic acid and saccharine. Then the coal, when coked in ovens, supplies immense volumes of both lighting and power gas, benzol (refined into motor spirit), etc. $2 \frac{1}{2}$ gallons of benzol, the product of a ton of coal, will drive a big motor-lorry 20 miles, a touring car 40 miles, or a sidecar 150 miles, it is claimed.

Considerable quantities of oil are extracted from shale. Mr. T. Scott Anderson, C.E., has stated that from experiments he conducted before the war he obtained from 50 to 98 gallons of oil per ton from shale. From cannel coal he secured up to 60 gallons per ton, and from bituminous coal a yield of 36 to 40 gallons per ton.

Recent experiments at the Metropolitan Laboratories, Twickenham, have resulted in the production of liquid coal, called by its inventor " Colloil." It is made from about 60 per cent coal dust (too small for briquetting) and 40 per cent crude fuel oil residue, mixed in a small machine. This should prove economically useful, if 
it can be made a sound commercial proposition; and its inventor is satisfied that by its use in any plant at present burning residue oil economies to the extent of 30 per cent can be achieved.

The existing high price of coal undoubtedly presses heavily upon the building trade, partly accounting for the dearth of new houses. According to statistics supplied by Mr. Percy M. Stewart, chairman of the Cement Makers' Federation-

Half a ton of coal is required to make a ton of cement.

A quarter of a ton of coal is required to make 1,000 bricks.

5 tons of coal are necessary to make 20,000 bricks, sufficient to build only a workman's cottage.

At the Congress of the Royal Sanitary Institute, Folkestone, 1921, Professor Leonard Hill mentioned that so inefficient are the present means of converting the thermal energy of coal into power, steam or electric, or into light, that according to the high authority of Professor W. A. Bone, 95 per cent of this energy is wasted, and simultaneously $£ 50,000,000$ worth of damage is done by the waste products! By carbonizing all coal at gas works, and using the coke for generating electric power and lighting, gas for heating, lighting and power, and securing the valuable by-products, an enormous saving of coal can be effected, and the nation's coal supply made five times greater without an extra ton being dug up. By low temperature carbonization of certain coals, a smokeless semi-coal can be obtained for fuel, and a light oil which can replace petrol. The need of the moment is to cheapen the production of gas and smokeless fuel. Professor Bone states that 89 per cent of the energy of a ton of coal is secured after carbonization at the gas works-in the gas 23 per cent, in the coke, 60 per cent, and in the tar, etc., 6 per cent. 
The problem of low-temperature carbonization has been a long and costly one, occupying over twenty years, involving an expenditure of a million of money on the erection and scrapping of various retorts; but Mr. David Brownlie, A.I.M.E., in the Manchester Guardian (20th Oct., 1921), assures us that a solution of the difficulties encountered has now been attained, and successful working is being carried on at Barnsley which should prove of great value in the conservation of coal With the retorts there it is found possible to utilize as much as 70 per cent of non-coking coal, and fine slack and other practically refuse coal from the collieries The product resulting, called "Coalite," is claimed to be an ideal smokeless fuel, and the gases and tar yielded in the process give a better and more varied yield of chemical by-products than by the hightemperature systems, including benzol, tuluol, xylol, solvent naphtha, heavy naphtha, phenol (carbolic acid), cresylic acid, creosote oil, and pitch Sulphate of ammonia is recoverable by the "Coalite" process in the ratio of 20 to $26 \mathrm{lb}$. per ton of coal carbonized, and the yield of coalite per ton of coal carbonized is from 12 to 14 cwt.

The table on page 115 shows the yield from a ton of coal by low-temperature carbonization and two other processes.

Judging from the published opinions of various experts, we certainly must not regard electricity as any aid to the conservation of coal in Britain. At a conference of the Northern District Committee of the British Commercial Gas Association, held at Sunderland, in May, 1919, Mr. F. W. Goodenough, chairman of the Executive, speaking on coal conservation, remarked that the public had been led to believe that the panacea for all or most of the difficulties in regard to coal 
conservation, transport, and housing, was to be found in the general use of electricity, not only for light and for motive power, but for all fuel purposes. This was absolute nonsense, and was so regarded by all well-informed electrical engineers.

The average electric generating station of to-day only produced to the consumer 7 heat units out of 100

Yield from One Ton of Average Conl (say 25-30 per cent volatile matter)

\begin{tabular}{|c|c|c|c|c|}
\hline & & $\begin{array}{l}\text { Low-temperature } \\
\text { Carbonization. }\end{array}$ & $\begin{array}{l}\text { High-temperature } \\
\text { Gasworks. }\end{array}$ & $\begin{array}{l}\text { e Carbonization. } \\
\text { Coke Ovens. }\end{array}$ \\
\hline $\begin{array}{l}\text { Temperature of ca } \\
\text { bonization. }\end{array}$ & & 1000 deg F & A bout l 800 deo F & About $1800 \mathrm{deg}, \mathrm{F}$ \\
\hline Gas . & & $\begin{array}{l}6,000-6,500 \text { cubic feet } \\
\text { of rich gas, } 700- \\
750 \text { B.Th.U. per } \\
\text { cubic foot. }\end{array}$ & $\begin{array}{l}12,000 \text { cubic feet of } \\
\text { medium quality } \\
\text { (town's) gas, } 550 \\
\text { B.Th.U. per cubic } \\
\text { foot. }\end{array}$ & $\begin{array}{l}11,500 \text { cubic feet of } \\
\text { poor quality coke- } \\
\text { oven gas, } 450 \\
\text { B.Th.U. per cubic } \\
\text { foot. }\end{array}$ \\
\hline Liquid & . & $\begin{array}{l}20 \text { gallons coalite oil } \\
\text { (fractionated to, } \\
\text { say, } 3 \text { gallons mo- } \\
\text { tor spirit, } 8-9 \text { gal. } \\
\text { Diesel or fuel oil, } \\
\text { and } 8-9 \text { gal. lubri- } \\
\text { cating oil). }\end{array}$ & $\begin{array}{l}10 \text { gallons coal tar .. } \\
\text { Fractionated to abou } \\
\text { spirit, carbolic aci } \\
\text { naphthalene, fuel o }\end{array}$ & $\begin{array}{l}8 \text { gallons coal tar } \\
\text { ut half-gallon motor } \\
\text { id, a large amount of } \\
\text { oil, etc. }\end{array}$ \\
\hline $\begin{array}{l}\text { Sulphate of ammor } \\
\text { (from the amm } \\
\text { nia). }\end{array}$ & & $15 \mathrm{lb}$. & $25 \mathrm{lb}$. & $28 \mathrm{lbs}$. \\
\hline Residue in retort & . & $\begin{array}{l}14 \text { cwt. of smokeless } \\
\text { fuel coalite con- } \\
\text { taining about } 9-10 \\
\text { per cent volatile } \\
\text { matter. }\end{array}$ & $\begin{array}{l}13 \frac{1}{2} \text { cwt. of soft coke, } \\
\text { containing about } 1 \\
\text { per cent volatile } \\
\text { matter. }\end{array}$ & $\begin{array}{l}14-14 \frac{1}{2} \text { cwt. of hard } \\
\text { coke, containing } \\
\text { less than } \frac{1}{2} \text { per } \\
\text { cen volatile } \\
\text { matter. }\end{array}$ \\
\hline
\end{tabular}

destroyed in the coal used to produce it-a loss of 93 per cent, and the most efficient showed a loss of 88 per cent. The best results anticipated in the new proposed "super" stations was only an efficiency of 18 per cent. In the case of gas, 50 per cent of the heat units in the coal used were returned as coke, 5 per cent were recovered as tar, 22.5 per cent reached the consumer as gas, and only 22.5 per cent were lost in manufacture and distribution.

To produce an equivalent amount of electric heat would involve the destruction of 4 tons of coal at the 
present generating stations, and 3 tons at the "super" stations of the future, as against 1 ton at the gasworks. To afford gas consumers equal service rendered them for a destruction of $10,000,000$ tons of coal (net), the electric generating stations would destroy $40,000,000$ tons, and the "super" stations 20,000,000 tons, as well as the valuable by-products recovered when coal is carbonized. To use electricity as a fuel on any scale is, therefore, out of the question from the point of view of coal conservation and coal's chemical constituents, as also from that of cost.

\section{Mining Miscellany}

Miniature Mines. The new Junction Colliery, Ashtonunder-Lyne, is claimed to be the smallest coal mine, and the only one " owned by its miners and mined by its owners," four men, who raise an average of $2 \frac{1}{2}$ tons of coal per day.

Another miniature colliery was that established by strikers at Newhall, Burton-on-Trent during 1920in a back garden! Two shafts were sunk, and the coal obtained was sold locally in barrow-loads at 1s. $6 \mathrm{~d}$. each.

Health in Coal. Dr. Halford Ross, a member of the Industrial League and Council, assures us that coal mining is " a very healthy industry, and accounted as one of the healthy trades."

If a miner cuts himself when he is covered with coal dust, his injury will heal quicker than if he is clean, Dr. Ross declares. Miners are not so subject to consumption as workers in many other industries.

Coal mining is also, contrary to popular supposition, one of the least dangerous occupations, as the writer has shown in published official statistics from time to time. 
Miners' Superstitions. All miners are superstitious, and their superstitions vary in different districts. Some of these are very curious indeed, especially among the Black Country miners. A resident of the Rowley Regis colliery district relates that on one occasion a large group of miners, proceeding to work between 5 and 6 a.m., noticed a woman cleaning her windows. With oaths and curses they all retraced their steps and remained at home the whole day! Seeing a woman at such an early hour led them to believe that a disaster would occur if they descended the pit that day.

Miners have frequently been warned of impending disasters by dreams of their relatives; and there are several fatalities on record resulting from men ignoring these strange warnings.

Court in a Coal Mine. There is at least one instance of judicial procedure taking place below the earth's surface. Newspapers reported on 16th November, 1921, that Judge Lindley, seeking first-hand evidence in a case at Mansfield County Court, descended a coal mine to obtain it. He wished to decide whether a scratch on a miner's face, alleged to have been caused by unprotected wire in Sutton Colliery, was the cause of the man's death.

On descending the mine, Judge Lindley discovered that the track on the roadway was some two or three feet from the wire. He therefore failed to see how the wire could have touched the man's face, and dismissed the widow's claim for compensation.

Black and White Fuel. In some districts where chalk abounds, thrifty householders make up very serviceable fires by mixing lumps of chalk with their coal. Both ingredients burn equally well, and when well alight, their appearance is identical. It is, of course, a very economical process, as the same lumps of chalk are used over again for several days. 
Food from Coal! At the Fuel Economy Exhibition, held in Trafalgar Square, London, in November, 1918, Professor Spooner mentioned that coal contained as many treasures as Pandora's box, and that it was quite likely that in the future we should use its by-products of edible oils and fats to make margarine. He exhibited a piece of coal weighing $1 \mathrm{lb}$., valued at $\frac{1}{4} \mathrm{~d}$., and stated that it contained sufficient energy, if that energy could be used without waste, to lift 550 people to the top of the Nelson Column.

Tale of a Toad. Tradition has given the world marvellous stories of toads being discovered embedded alive in rocks, as well as the familiar " toad in the hole," but here is an interesting modern tale from the Morning Post (23rd May, 1919)-

"A toad has been found buried in a coal seam at the Netherseal Colliery, Burton-on-Trent (writes a correspondent), 200 yards below the surface and a mile from the pit shaft. When a miner's pick struck into a pocket of clay, out rolled the toad. Three inches in length, with skin like that of a young alligator, it has no mouth, but it is evident it once possessed one, though the aperture is now sealed up. It is recovering its sight and moving about."

Storm in a Mine. The forces and freaks of Nature are truly wonderful, but most of us have imagined that coal mines at any rate were immune from thunder storms. Not so, it would appear, for a Central News report of 13th November, 1919, records a remarkable incident at Dalton-in-Furness. During a severe storm of snow and hail, accompanied by thunder, lightning descended a pit-shaft by the winding rope, and the current ran along the bottom of the pit for 200 yards. A man was knocked down and rendered unconscious, and a lad lost the use of his legs through the shock. 
Perpetual Fires. Though drowning is a fate to which coal mines are particularly liable, perpetual fire has been also an occasional cause of their abandonment. Near St. Etienne, says the Daily Express, there is a mine which has been on fire for many years, and another at Zwickau, Saxony, which caught fire in the fifteenth century, is still burning. We had an example of the same thing in the Burning Hills of Staffordshire, where for years-until the fire burned out-tropical plants grew luxuriantly.

After Long Silence. In November, 1921, a train of loaded tubs, which were filled a few moments before the big explosion of 1878, were found in an old disused working in the Prince of Wales Colliery, Abercarn. Tools and various articles were discovered just as they were dropped by the terror-stricken miners in face of the disaster, painfully remindful of the grim tragedy of over forty years ago.

Effects of an Explosion. Some idea of what an explosion in a mine is like can be gathered from investigations recorded in a paper read before the South Wales Institute of Engineers, reviewing certain anthracite colliery explosions. ${ }^{1}$

The most serious outburst of gas and dust took place in December, 1914, on taking out a pair of timbers, being preceded by reports which increased in intensity. The roads back to the upcast pit were filled with gas, and also the main intake, which is a cross-measure drift from the Red Vein, was filled for a distance of $\mathbf{5 0}$ yards for some considerable time. The quantity of air in the intake was normally $25,000 \mathrm{cub}$. ft. per minute. . . It will be seen that a large quantity of gas was given off. The quantity required to fill up the roads back to the upcast would be approximately $110,000 \mathrm{cub}$. ft., without

1 See Iron and Coal Trades Review, 27th Jan., 1922.

$9-(1458 \mathrm{H})$ 
taking into consideration the volume passing to the upcast for the period that the ventilation was suspended. From this fall 600 trams of dust were filled-apart from casualties and damage.

Examination of the coal sample taken from where the outburst happened was interesting. The lumps crumbled at touch to a powder, which was graded thus : Retained by 8 sieve, 1.5 per cent ; retained by 16 sieve, 0.9 per cent ; retained by 36 sieve, 8.6 per cent; retained by 100 sieve, 36.2 per cent; retained by 200 sieve, 16.5 per cent ; passed by 200 sieve, 36.3 per cent. The occluded gases contained 90 per cent of carbonic acid, and temperatures of $155^{\circ} \mathrm{Fah}$. were recorded in the small coal before the accumulation of dust was cleared away. The sides of the seam were hot for some weeks afterwards! In this sample only 54 cub. centimetres of occluded gases were given off from 100 grammes of the smaller lumps, the average for normal anthracite being as high as 500 to 600 cub. centimetres.

Coal's Medicinal Properties. During a lecture at the Manchester College of Technology, in March, 1922, Dr. Arnold Renshaw and Mr. Thomas Fairbrother explained some dye discoveries which are expected to revolutionize the treatment of disease. Infection is fought by injecting into the blood certain dyes, which kill infecting agents without harming the organs of the body.

Mr. Fairbrother dealt with the antiseptic action of the coal tar dyes. Results showed that certain classes had a greater or less tendency to antiseptic action. Basic dyes, such as crystal violet and auramine, showed strong antiseptic action, while others, such as the patent blues, acid greens, turquoise blues, and victoria blues, showed very little action.

Dr. Renshaw, giving a practical demonstration, took 
from behind the ear of a man in the audience who had suffered from a West African fever a drop of blood, a picture of which was projected on a screen. In the picture a worm could be seen moving about, and Dr. Renshaw explained how a dilution of the dye auramine injected into the blood instantly killed the worm. 


\section{INDEX}

AMERICAN anthracite, 83 mining engineers, Inst. of, 83,86 mining methods, 83 output, $1,5,25,83,88$ patent fuel, 93

Analyses, Irish anthracite, 81 patent fuel, 94 Scotch anthracite, 83 Welsh anthracite, 18

Anthracite, American, 83 analysis, 18 baking by, 72 beautiful district, 13

Canadian, 88

Chinese, 90 composition of, 11, 16 costs (comparative), 41, 43, 47,68 compounds, 90 domestic, 38 "duff," 34, 92 fires (rules), 24 "French" nuts, 9 gas-yield of, 72 "grains," 34

Irish, 78 official tests, $39,40,41,53$, 62 origin of, 7 outputs, American, 1, 5, 25, 83,88

$\longrightarrow$ Canadian, 89

- Great Britain, 25, 88

-, Irish, 78, 81

- Scotch, 82

- Welsh, 1, 94

"peas," 91

pioneers of, 3,29

power of, 29,75

process of manufacture, 32 resources, 3
Anthracite, Scotch, 82 seams, 3 , standard sizes, $\mathbf{3 4}$ steam-raising, 75 stoves, $43,44,45,46,62,64$ stove makers, 66

— nuts, 57

versus gas, 55 washing of, 32 Welsh coalfield, 1, 5

"Anti-waste" fuel, 92

Automobile Engineers, Inst. of, 73

BAKING by anthracite, 72 Barker, Professor, 43, 44, 109 Beautiful anthracite district, 13

Boiler-grate (" Florence "), 59 Boiler tests, 75

Boilers, domestic, 55

Bone, Professor W. A., 4, 113 Bristol, Royal Hotel, 39 British Commercial Gas Association, 114

— Th.U. and " Therms," 59

By-products of coal, 112, 113

Calthrop, Sir Guy, 69

Cambria Leader, 68

Canadian anthracite, 88

Carbonization, low-temperature, 114

Cardiff, Inst. of South Wales Engineers, 10, 40

Chalk and coal, 117

Chemical salts, 43

Chinese anthracite, 90

Cleeves' Western Valleys Anthracite Collieries, 3, 29, 30

Coal by-products, 112,113 
Coal conservation, 110, 113, 114,115

- sub-committee, 110 106

" Coalite," 114

Coal, liquid, 112

-, medical properties of, 120

Coal and Iron and By-Products Journal, 39, 69

Coal-smoke abatement, 103

- pollution, 104, 105

Coal storage, 100

- supplies, Royal Commission on, 12

Coalowners, 47

- losses, 26

Coals, spontaneous ignition, 96

Cobbles, 34

Collieries, life at the, 30

Compound fuels, 9095

Conservation, coal, 110, 113, 114,115

Cooking, English, 48

Cost of fuels (comparative), 41, $43,47,68$

Country Life, 45

Court in a mine, 117

Daily Express, 119

Daily Mail. and "Florence" grate, 60

Dean Swift, 82

Deep mining, 12

Domestic boilers, 55

Domestic Engineering, 40

Domestic grates, 39, 40, 41, 62

Dublin Weekly Journal, 82

"Duff," anthracite, 34, 92

Dutch stoves, 65

Electrical Review, 74

Electricity generation, 110, 115 Electrodes, 74

Employees-American mines, 25,88
Employees, Great Britain, 25, 88 , Irish mines, 81 Welsh mines, 3 English cooking, 48 Evelyn, John, 95, 107 Evening Standard, 63 Exploiters' difficulties, 28 Explosion, effects of, 119

Federation of British Industries, 26

Fisherden, Dr. Margaret, 41 "Florence " boiler-grate, 59 Fog (London) statistics, 105, 108

Food from coal, 118

"French" nuts, 9

Fuel Economy Review, 26

Fuels, compound, 90, 95

—, patent, 92, 93, 94

Galloway, W., 10

Gas-stove perils, 69

Gas-yield (anthracite), 72

Germany's patent fuel, 94

"Grains," 34

Grates, domestic, 39, 40, 41, 62

Health in coal, 116

Heat losses from soot, 54

Herald of Wales, 5

Hill, Professor Leonard, 104, 113

Horticulture, 25

Housing recommendations, 106 Hudson Coal Company, 84

"Ideal Homes" Exhibition, 60

In the Western Valleys of Wales, 2, 30, 43, 76

Industrial world and anthracite, 26, 72

used, 26

Institute of Automobile Engineers, 73 
Institute of Marine Engineers, 54

- of Mining Engineers (American), 83, 86

of S. Wales Engineers, 10,40

Ironmonger, 46, 55

Irish anthracite, 78

- Mining Co., the new, 81

KIng George V, 109

Kitchen conquest, 47

" Kooksjoie " anthracite range, 52

LAMP, miner's, 35

Liquid coal, 112

Llewelyn, Sir Leonard W., 26 London atmosphere statistics, 105

- fog, 104, 105, 108 65

Lord Newton's Committee, 106 Losses of coalowners, 26

Low - temperature carbonization, 114

MANChester Air - pollution Board, 41

Manchester Guardian, 114

Manufacture of anthracite, 32

Marine Engineers, Inst. of, 54

Medical properties of coal, 120

Metropolitan laboratories, 112

Mine, court in a, 117

$\longrightarrow$, explosion in a, 119

— fires, 119

- storm in a, 118

Miner's lamp, 35

Miners' superstitions, 117

Mining, American, 83

$\longrightarrow$, deep, 12

- , earliest methods, 2

- Engineers, Inst. of, 83

$\longrightarrow$ Irish, 79

—, Welsh, 10

miscellany, 116
Mines, miniature, 116

Morgan, J. D., 5

New Cross Hands Colliery, 3, 14,30

New Irish Mining Co., 81

Newton, Lord, 106

Northern Exploration Co., Ltd., 90

Norwegian Coal Co., 90

OfFICIAL tests of anthracite, $39,40,41,53,62$

Oil, calorific value of, 111

- versus coal, 111

Origin of anthracite, 7

Our Homes and Gardens, 44

Output, American, 83, 87

$\longrightarrow$, Canadian, 89

- Great Britain, 25, 88

-, Irish, 78, 81

-, Scotrh, 82

-, Welsh, 1, 94

Owens, Dr. J. S., 105

Patent fuels, 92, 93, 94

- Fuel Marketing Co., Ltd.,

92,93

"Peas," 91

"Pele," 28, 39, 92, 96

Pennsylvania coalfield, 6

Perils of gas-stoves, 69

Perpetual fires in mines, 119

Photographs of anthracite, 9, 57, 91

Pioneers of anthracite, 3, 29

Pony, the wonderful pit, 36

Power of anthracite, 29, 75

Preparation of anthracite, 32

Public Control Committee, 107, 109

RaILWAYS, coal consumption on, 106

Ranges, "King " of, 52

-, kitchen, 51

Redmayne, Sir R. A. S., 12

Research, Dept. of Scientific, 12 
Royal Commission on Coal Supplies, 12

Royal Hotel, Bristol, 39 Sanitary Institute, 113

" Rubbly Culm," 34

Rules of anthracite fires, 24

Russell (Archibald), Ltd., 83

SALTS, chemical preparations, 43

Seams, Welsh anthracite, 3

Scientific Research, Dept. of, 12

Scotch anthracite, 82

Sizes of anthracite, 34

Skeena Co., 89

Soot, heat losses from, 54

Smoke (coal) pollution, 104, 105

South Wales Daily Post, 69

South Wales Engineers, Inst. of, 10,40

Spitsbergen, 90

Spontaneous ignition in coals, Steam-raising, 75

[96
Storage, coal, 100

Storm in a mine, 118

Stove-makers, principal, 66

Stove nuts, 57

Stoves, anthracite, 43, 44, 45, $46,62,64$

- British, etc., 64

-, Dutch, 65

$\longrightarrow$, heating capacities, 64,65

Strahan, Dr., 8

Swift, Dean, 82

TESTS, boiler, 75 , official, $39,40,41,53,62$

, private, $43,44,45,46,53$,

$60,68,74,76,77,82,92,96$

"Therms" and B.Th.U., 59

WatkINS, Thomas H., 25

Washing of anthracite, 32

Welwyn Garden City, 61

Welsh anthracite, analysis, 18

Welsh coalfield, 1,5 


\title{
A LIST OF BOOKS
}

\author{
PUBLISHED BY
}

\section{Sir Isaac Pitman \& Sons, Ltd.}

(Incorporating WHITTAKER \& CO.)

\section{PARKER STREET, KINGSWAY,}

\section{LONDON, W.C.2}

The prices given apply only to the British Isles, and are subject to alteration without notice.

A complete Catalogue giving full details of the following books will be sent post free on application.

ALL PRICES ARE NET.

Accumulators, MANagement of, Sir D. Salomons $s . d$.

AERofoIls aND Resistance of AERodynamic

Bodies, Properties of. A. W. Judge • 180

aeronautical Design and Construction,

Elementary Principles of. A. W. Judge . 76

Aeronautics, Elementary. A. P. Thurston. - 86 Aeronautical Engineering, Text-Book of. A.

Klemin

Aeroplanes, Design or. A. W. Judge . . 140

Aeroplane Structural Design. T. H. Jones

and J. D. Frier . $\quad . \quad \cdot \quad \cdot \quad \cdot 210$

Aeroplanes AND Airships. W. E. Dommett . 19 Aircraft and Automobile Materials-Ferrous.

A. W. Judge $\quad . \quad$. $\quad . \quad . \quad .250$

Aircraft aND AUtomobile Materials-NON-

Ferrous and Organic. A. W. Judge • . 250

Aircraft, Dictionary of. W. E. Dommett • 20

Alignment Charts. E. S. Andrews . . . 20

alternating Current Machinery, Design of.

J. R. Barr and R. D. Archibald . . . $30 \quad 0$

Alternating Current Machinery; Papers on

THE DESIGN OF. C. C. Hawkins, S. P. Smith and

S. Neville • $\quad . \quad$. $\quad .210$

Alternating-Current Work. W. Perren Maycock 106 $x-5$ 
s. $d$.

Architectural Hygiene. B. F. and H. P. Fletcher 106 Arithmetic of Alternating Currbnis. E. $\mathrm{H}$.

Crapper $\%$

Arithmetic of Electrical Enginemring. Whit-

taker's

Arithmetic of Telegraphy and Telephony.

T. E. Herbert and R. G. de Wardt. • - 50

Armature Construction. H. M. Hobart and

A. G. Ellis $\quad . \quad$. $\quad . \quad . \quad .250$

Artificial Silk and Its Manufacture. J.

Foltzer. Translated by S. Woodhouse . . 210

Astronomers, Great. Sir R. Ball . • . 76

ASTRONOMY FOR EVERYBODY. Prof. S. Newcombe 76

ASTRONOMY FOR GENERAL READERS. G. F.

Chambers . . . . . . 40

Automobile and Aircraft Engines. A. W. Judge 30 - 0

Automobile Ignition and Valvi Timing, Start-

ING AND Lighting. J. B. Rathbun . 80

Baudót Printing Telegraph System. H. W.

Pendry

Blue Printing and Modern Plan Copying.

B. J. Hall • • • . . . . 60

Brewing and Malting. J. Ross Mackenzie 86

Cabinet Making, Art and Craft of. D. Denning 76

CAlculus for EngineERING Students. J. Stoney 36

CARPENTRY AND JoINERY. B.F. and H. P. Fletcher 106

Ceramic Industries Pocket Book. A. B. Searle 86

Chemical Engineering, Introduction to. A. F. Allen

Chemistry, A First Book of. A. Coulthard • 46

Conl Mining, Modern Practice of. Kerr and

Burns. Part 1,5/.; Parts 2, 3 and 4, each . 60

Colour in Woven Desicn: a Treatise on

Textile Colouring. R. Beaumont . . . 210

Compressed Air Power. A. W. and $Z$. W. Daw 210

Continuous-Current Dynamo Design, Elemen-

TARY PRINCIPLes OF. H. M. Hobart . . 106

Continuous Current Motors and Control Ap-

paratus. W. Perren Maycock . . .

Detail Design of Marine Screw Propellers.

D. H. Jackson . . . . . 60 
s. $d$.

Direct Current Electrical Engineering. J. R. Barr

Direct Current Electrical Engineering, the

Elements of. H. F. Trewman and G. E.

Condiffe.

Diving Manual and Handbook of Submarine

Appliances. R. H. Davis . • . . 76

Drawing and Designing. C. G. Leland . - 36

Drawing, Manual Instruction. S. Barter • 40

Dress, Blouse, and Costume Cloths, Design AND FABRIC MANUFACTURE OF. R. Beaumont . . . . . . 420

Dynamo, How to Manage the. A. R. Bottone . 20

Dynamo: its Theory, Design and Manufacture,

The. C. C. Hawkins. Vol. I . . .

Electric Light Fitting: a Treatise on Wiring For Lighting, Heating, \&c. S. C. Batstone . 60

Electrical Instrument Making for AMateurs.

S. R. Bottone . . . . . . . 60

Electric Bells and All About Them. S. R. Bottone . . . . . . .

Electric Circuit Theory and Calculations.

W. Perren Maycock . . . . . 106

Electric Guides, Hawkins'. 10 volumes, each 50

Electric Mining Machinery. S. F. Walker . 150

Electric Motors and Control Systems. A. T.

Dover

Electric Motors-Continuous, Polyphase aNd

Single-Phase Motors. H. M. Hobart . .

Electric Motors, A Small Book on. C.C. aNd

A.C. W. Perren Maycock . . . . 60

Electric Lighting and Power Distribution.

Vol. I. W. Perren Maycock . . . . 106

Electric Lighting and Power Distribution.

Vol. II. W. Perren Maycock . . . 106

Electric Lighting in the Home. L. Gaster . 6

Electric Lighting in Factories. L. Gaster and

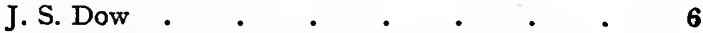

Electric Traction. A. T. Dover . . . 210

Electric Wiring, FitTings, Switches and Lamps.

W. Perren Maycock $\quad . \quad$. . . . 10 


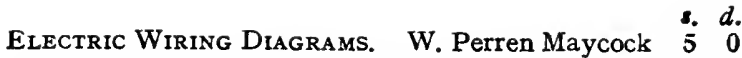
Electric Wiring Tables. W. Perren Maycock . 50 Electrical Engineers' Pocket Book. Whittaker's

Electrical Instruments in Theory and PracTICE. Mürdoch and Oschwald . . . 126 Electrical Machines, Practical Testing of. L. Oulton and N. J. Wilson . . . . 60

Electrical Transmission of Photographs. M. J. Martin

Electricity and Magnetism, First Book of. W. Perren Maycock .

Electro Motors: How Made and How Used.

S. R. Bottone

Electro-Platers' Handbook. G. E. Bonney . 50 Electro-Technics, Elements of. A. P. Young 76 Engineer Draughtsmen's Work: Hints to BeGINNERS IN DRAWING OfFICES.

Engineering Science, Primer of. E. S. Andrews.

Part 1, 3s. ; Part 2, 2s. 6d.; Complete . . 46

Engineering Workshop Exercises. E. Pull . 36

ENGINEERs' and ERectors' POCKET Dictionary :

English, Ghrman, Dutch. W. H. Steenbeek 26

English for Technical Students. F. F. Potter. 20

Experimental Mathematics. G. R. Vine

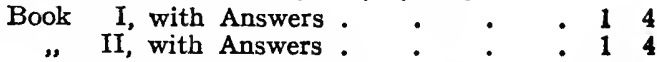

Explosives, Historical Papers on Modern. G.

W. MacDonald $. \quad . \quad$. $\quad . \quad$. $\quad .90$

Explosives Industry, Rise and Progress of THE BRITISH

Field Manual of Survey Methods and OperaTIONS. A. Lovat Higgins . . . . 210 Field Work for Schools. E. H. Harrison and C. A. Hunter . . . . . . 20 Files and Filing. Fremont and Taylor . . 210 Fitising, Principles of. J. G. Horner • . 76 Five Figure Logarithms. W. E. Dommett . 16 Flax Culture and Preparation. F. Bradbury 106 Fuselage Design. A. W. Judge . . . 30 Gas, Gasolene and Oil Engines. J. B. Rathbun 80 
Gas Engine Troubles and Installations. J. B. Rathbun . . . . . 80 Gas and OIl Engine Operation. J. Okill : 50 Gas, OIl, ind Petrol Engines: including Suction Gas Plant and Humphrey Pumps.

A. Garrard .

Gas Supply in Principles and Practice. W. H. Y. Webber . . . . . . 40 Geometry, the Elements of Practical Plane. P. W. Scott

Geology, Elementary. A. J. Jukes-Browne : 30

German Grammar for Sciznce Students. W.

A. Osborne ...$\quad$. 30

Graphic Statics, Elemintary. J. T. Wight $\bullet \begin{array}{lll} & 5 & 0\end{array}$ Handrailing For Geometrical Staircases. W.

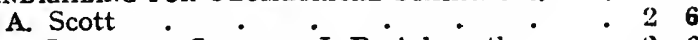

Heat, Light aNd Sound. J. R. Ashworth: i. 26

High Heavens, In the. Sir R. Ball. • . 106

Hosiery Manufacture. W. Davis . . . 90

HydRaulic Motors and Turbines. G. R.

Bodmer . . . . . . . 150

IlluminadTs and Illuminating EngINeERING,

MODERN. Dow and Gaster. . . 250

INDICATOR HANDBOOK. C. N. Pickworth . . 76

InDUCTION CoILs. G. E. Bonney . . . 60

Induction CoIL, Theory of THE. E. Taylor-Jones 126

Insulation of Electric Machines. H. W.

Turner and H. M. Hobart . . . . 210

lonic Valve, Guide to Study of the. W. D.

Owen
Ironfounding Practical. J. G. Horner • $^{2} 106$

Leather Work. C. G. Leland . . . . 50

Lektrik Lighting Connections. W. Perren Maycock . . . . . . . 10

LENS WORK For-AmateuRs. H. Orford •. 36

Lightning Conductors and Lightning Guards.

Sir O. Lodge

Logarithms for Beginners. C. N. Pickworth . 16

Machine Drawing, Preparatory Course to.

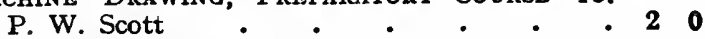

MAGNETISM AND EleCtricity, AN INTRODUCtory

Course of Practical. J. R. Ashworth - 30 
Magneto and Electric Ignition. W. Hibbert • • • 36

Manuring iand, Tables for Measuring and J. Cullyer . . . . . . 30

Marine Engineers, Practical Advice for. C. W. Roberts

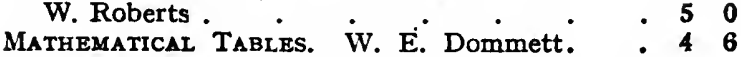

Mathematics, Mining (Preliminary). G. W. Stringfellow With Answers Do. - . . $\quad . \quad 2 \quad 20$

Mechanical Tables, Showing the Diameters AND Circumferences OF IroN BARS, ETC. J. Foden

Mechanical Engineers' Pocket Book. Whittaker's

Mechanics' and Draughtsmen's Pocket Book. W. E. Dommett

TuRning. J. G. Horner.

Metal Work-Rrpousse. C. G. Leland • . 50

Metal Work, Teacher's Handbook. J.S. Miller 40

MEtric aNd British Systems of Weights and

Measures. F. M. Perkin . . . . 36

Metric Conversion Tables. W. E. Dommett . 26

Milling, Modern. E. Pull . . . . 90

Mineralogy: the Characters of Minerals, THEIR Classification aNd Description. F. H. Hatch

Motion Picture Operation, Stage Electrics AND IllusioNs. H. C. Horstmann and V. H. Tousley

MOtOR TRUCK AND AUTOMOBILE MOTORS AND Mechanism. T. H. Russell . . . 80

Motor BoAts, HYdRoplanes aNd HydroaeroPLANES, T. H. Russell

Moving Loads on Railway Underbridges. $\mathrm{H}$. Bamford

Naval Dictionary, Italian-English aND

English-Itadian. W. T. Davis. $\quad$. 106

Optical Instruments, Modern. H. Orford . 40

Optics of Photography aNd Photographic

Lenses. J. T. Taylor . • • • 


\section{s. a.}

Pattern-Making, Principles of. J. G. Horner. 40 Pipes and Tubes: Their Construction and Jornting. P. R. Björling . • . . 66 Plant, Physiology Researches in. W. R. G. Atkins

Plywood and Glue, Manufacture and Use of, The. B. C. Boulton

Polyphase Currents, A. Still 76

Power Wiring Diagrams. A. T. Dover . . 76

Practical Electric Light Fititing. F. C. Allsop

Practical Sheet and Plate Metal Work. E. A. Atkins . $. \quad . \quad . \quad . \quad . \quad .100$

Radio-Telegraphist's Guide aNd Log Book. W. H. Marchant . $. \quad . \quad$. $\quad 56$

Railway Technical Vocabulary. L. Serraillier 76

Reinforced Concrete. W. N. Twelvetrees . 210 Reinforced Concrete Beams and Colums, Practical Design of. W. N. Twelvetrees: 76

REINF́ORCED CONCRETE MEMBERS, Simplified

Methods of Calculating. W. N. Twelvetrees 50

Reinforced Concrete, Detail Design in. E. S. Andrews . . . . . . 60

Roses and Rose Growing. R. G. Kingsley . 76

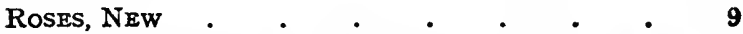

Russian Weights and Measures, Tables of. Redvers Elder . . . . . . 26

Safe loads on Steel Pillars, Tables of. E. S.

Andrews . $. \quad \cdot \quad \cdot \quad \cdot \quad . \quad .60$

Slide Rule. A. L. Higgins . . . . . 6

Sume Rule. C. N. Pickworth • . . . 36

Sort, Science of the. C. Warrell . . - 36

StaRRY Realms, IN. Sir R. Ball • . . 106

Steam Turbo-Alternator, The. L. C. Grant • 150

Steel Works Analysis. J. O. Arnold and F.

Ibbotson . . . . . . 126

Storage Battery Practice. R. Rankin . . 76

Stresses in Hooks and Other Curved Beams.

E. S. Andrews ..$\quad \cdot \quad \cdot \quad \cdot 60$

Submarintr Vessels, etc. W. E. Dommett . 50 
SURVEYing and SURVEying INSTRUMents. G. A.

T. Middleton . . . . . . . 60

Surveying, Tutorial Land and Mine. T. Bryson 106

Technical Dictionary, International. E.

Webber . . . . . . . 150

Telegraphy : an Exposition of The Telegraph

System of the British Post Office. T. E.

Herbert . . . . .

Telegraphy, Elementary. H. W. Pendry . 76

TElephone Handbook and Guide to THE

Telephonic Exchange, Practical. J. Poole 150

Textile Calculations. G. H. Whitwam . . 250

Transformers For Single and MUltiphase

Currents. G. Kapp

Trigonometry for Enginelrs, Primer of. W. G.

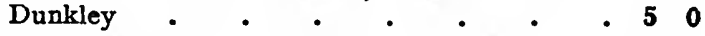

Triplane and the Stable Biplane. J. C.

Hunsaker . ${ }^{\circ} \cdot{ }^{\circ} \cdot{ }^{\circ} 30$

TURRet Lathe Tools, How to Lay OUt .. 60

Union Textile Fabrication. R. Beaumont • 210

Ventilation, Pumping, and Haulage, The

Mathematics of. F. Birks . . . 50

Volumetric Analysis. J. B. Coppock . . 36

Water Mains, The lay-Out of Small. H. H.

Hellins . . . . . . . 76

Wireless Pocket Book, Marine. W. H. Marchant 60

Wireless Telegraphy and Hertzian Waves.

S. R. Bottone

Wireless Telegraphy : a Practical handbook

FOR Operators and Students. W. H.

Marchant . . . . . . . 76

Wood-Block Printing. F. Morley Fletcher • 86

Woodcarving. C. G. Leland - . . : 50

WOODWORK, MaNual Instruction. S. Barter : 76

Wool Substitutes. R. Beaumont • . . 106

Catalogue of Scientific and Technical Books post free.

LONDON : SIR ISAAC PITMAN \& SONS, LTD. PARKER STREET, KINGSWAY, W.C.2 



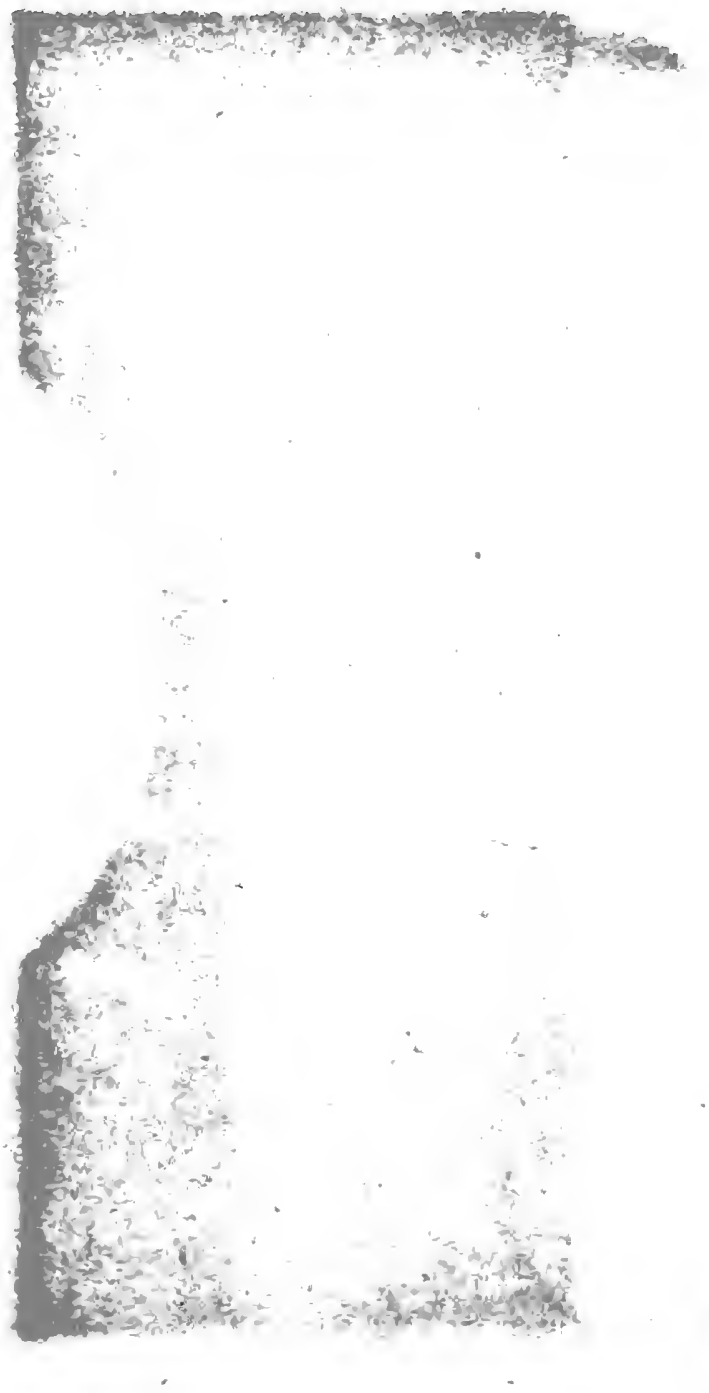




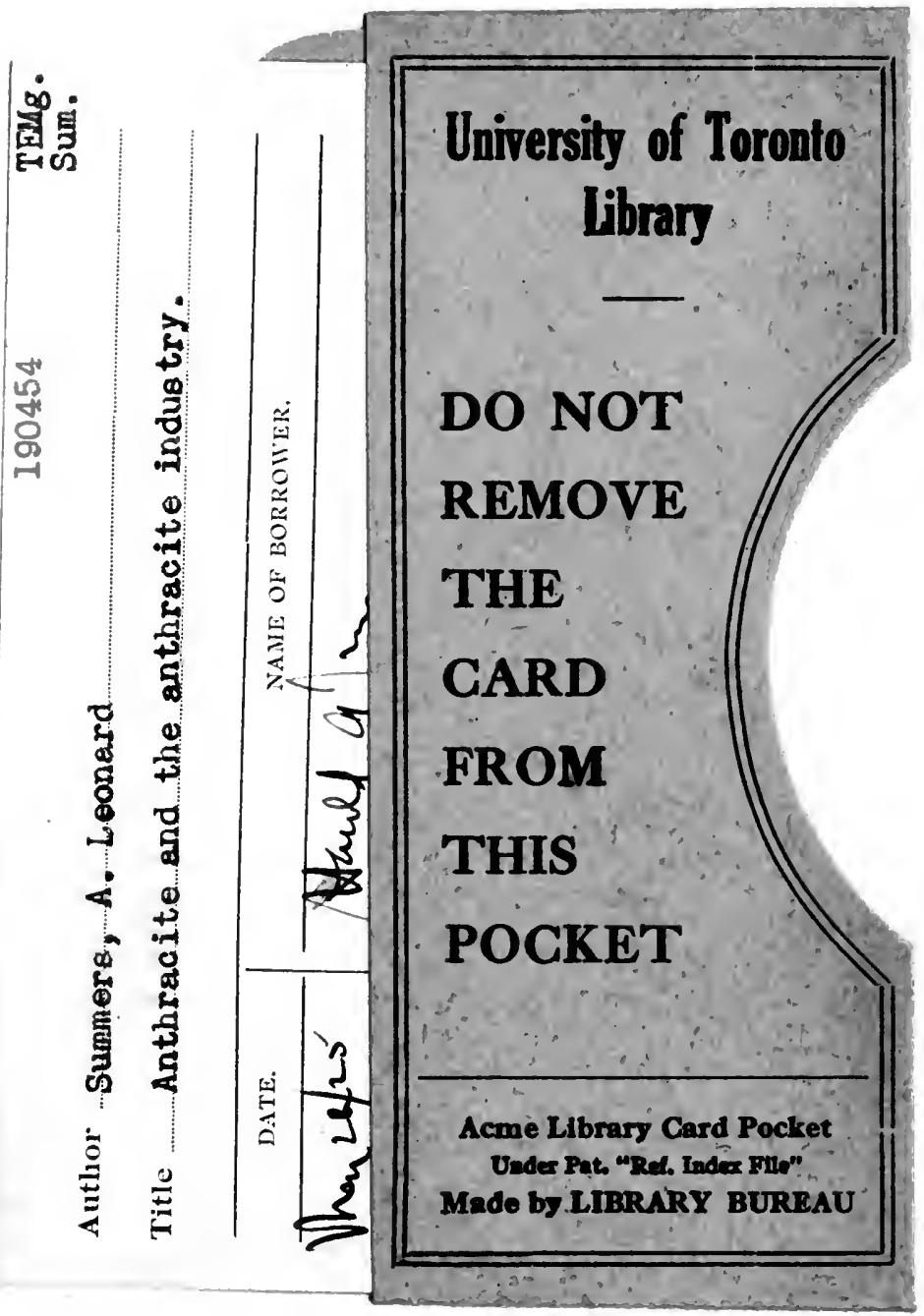


